\title{
PERSONS FOUND NOT CRIMINALLY RESPONSIBLE ON ACCOUNT OF MENTAL DISORDER (NCRMD) FOR SEXUAL OFFENCES: CHARACTERISTICS, RISK FACTORS, AND REVIEW BOARD DECISION MAKING.
}

by

Danielle M. Loney

Bachelor of Arts (Honours), University of Ontario Institute of Technology, 2015

\author{
A thesis presented to Ryerson University \\ in partial fulfillment of the \\ requirements to the degree of \\ Master of Arts \\ in the program of \\ Psychology
}

Toronto, Ontario, Canada, 2017

C Danielle Loney, 2017 


\section{AUTHOR'S DECLARATION FOR ELECTRONIC SUBMISSION OF A THESIS}

I hereby declare that I am the sole author of this thesis. This is a true copy of the thesis, including any required final revisions, as accepted by my examiners.

I authorize Ryerson University to lend this thesis to other institutions or individuals for the purpose of scholarly research.

I further authorize Ryerson University to reproduce this thesis by photocopying or by other means, in total or in part, at the request of other institutions or individuals for the purpose of scholarly research.

I understand that my thesis may be made electronically available to the public. 


\title{
PERSONS FOUND NOT CRIMINALLY RESPONSIBLE ON ACCOUNT OF MENTAL DISORDER (NCRMD) FOR SEXUAL OFFENCES: CHARACTERISTICS, RISK FACTORS, AND REVIEW BOARD DECISION MAKING.
}

\author{
Master of Arts \\ 2017 \\ Danielle M. Loney \\ Psychology \\ Ryerson University
}

\begin{abstract}
This thesis examined the characteristics of persons found NCRMD for sexual offences, their offences, and the degree to which empirically supported risk factors predicted Review Board decisions. Reasons documents dated from 2006 to 2015, and examining index sexual offences were collected from LawSource $\odot$. Search terms were derived from the Canadian Criminal Code (1985, c. C-46), and commonly accepted terminology for sexual offending. Findings suggest that persons found NCRMD for sexual offences present with general and sexual offence specific risk factors for recidivism. However, Review Board decisions were only predicted by factors related to clinical functioning and risk management factors. These findings suggest that further research is needed to examine risk assessment, decision making, and forensic mental health outcomes of persons found NCRMD for sexual offences. Implications for treatment of persons found NCRMD and knowledge dissemination to Review Boards are also discussed.
\end{abstract}




\section{Acknowledgements}

I would like to acknowledge everyone who was wholeheartedly invested in the successful completion of this thesis. Your support has made this project possible. 


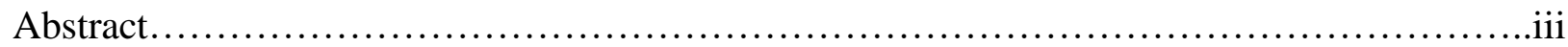

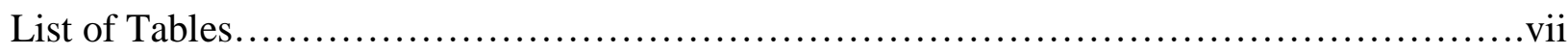

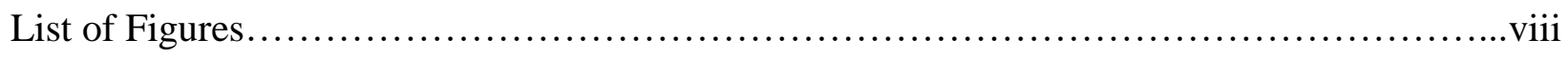

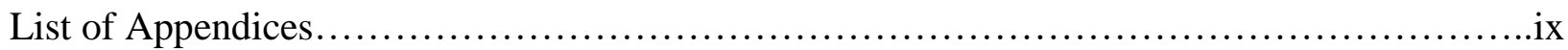

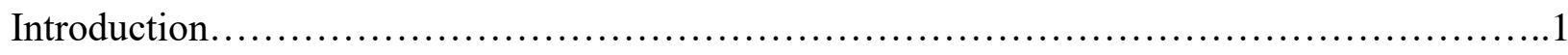

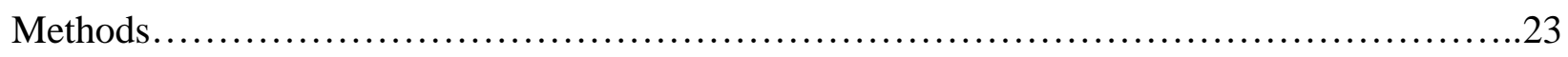

Sample of Studies.......................................................23

Selection criteria................................................23

Materials................................................................ 24

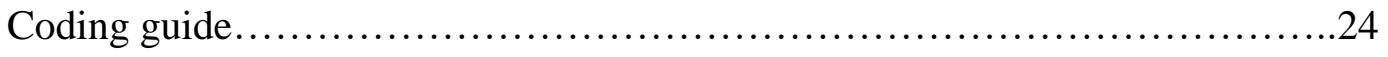

Historical Clinical Risk Management-20 Version 3 (HCR-20)..................25

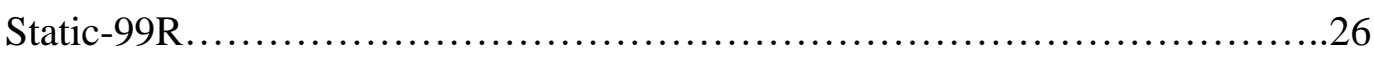

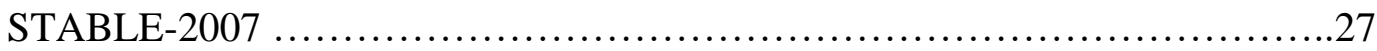

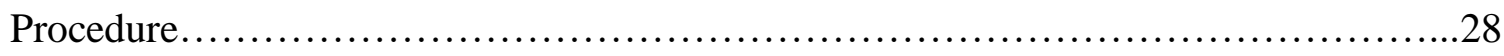

Database construction..........................................28

Statistical analyses................................................ 31

Descriptive statistics........................................ 31

Prediction of Review Board decisions and outcomes...................32

Statistical power for predicting decisions..........................33

Results.............................................................. 35

Review Board Reasons Characteristics................................. 35

Sample Characteristics ............................................. 36

Criminal History ................................................. 37

Offence Characteristics........................................... 37

Outcomes under the Purview of the Review Board.........................38

Factors Found in Review Board Reasons...................................39

Prediction of Outcomes............................................43 
Predictive effect of Static-99R risk factors on disposition decisions.....43

Static-99R total summed score...........................43

Predictive effect of HCR-20 ${ }^{\mathrm{V} 3}$ risk factors on disposition decisions.......44

HCR $-20^{\mathrm{V} 3}$ total summed score............................44

HCR-20 ${ }^{\mathrm{V} 3}$ historical, clinical, and risk management summed scores.

Predictive effect of hospital or clinical recommendation on disposition decisions. .48

Predictive effect of risk factors and time spent under purview of the Review Board on outcomes........................................48

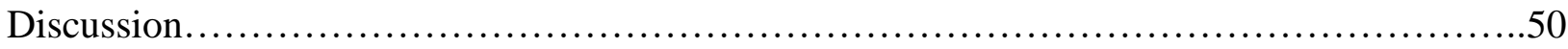

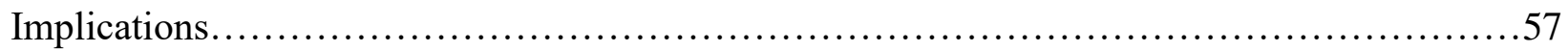

Review Boards Reasons Documents are Inconsistent............................57

Persons Found NCRMD for Sexual Offences are a Generally Homogeneous Group.....58

Need for Offence Specific Treatment Interventions in NCRMD populations............59

Factors Influencing Review Board Decisions...................................61

Clinician or hospital recommendation.................................66

General criminogenic risk factors..................................62

Sexual offence specific risk factors...................................63

Overall Outcomes.....................................................63

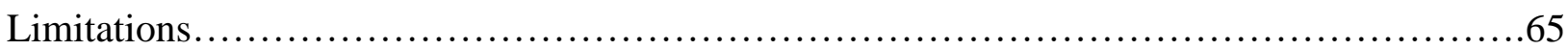

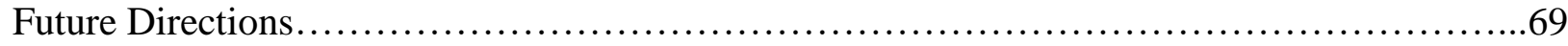

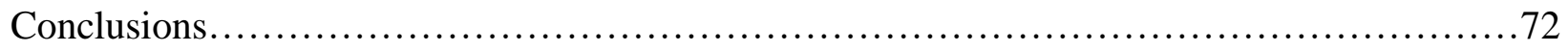

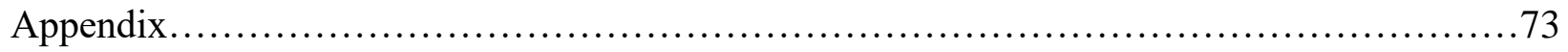

References.................................................................. 104 


\section{List of Tables}

1. Mann, Hanson, \& Thornton's (2010) Psychologically Meaningful Risk Factors..............8

2. Mentioned Use of Assessment Tools in Review Board Reasons Documents.................35

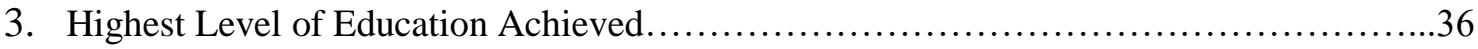

4. Relationship Status at the Time of Index Offence .................................. 36

5. Present, Absent, and Missing Static-99R Risk Factors...............................

6. Present, Absent, and Missing HCR-20 ${ }^{\mathrm{V} 3}$ Risk Factors................................... 


\section{List of Figures}

1. Static99-R Summed Scores.............................................40

2. HCR-20 ${ }^{\mathrm{V} 3}$ Summed Scores.............................................

3. HCR $-20^{\mathrm{V} 3}$ Historical Scale Summed Score ..................................42

4. HCR-20 ${ }^{\mathrm{V} 3}$ Clinical Scale Summed Score................................... 42

5. HCR-20 ${ }^{\mathrm{V} 3}$ Risk Management Scale Summed Score.............................43 


\section{List of Appendices}

1. Not Criminally Responsible Sexual Offence Coding Guide.......................73 
Persons found not criminally responsible on account of mental disorder (NCRMD) for sexual offences: Characteristics, risk factors, and Review Board decision making.

Not criminally responsible on account of mental disorder (NCRMD) designations have been steadily increasing in the Canadian context (Latimer \& Lawrence, 2006). In 2015, the Ontario Review Board reported that the number of persons subject to the Review Board had quadrupled since 1992 when the defence was introduced (Ontario Review Board, 2015). With increasing numbers of persons found NCRMD comes an increasing need for forensic services $-\mathrm{a}$ trending demand that has been noted internationally (Crocker, Braithwaite, Côté, Nicholls, \& Seto, 2011; Jansman-Hart, Seto, Crocker, Nicholls, Côté, 2011; Priebe et al., 2005; Seto et al., 2001). In light of more persons being designated NCRMD and increasing demands being placed on the forensic system that manages this population, it becomes increasingly important to understand the impact of this pattern on both public safety and on the fair administration of justice. One way to do this is to consider the characteristics of persons found NCRMD, and the factors that influence decisions about the management of persons found NCRMD within the forensic mental health system. Doing so will elucidate if decisions about this group are made in a way in line with what we know of risk for recidivism. This in turn can help ensure that the forensic system can reduce threats to public safety, and ensure that persons found NCRMD move through the system in an efficient and fair manner.

Despite this, there is a dearth of research that examines the characteristics or risk factors of persons found NCRMD. This is particularly true of persons who have committed sexual offences. Only two studies have included any analyses that consider persons found NCRMD for sexual offences (Crocker, Seto, Nicholls, \& Côté, 2013; Moulden, Chaimowitz, Mamak, \& 
Hawes, 2014). Though this research provides some insight into the characteristics of this group, more research is needed. It is argued that to properly assess and treat persons found NCRMD we must understand both their characteristics as persons declared NCRMD and as persons committing sexual violence. Thus, research is needed that illustrates the psychological and criminological characteristics of this population. Specifically, research is needed to examine the degree to which this population presents with empirically supported risk factors, and how decisions are made about the management and release of persons found NCRMD for sexual offences in the forensic mental health system.

This thesis will begin to fill this gap by assessing three areas: (1) the characteristics of persons found NCRMD for sexual offences; (2) the degree to which persons found NCRMD for sexual offences present with empirically supported risk factors (as defined in validated risk assessment tools); and (3) the relationships between the presence of risk factors in persons found NCRMD for sexual offences, and decisions made by Review Board tribunals about the management of this population within the forensic mental health system.

\section{The Forensic Mental Health System}

The NCRMD defence. As defined in the Canadian Criminal Code, a person is NCRMD for an offence when a mental disorder results in incapacity to appreciate the nature or quality of the offence, or that it was wrong (Criminal Code, R.S.C., 1985, c. C-46). The current iteration of the NCRMD defence was enacted by Bill C-30 in 1992. Bill C-30 updated the terminology used in this defence, which had previously been referred to as "not guilty by reason of insanity" and include outdated and ill-defined terms describing the defence (i.e. "natural imbecility" and disease of the mind). Under Bill C-30, it is now required that whatever party raises the possibility of the NCRMD defence is responsible for showing on the balance of probabilities that the 
defendant suffered from a mental disorder at the time of the offence, and that that disorder affected the defendant's ability to appreciate the nature and quality of their behaviour, or that it was wrong. Thus, the presumption of the NCRMD defence is that while the person found NCRMD is not contested for having committed an offence (actus rea), they did not have criminal intent for the offence (mens rea), and consequently cannot be criminally responsible for their actions. The next update to the NCRMD defence occurred in 1998. In the Supreme Court of Canada case, Winko v. British Columbia (1998), the Supreme Court ruled that a defendant found NCRMD should only be detained if they pose a threat to the public.

Characteristics of persons found NCRMD, and their offences. Crocker and colleagues (2015b) examined the characteristics of persons found NCRMD in the three largest Canadian provinces in efforts to contextualize who was being given this designation, and for what offences. Their sample consisted of 1800 persons found NCRMD in Ontario, Quebec, and British Columbia. Persons found NCRMD in this sample were found NCRMD for offences against the person (64.9\%), property offences (16.9\%), and other Criminal Code violations (e.g. weapons charges, driving and/or motor vehicle charges, violation of federal and/or provincial statutes) (18.2\%). Sexual assaults accounted for only $2.3 \%$ of this sample. Overall, the victims from all types of offences were a little more than half male, and most likely to be family members, followed by professionals, strangers, and other known persons. However, when persons found NCRMD for sexual offences, specifically, were considered, strangers accounted for $55 \%$ of victims. Notably, about half of the sample had some form of criminal history, and approximately one third of this sub-group had committed some form of offence against the person. 
With respect to personal characteristics, they found that persons found NCRMD were largely male (84.4\%), and were an average age of approximately 36 years old. About three quarters of persons in their sample were single, and about one in ten were homeless at the time of the offence. With respect to the sample's background, Crocker and colleagues noted some diversity, with documentation suggesting about a third of the sample was born outside of Canada, and about 3\% of the sample were of Indigenous status. The most common diagnosis in the sample was a psychotic spectrum disorder, followed by mood disorder, substance use disorder, and personality disorder. There were also high rates of comorbidity between psychiatric diagnoses, and substance use disorder.

The Canadian review board system. Once declared NCRMD, the accused comes under the purview of a Review Board, an independent tribunal which determines their disposition (Criminal Code, R.S.C., 1985, c. C-46; Criminal Code of Canada, R.S.C., 1985, c. C-46, s. 672.54). The Review Board must include a chairperson, typically a lawyer or judge, a psychiatrist, and one other member who is a lawyer, psychiatrist, psychologist, or lay person (Criminal Code, R.S.C., 1985, c. C-46, s.672). In making decisions about dispositions, Review Boards are required to make the least onerous and restrictive disposition available, while balancing the need to protect the public, the mental condition of the accused, their reintegration into society, and other relevant psycho-legal needs (Criminal Code, R.S.C., 1985, c. C-46).

As noted above,in making decisions about dispositions, Review Boards must consider the threat an accused person poses to public safety. Given that the Review Board's "most central and difficult task" is to predict future risk of harm ( $R v$. Owen, 2003), use of empirically-based risk of recidivism research could be of great assistance. Several psychosocial factors, known as risk factors have been shown to reliably predict recidivism in sexual offending populations (Andrews 
$\&$ Bonta, 2006). Knowledge of these risk factors has been utilised to develop empirically supported risk assessment tools to support clinical risk predictions. Meta-analytic research has found strong evidence that risk assessment can improve estimation of the likelihood of reoffending (Bonta, Law, \& Hanson, 1998; Campbell, French, Gendreau, 2009; Hanson \& Morton-Bourgon, 2009; Yang, Wong, \& Coid, 2010). Effective assessment for persons found NCRMD is an important aspect of risk assessment, but also to rehabilitation. Rehabilitation is important to Review Board decisions, due to its relationship to effective management in detention and in the community. The Supreme Court of Canada has outlined that all persons found NCRMD are entitled to rehabilitation and that restrictions to liberty are for the purpose of rehabilitation, not punishment (Winko v. British Columbia, 1998). Given the symbiotic relationship between rehabilitation and protection of the public, the assessment of threat and any subsequent rehabilitation are important factors in the selection of the least onerous and restrictive disposition to be assigned by Review Boards (Winko v. British Columbia, 1998).

\section{The Risk-Needs-Responsivity Model}

The dominant model guiding the assessment and rehabilitation (Hart, Sturmey, Logan, McMurran, 2011; Rotter \& Carr, 2013) is the Risk-Needs-Responsivity (RNR) model (Bonta \& Andrews, 2007). The RNR model outlines the essential components of rehabilitations and has been found to be the most effective method of reducing future offences (Andrews \& Bonta, 2010). Three principles guide the use of this model. The risk principle requires that the level of service match one's risk to reoffend. The need principle requires that criminogenic needs be assessed and subsequently targeted in treatment, and the responsivity principle requires treatment be tailored to maximize a person's ability to benefit from the intervention (Bonta \& Andrews, 2007). When rehabilitative efforts incorporate all three of these principles into treatment, 
treatments are more effective at reducing recidivism (Andrews \& Bonta, 2010). Based on these principles, an important first step in managing a client is to effectively assess the client's level of risk and criminogenic needs for treatment in order to guide rehabilitation, and custodial or community management (Bonta \& Andrews, 2007). This is typically done in a sexual offender risk assessment.

\section{Risk Assessment}

Sexual offender risk assessment is a process of estimating the likelihood that a person who has committed a sexual offence will commit further offences (Hanson, 1998). Persons who have committed sexual offences recidivate sexually at lower rates than commonly perceived by the public (Andrews \& Bonta, 2006; Hanson \& Bussiere, 1998; Harris \& Hanson, 2004). Research suggests that sexual recidivism occurs at a rate of approximately 10-15\% (Hanson \& Bussiere, 1998; Harris \& Hanson, 2004; Hanson \& Morton-Bourgon, 2009) and nonsexual recidivism occurs in approximately $36 \%$ of cases (Hanson \& Morton-Bourgon, 2005). Sexual offender risk assessment is thus important in several ways. Since not all persons committing sexual offences are equally likely to reoffend, risk assessment can help estimate the likelihood of recidivism and threat to public safety. This can assist decisions about eligibility for release to the public and under what conditions. Additionally, risk assessment helps to guide treatment decisions by assigning the highest level of treatment to the offenders with the greatest risk, and informing treatment targets, and making effective recommendations about risk management (Bonta \& Andrews, 2007; Hanson, 1998; Harris \& Hanson, 2004).

The history of risk assessment. Andrews, Bonta, and Wormwith (2006) have conceptualized the history of risk assessment as occurring in four generations. The first generation of risk assessment took the form of unstructured professional judgements. In this 
generation of assessment, estimations of risk were based upon correctional and clinical staff's experience and expertise. The second generation of risk assessment recognized the need for increased use of evidence-based decision making in estimations of risk. Actuarial assessment was borne of this generation of assessment, and considered individual and historical items statistically associated with offending. Considerable evidence supports actuarial assessment as being superior to unstructured professional judgements (Andrews et al., 2006; Hanson \& Morton-Bourgon, 2009). The third generation of risk assessment expanded upon this more structured method of assessment, and sought to include both historical factors, in addition to theoretically relevant dynamic and changeable items that could account for changes in the circumstance or presentation of the person being assessed. This generation was also useful for guiding intervention and identifying targets for change in treatment. Finally, the fourth generation of assessment builds upon the third generation, and focuses on the provision of continuous assessments of historical, dynamic, and other personal factors relevant to treatment, in order to better integrate risk assessment into case management.

Risk factors. Individually, the items used in risk assessments can be referred to as risk factors. Risk factors have generally been classified as either static or dynamic (Andrews \& Bonta, 2006; Bonta, 1996). Static risk factors are those historical or fixed aspects of a person's history associated with increased recidivism risk (e.g. history and characteristics of prior offending). Static factors cannot be targeted for improvement, however, and are subsequently not suitable to consider in rehabilitative efforts. Dynamic risk factors, in contrast, are psychological or behavioural characteristics that are amenable to change, and are the most useful factors to consider in the context of rehabilitation (Andrews \& Bonta, 2006; Andrews et al. 2006). 
Research has made considerable efforts to identify the risk factors that have shown to be empirically related to recidivism to assist in efforts to conduct evidence based assessments. Meta-analyses provide the most clarity in these efforts, since they can aggregate the predictive effects of various risk factors across other studies. Hanson and Morton-Bourgon's (2005) metaanalysis of adult and adolescent persons who have committed sexual offences found two factors were the major predictors of recidivism. These factors were deviant sexual preference (i.e. enduring attractions to illegal or highly unusual sexual acts) and antisocial orientation (i.e. presence of antisocial personality and/or antisocial traits and a history of rule violation). Psychological problems, including major mental illness, were not shown to be predictive of Table 1

Mann, Hanson, \& Thornton's (2010) psychologically meaningful risk factors

\begin{tabular}{|c|c|c|c|}
\hline Empirically supported & Promising & $\begin{array}{c}\text { Unsupported, with } \\
\text { interesting exceptions }\end{array}$ & $\begin{array}{c}\text { Unrelated to } \\
\text { recidivism }\end{array}$ \\
\hline $\begin{array}{l}\text { Sexual preoccupation } \\
\text { Deviant sexual interest } \\
\text { Offence supportive attitudes } \\
\text { Emotional congruence with children } \\
\text { Lack of intimate adult relationships } \\
\text { Lifestyle impulsivity } \\
\text { Self-regulation problems } \\
\text { Poor cognitive problem solving } \\
\text { Resistance to rules/ supervision } \\
\text { Grievance hostility } \\
\text { Negative social influences }\end{array}$ & $\begin{array}{l}\text { Hostility toward women } \\
\text { Machiavellianism } \\
\text { Callousness/lack of concern } \\
\text { Dysfunctional coping }\end{array}$ & $\begin{array}{c}\text { Denial } \\
\text { View of self as inadequate } \\
\text { Major mental illness } \\
\text { Loneliness }\end{array}$ & $\begin{array}{c}\text { Depression } \\
\text { Poor social skills } \\
\text { Poor victim empathy } \\
\text { Treatment motivation }\end{array}$ \\
\hline
\end{tabular}

recidivism in this analysis. In their meta-analysis and review, Mann, Hanson, and Thornton (2010) sought to clarify which factors are empirically related to risk. Their findings are summarized in Table 1. Similar to Hanson and Morton-Bourgon (2005), Mann and colleagues (2010) found that, overall, major mental illness did not predict recidivism, though there were enough notable exceptions to suggest this be explored further, to understand under which conditions, mental illness might exert an effect on recidivism. Factors that were empirically related to recidivism were those risk factors or criminogenic needs largely in line with the RNR 
model. These factors are referred to as the "Central Eight" and are the eight factors consistently found to relate most strongly to recidivism (Andrews \& Bonta, 2006; Andrews \& Bonta, 2010). These eight factors are 1) a history of antisocial behaviour; 2) antisocial personality patterns; 3) antisocial cognitions; 4) antisocial associates; 5) family and marital circumstances; 6) issues in school and/or work; 7) issues in prosocial leisure activities; and 8) substance abuse. Nonetheless, the ultimate recommendation from this body of work is to avoid estimating risk based on any single risk factor (Hanson \& Morton-Bourgon, 2009; Mann et al., 2010), instead using comprehensive assessments of a range of psychological risk factors to predict risk.

Actuarial and structured professional judgement assessment tools. Given the need to consider a variety of risk factors in the estimation of risk, risk assessment tools have been widely adopted as structured methods to guide such assessment (Neal \& Grisso, 2014). Structured approaches to assessment are preferred for their demonstrated superiority to unstructured professional opinion with respect to predictive validity (Hanson \& Morton-Bourgon, 2009) and due to the transparency and reliability of risk assessment tools (Fazel, Singh, Doll, \& Grann, 2012). Given that assessing clinicians are ethically responsible for making the best decisions for their clients, the evidence supporting the utility and validity of risk assessment tools suggests that use of these tools in assessment is ethically required (Dawes, 2005). For a clinician to assume they can make more accurate judgements - contrary to existing evidence - is in and of itself unethical (Dawes, 2005). In the field of risk assessment, two of the most commonly used forms of structured assessment tools are actuarial risk assessment tools and structured professional judgement (SPJ) tools.

Actuarial risk assessments are empirically based assessments that provide probability estimates for an individual's likelihood of recidivating (Bonta \& Andrews, 2007). Actuarial tools 
include clear definitions for their items, item coding rules to improve reliability, rules for combining items into total scores, and probability estimates of the likelihood of reoffending related to the tool's total scores (Meehl, 1954). Actuarial tools have been found appropriate for use in a variety of offending populations, including persons who have committed sexual offences (Hanson \& Bussiere, 1998) and "mentally disordered offenders" (MDOs) (i.e. persons in the correctional system diagnosed with mental disorders) (Bonta et al., 1998).

SPJ tools are developed using clinical data and existing research to identify areas of risk, which are then defined and operationalized (Douglas, Ogloff, \& Hart, 2003). In SPJs, the final estimation of risk depends on the clinician's judgement of the person's specific risks in the identified areas, as opposed to probabilistic estimates.

Each type of risk assessment tools has its pros and cons for use. Actuarial assessments have been criticized for being a-theoretical, and for including only static risk factors, which prevents these tools from being able to account for improvements in recidivism risk due to rehabilitative efforts (Andrews \& Bonta, 2006). However, some actuarial tools have sought to include dynamic risk factors to address these concerns (e.g. STABLE-2007, Hanson, Harris, Scott, \& Helmus, 2007). Further, despite raised concerns, actuarial tools have been shown to have good predictive validity in diverse groups of persons who have committed sexual offences. Hanson and Morton-Bourgon's (2009) conducted a meta-analysis of 118 distinct prediction studies of over 45,000 general persons who committed sexual offences in 16 countries. They found that actuarial tools had good predictive validity with respect to predicting sexual recidivism, with moderate to large effect sizes across types of recidivism ( $d=0.67$ to 0.97$)$ and significantly outperformed unstructured professional judgement. 
SPJ tools, on the other hand, have been criticized for their considerable variability and inability to specify absolute and meaningful risk levels (Hanson \& Morton-Bourgon, 2009), and for including professional discretion in determining the level of risk present, since professional discretion can fall victim to several of the same shortcomings as unstructured professional judgement (e.g. subjectivity) (Kropp \& Hart, 2004). The proposed benefit of SPJ assessments is that its element of professional discretion is valuable in identifying which factors are most relevant to a person's risk, and identifying those that may be important to address in interventions (Douglas et al., 2003). SPJ tools are also able to account for risk factors amenable to change in intervention, and are useful to assessment and to informing interventions (Bonta \& Andrews, 2007). Like actuarial tools, SPJ tools have also been shown to significantly outperform unstructured clinical opinions with respect to their predictive validity (Hanson \& MortonBourgon, 2009).

Many have debated the superiority of one family of assessment tools over the other. Some meta-analyses have shown actuarial tools to be superior in terms of predictive ability (Hanson \& Morton-Bourgon, 2009) while others have shown that SPJ tools and actuarial tools are equally as effective in predicting recidivism (Fazel et al., 2012). Further, some research has suggested that the element of professional assignation of a risk level improves upon simply considering risk factors included on SPJ tools in a mechanical fashion (e.g. Pedersen, Rasmussen, \& Elsass, 2010).

Regardless of one's personal preference for actuarial or SPJ tools, research supports that assessments using structured risk tools improve prognosis of risk. Research has not come to a consensus on any one risk assessment method or tool that consistently predicts recidivism over all others (Hanson, 2009; Singh, 2015). Instead, assessors selecting tools for use should consider 
which assessment tools best fits their needs with respect to the population and outcomes it was designed to assess (Singh, 2015).

\section{The Role of Mental Health in Risk for Recidivism}

While the role of mental illness in index offences that lead to a finding of NCRMD cannot be overlooked, mental illness is not necessary or sufficient in explaining violence or offending, despite public perception and stigma connecting these phenomena (Stuart, 2003). Indeed, one meta-analysis found that presence of a mental disorder is related inversely to general and violent recidivism (Bonta et al., 1998). Instead, the effect of mental health concerns has been suggested to affect one's level of stability and stress, which can increase the likelihood that pre-disposing risk factors will be problematic for the person under consideration. That is, mental illness is likely to act as a catalyst for pre-existing risk for deviance or recidivism (Skeem, Steadman, Manchak, 2015). This explanation of the role of mental health in offending has been supported by research and practice in two key areas.

First, research has shown that persons with mental illness in the justice system present with general risk factors for reoffending (Skeem et al., 2015) and that risk factors for both general and violent recidivism are similar to persons who commit offences and who do not suffer from mental illness (Bonta et al., 1998) This includes risk factors related to antisocial orientation, such as antisocial personality and antisocial traits, and a history of rule violation (Bonta et al. 1998). Persons convicted of sexual offences who also suffer from mental illness, have also shown similarities in their sexual offence specific risk factors for recidivism, including age and number of previous convictions (Phillips et al., 2005).

Seeking to clarify the risk relevant role of clinical factors, such as mental illness, relative to empirically supported risk factors (i.e. the Central Eight, Andrews \& Bonta, 2006; Andrews \& 
Bonta, 2010), Bonta, Blais, and Wilson (2014) conducted a meta-analysis of risk and recidivism in MDOs. Results from 126 studies in 96 unique samples found that Central Eight risk factors predicted general and violent recidivism, whereas clinical factors did not. The only clinical factor that predicted both forms of recidivism was a diagnosis of antisocial personality or psychopathy, which is also addressed in the Central Eight's Antisocial Personality Pattern, and was found to be particularly predictive of risk in persons found "not guilty by reason of insanity" compared to MDOs without that designation. They further found that having no diagnosis of mental disorder predicted general or violent reoffending.

Second, there is a lack of evidence that mental health diagnoses are related to recidivism in persons who have committed sexual offences (Kingston, Olver, Harris, Wong, \& Bradford, 2015) nor that psychiatric treatment alone can improve recidivistic outcomes (Morgan et al., 2012; Peterson, Skeem, Kennealy, Bray, \& Zvonkovic, 2014; Peterson, Skeem, Hart, Vidal, \& Keith, 2010; Skeem et al., 2015). In Canadian samples of persons who have committed sexual offences, and who are accessing inpatient or outpatient mental health services, Kingston and colleagues (2015) found mental health diagnoses were not predictive of recidivism alone, nor in multivariate analyses. Further, in a review of treatment outcome studies, Morgan et al. (2012) found that treatment of mental illness in criminal justice settings did not reduce recidivism. In contrast, in reviews (Looman \& Abracen, 2013) and treatment studies (Abracen, Gallo, Looman, \& Goodwill, 2015) that consider combined attention to both criminogenic needs and mental health needs illustrated significant reduction in recidivism (Skeem et al., 2015).

Findings from these two areas of work suggest that mental illness itself does not predict recidivism, and that persons who commit offences and suffer from mental illness still present with risk factors for reoffending. Further, findings suggest that treating criminogenic needs in 
this population, as opposed to solely focusing on psychiatric treatment, can improve outcomes. Accordingly, further attention is needed on how existing knowledge of RNR based treatment (Andrews \& Bonta, 2006; Andrews \& Bonta, 2010) can be extended to persons committing offences with serious mental illness, such as persons found NCRMD for sexual offences (Skeem et al., 2015). To facilitate further implementation of treatment of criminogenic needs in persons with serious mental illness, one suggestion in the literature is to conceptualize serious mental illness as a responsivity factor within the RNR model of treatment (Skeem et al., 2015). This approach may be one worth considering for persons found NCRMD for sexual offences, if they demonstrate similar patterns of risk as other groups of persons who commit sexual offences.

\section{Assessment in the Forensic Context}

In an international survey of psychologists and psychiatrists in professional forensic mental health associations, Neal and Grisso (2014) found high rates of structured assessment tool use. Clinicians reported the use of assessment tools to guide violence risk assessments, risk assessments for those convicted of sexual offences, and criminal responsibility assessments $(89 \%, 96.9 \%$, and $71.8 \%$ of respondents, respectively). However, findings also suggested considerable variability in the types of tools used in these forensic assessments. Neal and Grisso found reports of 110 different assessment tools being used in violence risk assessments, 78 different tools reported for risk assessments of sexual risk, and 69 different tools reported for criminal responsibility assessments. When clinicians used assessment tools, they reported doing so to use an evidence-based method, or to increase the credibility or standardizability of the assessment. Those clinicians who did not report using assessment tools most often reported neglecting assessment tools because they trusted their clinical judgement, or perceived some limitation associated with the assessment tools. This is troubling, as a large body of research has 
consistently found unstructured clinical judgement to be inaccurate, particularly in comparison to structured forms of assessment (Hanson \& Morton-Bourgon, 2009).

After concluding their review, Neal and Grisso (2014) concluded that forensic evaluators have commonly adopted the practice of using structured tools to guide their assessments. The next step in the field of assessment should thus be determining how to utilize assessment tools in an effective and efficient way. They suggest this includes favouring measures that have strong psychometric properties, choosing tools based on their incremental validity, and developing methods of structured decision making which are complete but use the most efficient amount of data.

Assessment for Review Board hearings. Neal and Grisso's international survey did not provide information on the assessment of risk for persons found NCRMD, specifically. What little research exists suggests that, unlike most areas of forensic assessment, structured risk assessments are used inconsistently in assessing the risk of persons found NCRMD (Crocker, Nicholls, Charette, \& Seto, 2014). Research suggests that few risk factors are mentioned in hospital reports (Côté, Crocker, Nicholls, \& Seto, 2012), and that risk assessment tools and risk factors are discussed in a minority of cases (Wilson, Crocker, Nicholls, Charette, \& Seto, 2015). Further, according to Crocker and colleagues (2014), structured risk tools were only mentioned in $17.3 \%$ of Review Board hearings, despite the availability of risk assessment information within the review reports.

\section{Review Board Decisions about Persons found NCRMD}

Little research examines how Review Boards make decisions about the disposition of persons found NCRMD. What research exists suggests Review Board decisions are unrelated to some validated risk assessments and/or their risk factors (Côté et al., 2012; Crocker et al., 2011; 
Hilton \& Simmons, 2001) or are related to or predicted by factors with little to no empirical relation to risk. Indeed, findings have suggested that decisions about discharge (i.e. release into the community) are influenced by non-risk related factors. For example, the nature and severity of one's index offence, and a diagnosis of a psychotic spectrum disorder reduce the chance of discharge, while a mood disorder diagnosis increases the chance of being discharged (Crocker et al., 2015a). Across this body of work, non-risk related factors related to decisions include clinical factors, attractiveness, psychiatric history, demographic characteristics, and index offense severity (Côté et al., 2012; Crocker et al., 2011; Crocker et al., 2014; McDermott \& Thompson, 2006; McDermott et al., 2008; McKee, Harris, \& Rice, 2007; Wilson et al., 2015; Wilson, Nicholls, Charette, Seto, \& Crocker, 2016). Research on the factors that predict the total length of time persons found NCRMD spend under the purview of the Review Board have a similar pattern of findings, and suggest that time spent under purview is typically related to non-risk related factors (Martin \& Martin, 2016, for discussion)

What research exists also suggests that Review Board decisions are often related to clinician recommendation (Côté et al., 2012; Crocker et al., 2011; Crocker et al., 2014; Hilton \& Simmons, 2001; McKee et al., 2007). Though this seems like a promising finding intuitively, clinician judgements have been shown to be susceptible to low reliability, systematic error, and bias (Hilton and Simmons, 2001). Additionally, some research has found recommendations and decisions were not in line with the actuarial risk, only consider clinical management and treatment effects, and may not accurately identify which persons are of the lowest risk and may be most appropriate for reduced security or discharge (Hilton \& Simmons, 2001). This may be explained by research on how recommendations are made by forensic mental health teams. Such research suggests that when teams discuss recommendations, there is a lack of conversation 
about risk (Lyall \& Bartlett, 2010). Additionally, there is some evidence that when forensic treatment teams discuss their recommendations, only some types of recommendations are predicted by empirically validated risk factors, while others are only related to clinical incidents (Martin \& Martin, 2016). Thus, the degree to which evidence based methods are being used by clinicians to make recommendations is unclear.

Discussion of what factors are related to Review Board decisions is not simply a theoretical problem about decision making processes. These decisions guide one's progression through the forensic mental health system. Given that the purpose of risk assessment is to protect the public while also ensuring persons found NCRMD receive the least onerous and restrictive disposition (Criminal Code, R.S.C., 1985, c. C-46), it is important that this process consider existing evidence on how to evaluate risk. This could result in serious consequences for the public and implications for the liberties of persons who have been absolved of criminal responsibility, yet find themselves continuing to be subject to the forensic mental health system.

The most recent evidence, however, does suggest that Review Board decisions are increasing the degree to which they discuss and consider some risk relevant information in recent years. Some research has found that when risk assessments themselves are not considered, Review Boards still discuss empirically valid and/or legally relevant criteria (Côté et al., 2012; Crocker et al., 2014; Wilson et al., 2015), particularly those that are featured on the risk assessment tool, the Historical Clinical Risk Management-20 (HCR-20; Webster, Douglas, Eaves, \& Hart, 1997). This includes factors related to mental health, treatment response, and criminal history (Côté et al., 2012; Crocker et al., 2014; Wilson et al., 2015). Wilson and colleagues (2016) found that the clinical factors of the HCR-20 did influence Review Board decisions, particularly those that occurred after rehospitalization while on conditional discharge 
(i.e. more clinical factors predicted detention), though factors on the historical scale did not have an effect. Further, authors found that the use of a structured risk assessment reduced the likelihood of detention, which was suggested may be due to increased confidence in clinician recommendations, and subsequently greater confidence in deciding upon less restrictive dispositions. Authors noted that this highlighted the need to continue efforts to integrate structured tools consistently into clinical forensic practice and into Review Board decisions.

This research on persons found NCRMD for all types of offences highlights the need for further work in research and practice to ensure decisions made by Review Boards are based on empirical information that can help Boards make well informed decisions. It also begs the question of how factors influencing Review Board decisions may differ between persons found NCRMD for specific types of offences. This may be particularly important for persons committing sexual offences, given the high profile of these types of offences in the media, public concern about these types of offences, and the bias these factors may introduce. Further, there are a plethora of well researched and often used risk assessments designed to examine recidivism risk in persons committing sexual offences, specifically.

Assessing risk in persons found NCRMD for sexual offences. Despite the importance of risk to understanding threat to public safety, and to assessment and rehabilitation, only two studies have considered persons found NCRMD for sexual offences, specifically.

\section{Comparing persons committing sexual offences in correctional and forensic}

populations. Moulden and colleagues (2014) sought to compare persons who have committed sexual offences in correctional (i.e. that are managed in the federal or provincial correctional services) and forensic (i.e. that are managed within forensic mental health systems, specifically) populations. Several differences were found between these populations. Persons who committed 
sexual offences in the forensic system were more likely to have more hospital admissions, be single, commit fewer intrusive sexual acts, and suffer from a serious mental illness, particularly psychosis. For those persons with child victims, those in the forensic system were also more likely than correctional populations to have stranger victims, and be diagnosed with a personality disorder, while persons in the forensic system with adult victims had more education, and were less likely to use weapons in their offences. Moulden and colleagues suggested that this indicated a greater trend toward antisociality and intrusive acts in correctional as opposed to forensic populations. In turn, this could indicate an important potential difference in risk and management needs between these groups, and the ability to generalize assessment and treatment between these groups (Moulden et al., 2014). Another important factor that warrants consideration between these groups is the impact of mental illness on social functioning, and capability to meet needs for intimacy and emotional connections in socially appropriate ways (Moulden et al., 2014). The difference in several factors in these groups supports future research on risk factors, and risk assessment in forensic contexts. This could help to determine important similarities and differences in the needs of persons found NCRMD for sexual offences, and where our current knowledge of sexual offending may be generalized to persons found NCRMD.

Persons found NCRMD for serious violent offences. In a larger study of persons found NCRMD for serious violent offences (“SVOs"), Crocker and colleagues (2013) examined several characteristics of persons who had committed sexual offences in this group. With respect to demographics, persons found NCRMD for sexual offences were an average of 32.5 years old, and were $97.6 \%$ male. Psychotic disorders were most commonly diagnosed in this population, followed by substance use disorders, and mood disorders. Disorders were commonly comorbid. Fifty percent of persons found NCRMD for sexual offences had criminal histories, $40.5 \%$ of 
which were violent. Compared to other persons found NCR for SVOs, this study found persons found NCRMD for sexual offences frequently have higher rates of previous offences, and higher rates of stranger victims, both of which have been shown to predict recidivism (Hanson \& Thornton, 2000). Indeed, compared to other persons found NCRMD for SVOs, persons found NCRMD for sexual offences had higher rates of both violent and non-violent recidivism (Crocker et al., 2013). Yet, persons found NCRMD for sexual offences had the lowest rates of detention in a forensic mental health setting upon being found NCRMD, and had the highest rates of absolute discharge $(60 \%)$ at the end of the study's follow up period (Crocker et al., 2013). Persons found NCRMD who committed sexual offences also had the shortest length of time under the purview of the Review Board, at an average of 1.8 years (Crocker et al., 2013).

The characteristics of persons found NCRMD for sexual offences. These two studies begin to shed some light of the characteristics of persons found NCRMD for sexual offences. Both studies suggest that this group presents with risk factors, including single-hood, stranger victims, and frequently violent criminal histories. Crocker and colleagues (2013) also found that this group had higher rates of recidivism than other persons found NCRMD for SVOs while also receiving shorter and less restrictive stays.

\section{Present Thesis}

Existing research on Review Board decisions, risk assessment, and persons found NCRMD for sexual offences highlight the need for research examining the effective assessment and management of this population. The present thesis attempts to fill some of the gaps in knowledge about persons found NCRMD for sexual offences. Four key areas were explored: 1) the characteristics of Review Board Reasons documents for decisions made about persons found NCRMD for sexual offences; 2) the characteristics of persons found NCRMD for sexual 
offences and the offences they commit; 3 ) the presence of empirically supported risk factors in persons found NCRMD for sexual offences, and 4) how Review Boards use risk information in decision making about persons found NCRMD for sexual offences.

This thesis first considered the characteristics of Review Board Reasons. This elucidated the types of information predictive of Review Board decisions. Previous research that has shown Review Boards do not report risk information consistently in their reasons. Research has also suggested that Review Board decisions are not consistently predicted by empirically supported risk assessment tools and risk factors. Thus, my first hypothesis was that Review Boards would be inconsistent in their consideration of risk assessment tools, and risk relevant information in their decision making. My second hypothesis was an extension of this, and specifically considered how Review Boards would consider sexual offence specific risk information. Given Review Boards do not consider risk information in general, it is hypothesised that they will be unlikely to consider offence specific information.

This thesis then explored the characteristics of persons found NCRMD for sexual offences to provide further detail and commentary on the features of this population. It examined the demographic characteristics, psychiatric diagnoses, criminal history, initial dispositions, and length of time under purview of review boards. This framework is consistent with the work of Crocker et al. (2013), which examined the characteristics of SVOs found NCRMD.

Finally, this thesis considered the presence of recidivism related risk factors in persons found NCRMD for sexual offences. It further examined how these risk factors and outcomes of structured risk assessments were related to tribunal decisions. My third hypothesis was that persons found NCRMD for sexual offences would display risk related characteristics, consistent with past findings (e.g. Crocker et al., 2013). My fourth hypothesis was that, beyond general risk 
factors, persons found NCRMD for sexual offences would present with risk factors for re-offense as included on sexual offence specific risk assessments, consistent with findings that MDOs convicted of sexual offences do present with risk factors for sexual recidivism (Bonta et al., 1998; Crocker et al., 2013). Despite the prediction that this group would present with general and sexual risk factors for recidivism, my fifth and final hypothesis was that dispositions would be unrelated to the presence of most empirically validated risk factors as indicated on supported risk assessment tools. Such disconnect between risk assessment and tribunal decisions has been shown in several studies considering assessment of persons found NCRMD, generally (Côté et al., 2012; Crocker et al., 2011; Crocker et al., 2014; Hilton \& Simmons, 2001; McKee et al., 2007). However, this literature is limited, and does not include specific examination of persons found NCRMD for sexual offences. The present results further explored this trend in this specific population. 


\section{Methods}

\section{Sample of Studies}

This thesis' sample was drawn from the legal database LawSource®, a WestLaw Next Canada product. This is a comprehensive, publicly available (Access to Information Act, 1985) database of legal reports. Cases were collected through a search of this database for cases adjudicated by tribunal boards and non-appeal courts. The search included documents from all provinces and territories, written in either English or French. Cases eligible for inclusion for this thesis were identified through systematic search of key terms. All searches included the key term not criminally responsible. Searches were then conducted for each of the following offence related terms, with and without the addition of the key term review board. Offence related search terms were: sexual assault, indecent act, indecent exposure, voyeurism, invitation to sexual touching, sexual interference, sexual exploitation, child pornography, and child molestation. Key terms were derived from terms referenced in the Canadian Criminal Code (1985, c. C-46), and commonly accepted nomenclature for sexual offending. Results from searches were refined to include only criminal cases, limited to the date range of January 1, 2006 to December 31, 2015, and cases presented to non-appeal court, and boards and tribunals.

Selection criteria. A total of 3,860 files were identified in the initial search of LawSource®. Four selection criteria for inclusion were then applied. First, cases must have resulted in an NCR designation. Second, cases must pertain to an index offence that received a charge for a sexual offence. Third, the index offence must have occurred between the dates of January 1, 2006 and December 31, 2015. Fourth, each case must have a minimum of one Review Board Reasons document available for access. After applying these selection criteria, 92 cases were identified for inclusion. 
Eligible cases were then sorted by name. Names from eligible cases were then entered into LawSource®. Additional court documents relevant to the person's index sexual offence were identified based on preliminary review of document text. Additional documents were eligible for inclusion if written prior to December $31^{\text {st }}, 2015$, the end of this thesis' follow up period. Any duplicate documents were removed. Once cleaning was completed, documents were compiled into the database. This resulted in a final sample of 327 legal documents, related to the index sexual offences of the 92 unique persons found NCRMD in this sample.

\section{Materials}

Coding guide. The coding guide used to build this project's database was developed by the author of this thesis. The coding guide (Appendix) includes 216 variables in 8 domains. The domains were: 1) case sorting variables; 2) variables identifying the nature of the sexual offence; 3) details of concurrent index offences; 4) details on the Review Board decisions; 5) details of the offence; 6) characteristics of the person found NCRMD; 7) psychological factors; and 8) risk factors supported by validated risk tools. Analyses in the current thesis utilized 142 of these variables, only excluding variables that were not present in the currrent sample (e.g. low frequency offence behaviours), various case sorting variables, or variables whose constructs were either not relevant to current analyses, or whose constructs were addressed in multiple variables and thus were redundant to current analyses.

This thesis considers risk factors included in both actuarial and SPJ risk assessment tools to conceptualize risk in the forensic mental health system. Actuarial tools that consider static and dynamic risk factors were used in this thesis. Static risk factors are typically historical factors that are unamenable to treatment intervention, whereas dynamic factors relate to criminogenic needs, that are more psychological and/or behavioural in nature, and can be targeted to reduce 
risk (Andrews \& Bonta, 2006). SPJ tools used in this thesis also considered a combination of historical and dynamic risk factors. By using this variety of tools, this thesis provides broader perspective on which types of tools may be most useful in the forensic mental health context, specifically. It also allows us to more broadly consider what types of factors are currently related to Review Board decisions.

Risk information was considered mechanically from the first available Review Board Reasons document during the study period. Mechanical coding schemes as defined in the coding guide code for the presence, absence, or inability to code risk factors supported by the STATIC99R (Hanson \& Thornton, 2000), HCR-20 V33 (Douglas, Hart, Webster, \& Belfrage, 2013), and the STABLE-2007 (Hanson et al., 2007). After initial coding, the risk factors related to each tool were summed to create a "summed score" variable for each tool. In the case of the HCR-20 V3, summed scores were also calculated for each subscale of the tool (i.e. Historical, Clinical, and Risk Management). It is important to note that though the risk assessment manuals and coding rules were used to determine the presence or absence of risk factors, this does not represent a true risk assessment score, as the materials required by coding manuals (i.e. Brankley, Helmus, \& Hanson, 2017; Douglas et al., 2013; Phenix et al., 2016) were not available.

Historical Clinical Risk Management-20 Version 3 (HCR-20). The HCR-20 (Douglas et al., 2013) is a SPJ violence risk assessment tool. Twenty items related to historical psychosocial factors, current clinic factors, and factors related to risk management are assessed and judged for their presence by a clinician. The 10 historical factors are a history of problems with: 1) Violence; 2) Antisocial behavior; 3) Interpersonal Relationships; 4) Employment; 5) Substance use; 6) Major mental disorder; 7) Personality disorder; 8) Traumatic Experiences; 9) Violent attitudes; and 10) Treatment or supervision response. The 5 clinical factors are recent 
problems with: 1) Insight; 2) Violent ideation or intent; 3) Symptoms of major mental disorder;

4) Instability; and 5) Treatment or supervision. The 5 risk management factors are future problems with: 1) Professional services and plans; 2) Living situation; 3) Personal support; 4) Treatment or supervision support; and 5) Stress or coping.

The presence and relevance of these factors are used by the clinician to assign a risk level to the person being assessed (i.e. low, moderate, high). The HCR-20 has been successfully applied in forensic mental health settings (Douglas, 2014). In forensic psychiatric settings, the HCR-20 has been shown to have good interrater reliability (ICC=.71-91) (Doyle, 2013; Holzinger, Eucker, Kotter, \& Muller-Isberner, 2013). It has also been shown to have good predictive validity in forensic populations, when items are scored mechanically $(A U C=.73-.74)$ (Doyle, 2013; Pedersen et al., 2010) and when final risk judgements are provided by professionals $(A U C=.78)$ (Pedersen et al., 2010).

Static-99R. The Static-99R (Hanson \& Thornton, 2000) is a well-established actuarial sexual risk assessment. The Static-99R assesses historical risk factors related to personal history, criminal history, and victimology (Hanson \& Thornton, 2000). Ten factors comprise the Static99R: 1) Age; 2) Living with a lover; 3) Index non-sexual violence convictions; 4) Prior nonsexual violence convictions; 5) Prior sex offences; 6) Prior sentencing dates; 7) Convictions for non-contact sex offences; 8) Unrelated victims; 9) Stranger victims; and 10) Male victims.

The Static-99R is the most commonly used actuarial risk assessment tool for sexual risk in North America (McGrath, Cumming, Burchard, Zeoli, \& Ellerby, 2010) and internationally (Neal \& Grisso, 2014). Its popularity is likely due to its strong psychometric properties. The Static-99R has been consistently shown to have good predictive validity. Meta-analyses have found moderate predictive validity overall ( $A U C=.69-70)$ (Helmus, Hanson, Thornton, 
Babchishin, \& Harris, 2012). Examinations of the tool's use in practice, however, show strong predictive effects (AUC $\geq .80$ ) (Hanson, Lunetta, Phenix, Neeley, \& Epperson, 2014; Hanson, Helmus, \& Harris, 2015) and predictive validity across forms of recidivism (sexual, violent, and general) (Hanson et al., 2015). Beyond this, the tool shows good inter-rater reliability in application. Research considering the reliability estimates for assessments conducted by community supervision officers, and corrections and probation officers have shown results ranging from acceptable (ICC=.78) (Hanson et al., 2015) to excellent (ICC=.91) (Hanson et al., 2014) across studies.

STABLE-2007. The STABLE 2007 (Hanson et al., 2007) is an actuarial risk assessment of sexual risk that considers risk relevant propensities that can be targeted in intervention and management of persons who have committed sexual offences. The STABLE-2007 has been successfully applied in correctional settings, and is the most commonly used measure of sexual offence related needs in Canada and the United States (Kelley, Barahal, Thornton, \& Olson, 2015; Hanson et al., 2015). When used by trained raters, the STABLE-2007 shows excellent reliability (ICC >.90) (Eher, Matthes, Schilling, Haubner-MacLean, \& Rettenberger, 2012; Fernandez, 2008). Meta-analysis has also shown that the STABLE-2007 can predict recidivism, and add incrementally to the predictive validity of the Static-99R (Brankley, Babschishin, \& Hanson, 2017). The instantaneous hazard ratio value of 1.07 in this meta-analysis suggests that, above the variance explained by the Static-99R, each additional point on a STABLE-2007 assessment increases the chance a person convicted of a sexual offence will commit sexual recidivism by $7 \%$. However, it is important to note that fidelity and training can have considerable effects on the validity of the STABLE-2007 (Hanson et al., 2015). 


\section{Procedure}

Database construction. The author of this thesis acted as coder for this database. Utilizing the project coding guide, cases were entered into an SPSS database. The first available Review Board Reasons document for each case was used to code offence details, personal characteristics, judgement details, psychological factors, and empirically supported risk factors. The last available Review Board Reasons document for each case was used to determine the length of time the person found NCRMD for sexual offences spent under the purview of the Review Board, and their final disposition within the study period.

To ensure reliability of coding procedures, an independent coder recoded a random sample of approximately $10 \%$ of cases $(n=10)$. Cohen's kappa analyses examined the reliability of categorical data in the data base $(n=136)$. Kappa was calculated for each variable, in addition to being averaged to provide understanding about the overall reliability of the sample. The average reliability of categorical data showed almost perfect agreement $(k=.88)$ (Landis \& Koch, 1977). It should be noted that five items ${ }^{1}$ had a kappa value of zero $(k=.000)$ due to one rater coding these variables as a constant (i.e. that no or all cases in the reliability sample presented with a variable of interest). Three of these items had a percentage agreement of $91.7 \%$, and two of these items had a percentage agreement of $83.3 \%$, showing strong agreement between raters despite inability to calculate a kappa value. When these five items were removed from the average kappa value, there was a slight improvement to reliability, with the categorical data continuing to show almost perfect agreement $(k=.90)$ (Landis \& Koch, 1977).

\footnotetext{
${ }^{1}$ The items for which $k=.000$ were Indigenous status, having a victim that was a friend, engaging oral sexual offence behaviours, Stable-2007 item general social rejection or loneliness, and HCR-20 $0^{\mathrm{V} 3}$ item history of problems with traumatic experiences.
} 
When the reliability of subgroups of categorical data were considered, it became apparent that while the vast majority of variables had excellent reliability, the STABLE-2007 items had the poorest reliability. The STABLE-2007 items had a combined reliability of $k=.64$, which falls below Krippendorff's (1980) suggestion that conclusions should not be drawn for variables with Kappa values of less than 0.67. Additionally, seven of the thirteen individual STABLE-2007 items did not meet the criteria of $k>.67$, these were: 1) Capacity for relationship stability $(k=.52)$; 2) Hostility towards women $(k=.21)$; 3) Lack of concerns for others $(k=.55)$; 4) Impulsive acts $(k=.49)$; 5) Negative emotionality ( $k=.59)$; 6) Sex Drive/Preoccupation ( $k=.60)$; and 7) Deviant sexual interests $(k=.43)$. According to Landis and Koch (1977), these values range from only slight to moderate agreement. Given that the majority of STABLE-2007 individuals items and its aggregate reliability were below Krippendorf's (1980) more conservative suggested minimum reliability criteria and are seen as less reliable in Landis and Koch's less stringent criteria, the risk factors of the STABLE-2007 were excluded from analyses.

In contrast, the Static-99R items $(k=1.0)$ and HCR-20 ${ }^{\mathrm{V} 3}$ items $(k=.83)$, had perfect or almost perfect agreement (Landis \& Koch, 1977), and met Krippendorff's cut off of $k=.67$. With respect to HCR-20 ${ }^{\mathrm{V} 3}$ variables, only three of twenty items did not meet minimum reliability criteria of $k=.67$ (Krippendorff, 1980): 1) History of problems with relationships ( $k=.63) ; 2$ ) Future problems with professional services and plans ( $k=.53)$; and 5) Future problems with personal support $(k=.50)$. Though these items fell below the more conservative cut-off asserted by Krippendorff (1980), they still fall within the moderate to substantial ranges of agreement according to Landis and Koch (1977). As such, since the HCR-20 ${ }^{\mathrm{V} 3}$ aggregate reliability is sufficient, and only 3 items fall below the more conservative Krippendorf (1980) cut-off, but stay 
within a less conservative range of moderate to substantial agreement (Landis \& Koch, 1977), HCR-20 ${ }^{\mathrm{V} 3}$ items were retained in analyses.

Non-risk related items showed exceptional reliability $(k=.94)$. Only six of eighty-nine variables did not meet minimum reliability criteria of $k>.67$. These variables were: 1) Victim age group $(k=.43), 2)$ Witness to the offence $(k=.43), 3)$ Multiple victims $(k=.63), 4)$ Victim injury $(k=.40), 5)$ Other concurrent violent offence $(k=.63)$, and 6) Criminal history provided $(k=.57)$. Each of these items was only used in descriptive analyses, and fell within a range of moderate agreement (Landis \& Koch, 1977) and so were retained. However, interpretations of findings based on these items should be made cautiously.

Interclass correlation (ICC) analyses using two-way mixed, absolute match, averagemeasures (McGraw \& Wong, 1996) were run to determine the inter-rater reliability of the continuous data in the database, which included variables related to age, number and types of offences and NCRMD findings, the number of victims, and total time spent under purview of the Review Board. The reliability of the variable assessing the word count of Review Board Reasons documents was assessed with two-way mixed, consistency, average-measures ICC (McGraw \& Wong, 1996). An average of ICC values showed that inter-rater reliability was excellent $(I C C=.95)$ (Cicchetti, 1994). No individual variables fell below an ICC value of .7, suggesting the reliability of each variable was good to excellent (Cicchetti \& Sparrow, 1981).

Overall, the reliability of the data for this project was deemed to be sufficient. The interrater reliability analyses for this project suggested that coders had substantial agreement in their rating on variables of interest related to descriptive characteristics of the sample and their offences, and on risk factors from the Static-99R and HCR-20 ${ }^{\mathrm{V} 3}$. Some items, noted above, suggest a modest amount of error variance in the data due to differences in coders' subjective 
ratings. However, the overall ratings are sufficient for use in testing the hypotheses of this research.

\section{Statistical analyses.}

Descriptive statistics. Descriptive statistics provided commentary in four domains. First, on the characteristics and composition of the population of persons found NCRMD for sexual offences in this sample. Second, on the nature of their offences. Third, on the nature of Review Board decisions and their outcomes. Fourth, on the degree to which risk factors supported by empirically validated tools are present or mentioned in the reasons for Review Board decisions. All descriptive analyses used frequencies in addition to measures of central tendency, where appropriate.

The characteristics and composition of the sample were analyzed in several ways. Consideration of the demographic characteristics of the sample include age, gender, ethnicity, and diagnoses. Analyses also consider aspects of individuals' personal backgrounds, including education and employment, personal relationships, experiences with homelessness at the time of the offence. Finally, this thesis considers the presence and nature of the sample's criminal histories, as reported in Review Board documentation.

To examine the nature of the offences committed, several aspects of the offences themselves were examined. This includes legal information including the number of sexual offences and charges in the index offence, as well as concurrent non-sexual offences and charges. Analyses also consider if offences were contact or non-contact, the specific behaviours involved in offences, and the environment in which the offence took place. Finally, the victimology of the sample was examined, and included the number of victims, the age and gender of victims, and the nature of the relationship between the victim and perpetrator. 
Outcomes under the purview of the Review Board included aspects of the tribunal decisions, as well as characteristics of the reasons documents provided by the Review Board regarding their decisions. Hearing outcomes from the first available Review Board decision documents were recorded, with respect to both the disposition made (i.e. detention order, conditional discharge, absolute discharge), and if the persons had the privilege to live in the community under their disposition. Review Board decision documents were analyzed in terms of their length, the type of information provided in their reasons, and the degree to which Review Boards reported on the use of risk assessments and risk tools in their decisions.

The fourth and final aspect of descriptive analyses considered the degree to which risk factors supported by empirically validated tools are present or mentioned in reasons documents. Risk factors supported by the Static-99R, HCR-20V3, and STABLE-2007 assessments were considered. The degree to which empirically supported risk information is mentioned was analyzed, and the degree to which this sample presents with these risk factors was considered.

Prediction of Review Board decisions and outcomes. Regression analyses considered the degree to which risk factors predicted Review Board decisions. Binary logistic regressions were used when predicting Review Board decisions. Separate analyses were run for each decision outcome (i.e. detention, conditional discharge, absolute discharge, and community living privilege), as well as for each risk tool's summed score (i.e. Static-99R, HCR-20 ${ }^{\mathrm{V}}$, and STABLE-2007). For the HCR-20 ${ }^{\mathrm{V} 3}$, further analyses were run for the summed score for the tool's subscales as well to elucidate the effects of the scales on the overall effect of the HCR$20^{\mathrm{V} 3}$ risk factors. Binary logistic regressions were also run to examine the effect of hospital recommendations (i.e. detention, conditional discharge, absolute discharge, and community living privilege) on decision outcomes. 
Linear regressions considered the degree to which risk factors predicted the total length of time a person found NCRMD for sexual offences would spend under the purview of the review board. Once again, separate analyses were run for each decision outcome and each risk tool's summed score. Analyses of the HCR-20 ${ }^{\mathrm{V} 3}$, s subscales were run to examine the effects of the scales on the overall effect of the HCR- $20^{\mathrm{V} 3}$ risk factors.

Finally, hierarchical binary logistic regressions examined the predictive effects of time, and risk factor sums on the final decision made about each member of the sample within the study period. Time spent under the purview of the Review Board was entered into Block 1 of the analysis to account for the passage of time while under purview of the Review Board. Block 2 of the analyses added risk factor sums to the prediction. Again, separate analyses were run for each decision outcome (i.e. detention, conditional discharge, absolute discharge, and community living privilege).

Statistical power for predicting decisions. There is no consensus in the field as to how to best estimate statistical power and sample size for logistic regression analyses (Demidenko, 2007), which is the primary analysis used in this work. Some have suggested the "rule of ten" as a rule of thumb to use in such analyses. This rule of thumb suggests that to ensure there is adequate variability to allow for confidence in observed effects, each outcome in the dependent variable should have 10 events (Harrell, Lee, \& Mark, 1996; Harrell, Lee, Matchar, \& Reichert, 1985; Peduzzi, Concato, Kemper, Holford, \& Feinstein, 1996). However, some research has also shown 5 events is adequate to achieve sufficient levels of variability (Peduzzi et al., 1996; Vittinghoff \& McCulloch, 2007). Others have suggested more complex statistical methods that use prior estimates of effect sizes to estimate variability in future research (e.g. Demidenko, 2007; Demidenko, 2008). However, given the absence of definitive opinion in the body of 
research, and the nature of the current research statistical methods may not be the most appropriate selection. Statistical power analysis is not an ideal choice as this thesis uses a unique and understudied group, and as such it is not clear what effect size from previous research would be used in this analysis. Thus, this work will use the "rule of ten" as an ideally moderate threshold for evaluating if there is some evidence that analyses can detect effects of interest. However, given findings that 5-10 events may also be sufficient for detecting events of interest (Peduzzi et al., 1996; Vittinghoff \& McCulloch, 2007) we will consider outcomes with 5-10 events sufficient for inclusion in analyses, though interpretations of such outcomes should note the limitations of using a lower threshold.

Basic descriptive statistics examined the main outcomes of interest at the current disposition. This included Review Board decisions at the current disposition, and included decisions to detain, conditionally discharge, absolutely discharge, and community living privileges. Detention orders, conditional discharges, and community living privileges all met the rule of thumb of the "rule of ten." Though absolute discharge did not have a minimum of 10 events in each outcome variable, it did have 7 events. Though this did not meet our ideal moderate threshold of 10 events, it did exceed 5 events. As suggested above (Peduzzi et al., 1996; Vittinghoff \& McCulloch, 2007) 7 events is seen by some as a sufficient minimum number of events, despite falling slightly below the "rule of thumb." Thus, one can have moderate confidence that these analyses had adequate statistic power to detect effects of interest. 


\section{Results}

\section{Review Board Reasons Characteristics}

All cases collected in this sample were collected from Ontario Review Boards. Review Boards were found to provide inconsistent information with respect to their reasons for decision making. Reports varied drastically in length, from 1,038 to 9,857 words ( $M=2943.48$, $S D=1199.26$ ), and did not provide the same information across reports. Only $92.5 \%$ of reports identified a diagnosis, $81.5 \%$ identified any personal history or background information, and Table 2

Mentioned use of Assessment Tools in Review Board Reasons Documents

\begin{tabular}{lc}
\hline Risk Tool & $\begin{array}{c}\text { Frequency of mentioned use } \\
\mathrm{n}(\%)\end{array}$ \\
\hline HCR-20 & $12(13.04 \%)$ \\
PCL-R & $11(11.96 \%)$ \\
VRAG & $5(5.43)$ \\
SORAG & $3(3.26 \%)$ \\
Static-99 & $2(2.17 \%)$ \\
LSI-R & $1(1.1 \%)$ \\
"actuarial" & $1(1.1 \%)$ \\
(i.e. tool not specified) & \\
\hline
\end{tabular}

only $79.3 \%$ provided any indication of criminal history. There was further inconsistency in how risk was discussed; only $35.9 \%$ of cases referenced formal risk assessment in any way, $15.2 \%$ of cases assigned a risk level, and $21.7 \%$ specified risk assessment tools used in the assessment (Table 2). When risk assessments were described, just under half of these cases implemented more than one risk tool $(n=9,9.8 \%)$. 


\section{Sample Characteristics}

Persons found NCRMD for sexual offences were primarily male (95.7\%) with a mean age of 35.54 years $(S D=14.2$; range $=17-77)$ at the time of index offence. Though ethnicity could not be assessed in detail given that legal documents do not typically provide ethnicity information, $32.6 \%$ of the sample was noted as having been born outside of Canada, and $4.3 \%$ were noted as being of indigenous status. This indicates that the sample was quite diverse. The sample was also reported to have low levels of employment, education (Table 3), and were often

Table 3

\begin{tabular}{lc} 
Highest Level of Education Achieved & \\
\hline Level of Education & $\begin{array}{c}\text { Frequency } \\
(\%)\end{array}$ \\
\hline Less than high school & $28.3 \%$ \\
High school/equivalent & $12.0 \%$ \\
Some College & $3.3 \%$ \\
College & $5.4 \%$ \\
Some University & $9.8 \%$ \\
University & $5.4 \%$ \\
Some Graduate/Professional & $3.3 \%$ \\
Graduate/Professional & $1.1 \%$ \\
Missing & $31.5 \%$ \\
\hline
\end{tabular}

single (Table 4). Only $9.8 \%$ of the sample were noted as being employed at the time of offence (38\% missing data) and $21.7 \%$ of the sample were noted as having some history of unstable employment (45.7\% missing data). Of the $68.5 \%$ of sample whose educational history was provided, $28.3 \%$ had not completed high school, $12 \%$ had completed high school only, and

Table 4

Relationship Status at the Time of Index Offence

\begin{tabular}{lc}
\hline Relationship Status & $\begin{array}{c}\text { Frequency } \\
(\%)\end{array}$ \\
\hline Single & $58.7 \%$ \\
Relationship, living apart & $6.5 \%$ \\
Married/Common-law & $12 \%$ \\
Divorced & $5.4 \%$ \\
Widow(er) & $1.1 \%$ \\
Missing & $16.3 \%$ \\
\hline
\end{tabular}


$28.3 \%$ had at least begun some form of post-secondary education (Table 3 ). The majority of the sample was single at the time of the offence $(58.7 \%$ ) (Table 4 ), and $20.7 \%$ were noted as having children (19.6\% missing data). At the time of the index offence, $14.1 \%$ of the sample was homeless.

Our sample also presented with a range of diagnoses of mental disorder, as diagnosed by a mental health professional. The most common diagnosis was a schizophrenia spectrum/psychotic disorder (69.6\%). This was followed by substance use disorder (53.3\%), alcohol use disorder (27.2\%), mood disorder (19.6\%), paraphilia (8.7\%), diagnosis of antisocial personality disorder and/or psychopathy (7.6\%), and other disorders (13.1\%). Diagnoses were often comorbid (53.3\% of the samples), and comorbidities often included substance and/or alcohol use disorder (41.3\% of the sample).

\section{Criminal History}

Persons in this sample often had some form of criminal history; $41.3 \%$ had previous charges on their record, $38 \%$ had previous convictions, and $8.7 \%$ had a previous finding of NCRMD. Of those who were found to have previous convictions or NCRMD findings (i.e. presumed by court of law to have committed the act of which they were accused), $38 \%$ had previous non-violent convictions or findings, 33.7\% had previous violent convictions or findings, and $14.1 \%$ had previous sexual offence convictions or findings.

\section{Offence Characteristics}

Of the 121 sexual offences committed, offences were found to most often include charges of sexual assault (75.2\%), followed by indecent acts (21.5\%). NCRMD findings for sexual offending were often concurrent with other NCRMD findings. The index cluster of offences in which sexual offence findings were situated had a mean of 3.31 findings per person found 
NCRMD $(S D=2.3)$, and ranged from a single finding to 11 current findings. The most common concurrent finding was that of assault (26.4\%), and 36.3\% of concurrent findings overall were violent offences of some kind.

The majority of index sexual offences included some form of contact (79.3\%). The most common contact offence behaviours were fondling or grabbing the victim $(53.7 \%)$, followed by some form of contact or assault to the victim's vagina (21.5\%). Penetrative acts of assault were less common than non-penetrative acts, with $9.1 \%$ of cases involving vaginal penetration and $2.5 \%$ of cases involving anal penetration. The most common non-contact behaviours in this sample of cases were exposure (19.8\%), and masturbation (17.4\%). Witnesses were present to $51.2 \%$ of offences, and $66.1 \%$ of offences took place in some form of public space.

The majority of the sample had a single victim (53.7\%) of their index offence. The sample overall had a mean of 1.91 victims each $(S D=1.3)$, and the total number of victims ranged from 1 to 5 . Victims were relatively homogenous. Adults accounted for $71.9 \%$ of identifiable victims, $15.7 \%$ of victims were minors, and in one case $(0.8 \%)$ a person exposed themselves to an adult and child (a parent-child dyad). Identifiable victims were primarily female (86.8\%; males $5.8 \%$ ). Victims were most often strangers (68.6\%), followed by acquaintances (17.4\%), family members $(4.1 \%)$, friends $(1.7 \%)$, a partner $(1.7 \%)$, or a victim of stalking $(0.8 \%)$.

\section{Outcomes under the Purview of the Review Board}

Based on the first Review Board reasons document available in the study period (referred to from this point forward as the current disposition), persons in this sample were most likely to be placed under a detention order $(76.1 \%)$, in a general $(44.6 \%)$, secure $(28.3 \%)$ or maximumsecurity setting (3.3\%). If not detained, persons found NCRMD for sexual offences were conditionally discharged (14.1\%) or absolutely discharged (7.6\%). At their current disposition, 
$35.9 \%$ of the sample were living in the community. Review Board decisions in the current dispositions had high rates of agreement with the hospital or clinician's recommendations to the Review Board (91.3\%).

Within the study period, this sample spent an average of 44 months ( $S D=27.2)$ under the purview of the Review Board. Length of time spent under the purview of Review Boards varied considerably, ranging from 2 to 118 months. At the end of the study period, the most common disposition was a detention order (47.8\%; $27.2 \%$ general, $18.5 \%$ secure, $2.2 \%$ maximum). This was followed by being absolutely discharged (31.5\%), and conditionally discharged (13\%). At the time of their last known disposition in the study period, $60.9 \%$ of this sample were living in the community.

\section{Factors Found in Review Board Reasons}

We then considered which factors were considered by Review Boards when describing their reasons for current dispositions. Persons found NCRMD for sexual offences often presented with empirically supported risk factors. This sample presented with an average of 3.63 risk factors $(S D=1.71)$ as described on the Static-99R (Table 5). According to the Justice Center's five level risk and needs system (Hanson, Bourgon, McGrath, Kroner, D’Amora, Thomas, \&

\section{Table 5}

Present, Absent, and Missing Static-99R Risk Factors

\begin{tabular}{lccc}
\hline Risk Factor & $\begin{array}{c}\text { Present } \\
(\%)\end{array}$ & $\begin{array}{c}\text { Absent } \\
(\%)\end{array}$ & $\begin{array}{c}\text { Missing } \\
(\%)\end{array}$ \\
\hline Age (Young) & $42.1 \%$ & $57.9 \%$ & $0 \%$ \\
Lived with a Lover & $47.9 \%$ & $23.1 \%$ & $28.9 \%$ \\
Index Non-Sexual Violence & $33.1 \%$ & $66.9 \%$ & $0 \%$ \\
Prior Non-Sexual Violence & $32.2 \%$ & $52.1 \%$ & $15.7 \%$ \\
Prior Sexual Offences & $11.6 \%$ & $72.7 \%$ & $15.7 \%$ \\
Prior Sentencing Dates (4+) & $9.9 \%$ & $61.2 \%$ & $18.2 \%$ \\
Non-Contact Convictions & $4.1 \%$ & $77.7 \%$ & $18.2 \%$ \\
Unrelated Victims & $93.4 \%$ & $3.3 \%$ & $3.3 \%$ \\
Stranger Victims & $74.4 \%$ & $21.5 \%$ & $4.1 \%$ \\
Male Victims & $6.6 \%$ & $86.0 \%$ & $7.4 \%$ \\
\hline
\end{tabular}


Tavarez, 2017) that acts as a framework in the most recent version of the Static-99R Manual (Phenix et al., 2016), this number of risk factors would approximately align with a Level III (average risk) or Level IVa (above average risk) risk level. The total number of factors present in

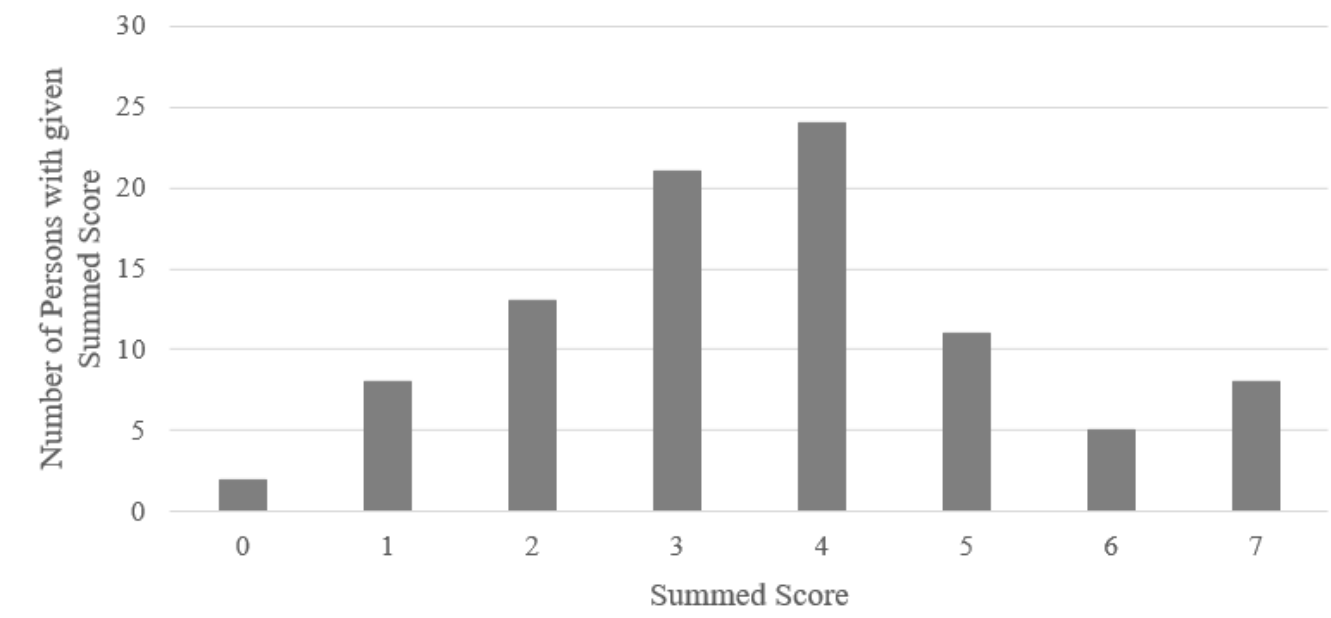

Figure 1. Static99-R Summed Scores. Figure represents the number of persons with each total summed score in the sample. members of this sample ranged from 0 to 7 factors (Figure 1).

With respect to the HCR-20 $0^{\mathrm{V} 3}$, this sample presented with an average of 7.32 risk factors $(S D=3.42)$ (Table 6), and the number of factors present ranged from 1 to 17 (Figure 2). When the $\mathrm{HCR}-20^{\mathrm{V} 3}$ scales were examined, analyses showed an average of $4.16(S D=2.24)$ Historical risk factors (Figure 3), 1.83 ( $S D=1.25$ ) Clinical risk factors (Figure 4), and 1.36 ( $S D=1.16)$ Risk Management risk factors (Figure 5), were present in the sample. 
Table 6

Present, Absent, and Missing HCR-20 V3 Risk Factors

\begin{tabular}{lccc}
\hline Risk Factor & $\begin{array}{c}\text { Present } \\
(\%)\end{array}$ & $\begin{array}{c}\text { Absent } \\
(\%)\end{array}$ & $\begin{array}{c}\text { Missing } \\
(\%)\end{array}$ \\
\hline H1 - Problems with Violence & $45.5 \%$ & $41.3 \%$ & $13.2 \%$ \\
H2 - Problems with other Antisocial Behaviour & $28.9 \%$ & $55.4 \%$ & $15.7 \%$ \\
H3 - Problems with Relationships & $51.2 \%$ & $23.1 \%$ & $25.6 \%$ \\
H4 - Problems with Employment & $49.6 \%$ & $19.8 \%$ & $30.6 \%$ \\
H5 - Problems with Substance Use & $55.4 \%$ & $37.2 \%$ & $7.4 \%$ \\
H6 - Problems with Major Mental Disorder & $89.3 \%$ & $10.7 \%$ & $0 \%$ \\
H7 - Problems with Personality Disorder & $11.6 \%$ & $84.3 \%$ & $4.1 \%$ \\
H8 - Problems with Traumatic Experiences & $8.3 \%$ & $77.7 \%$ & $14.0 \%$ \\
H9 - Problems with Violent Attitudes & $2.5 \%$ & $50.4 \%$ & $47.1 \%$ \\
H10 - Problems with Treatment or Supervision Response & $63.6 \%$ & $30.6 \%$ & $5.8 \%$ \\
C1 - Problems with Insight & $69.4 \$$ & $20.7 \%$ & $9.9 \%$ \\
C2 - Problems with Violent Ideation and Intent & $1.7 \%$ & $80.2 \%$ & $18.2 \%$ \\
C3 - Problems with Symptoms of Major Mental Illness & $77.7 \%$ & $19.8 \%$ & $2.5 \%$ \\
C4 - Problems with Instability & $21.5 \%$ & $74.4 \%$ & $4.1 \%$ \\
C5 - Problems with Treatment or Supervision Response & $22.3 \%$ & $73.6 \%$ & $4.1 \%$ \\
R1 - Problems with Professional Services and Plans & $13.2 \%$ & $35.5 \%$ & $51.2 \%$ \\
R2 - Problems with Living Situation & $39.7 \%$ & $47.1 \%$ & $13.2 \%$ \\
R3 - Problems with Personal Support & $19.0 \%$ & $43.8 \%$ & $37.2 \%$ \\
R4 - Problems with Treatment or Supervision Support & $57.0 \%$ & $19.0 \%$ & $24.0 \%$ \\
R5 - Problems with Stress or Coping & $14.0 \%$ & $4.1 \%$ & $81.8 \%$ \\
\hline
\end{tabular}

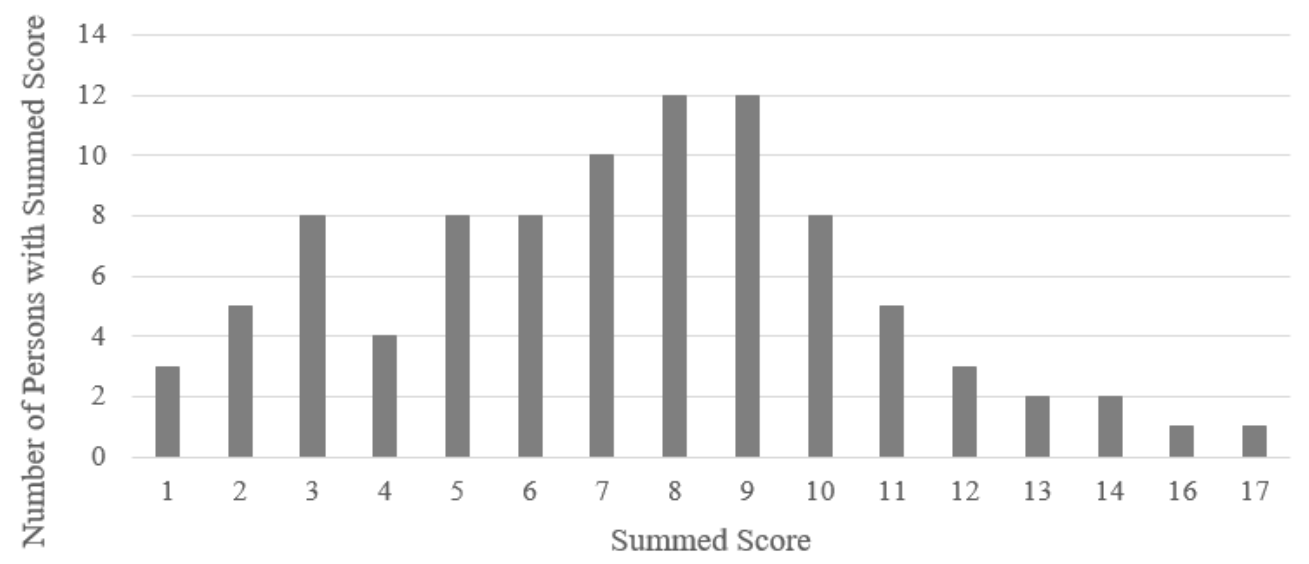

Figure 2. HCR-20 $20^{\sqrt{3}}$ Summed Scores. Figure represents the number of persons with each total summed score in the sample. 


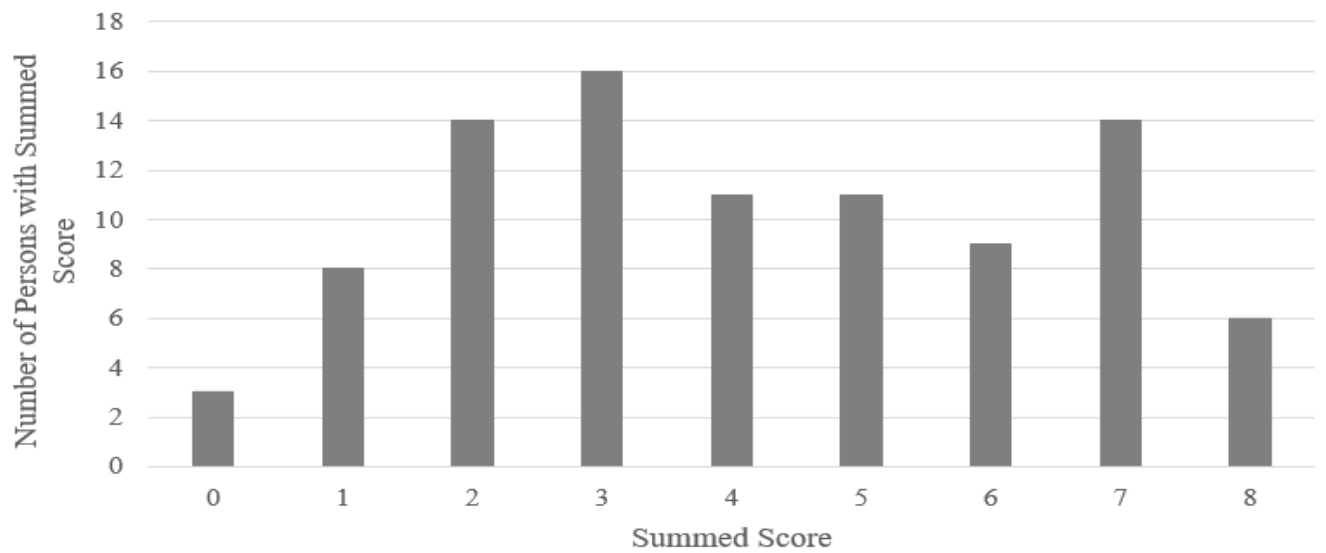

Figure 3. HCR-20 $2{ }^{\mathrm{V} 3}$ Historical Scale Summed Score. Figure represents the number of persons with each summed score on the historical scale of the HCR- $20^{\text {v3 }}$.

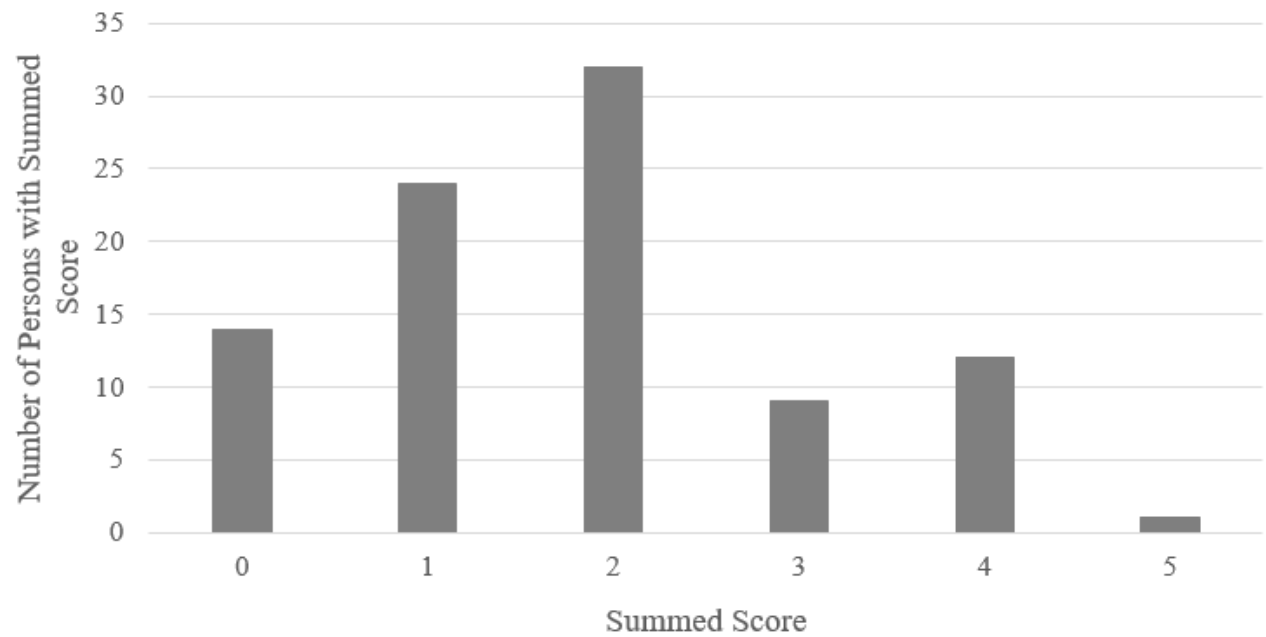

Figure 4. HCR-20 $\mathrm{V}^{\mathrm{3}} \mathrm{Clinical}$ Scale Summed Score. Figure represents the number of persons with each summed score on the clinical scale of the HCR- $20^{\mathrm{V} 3}$. 


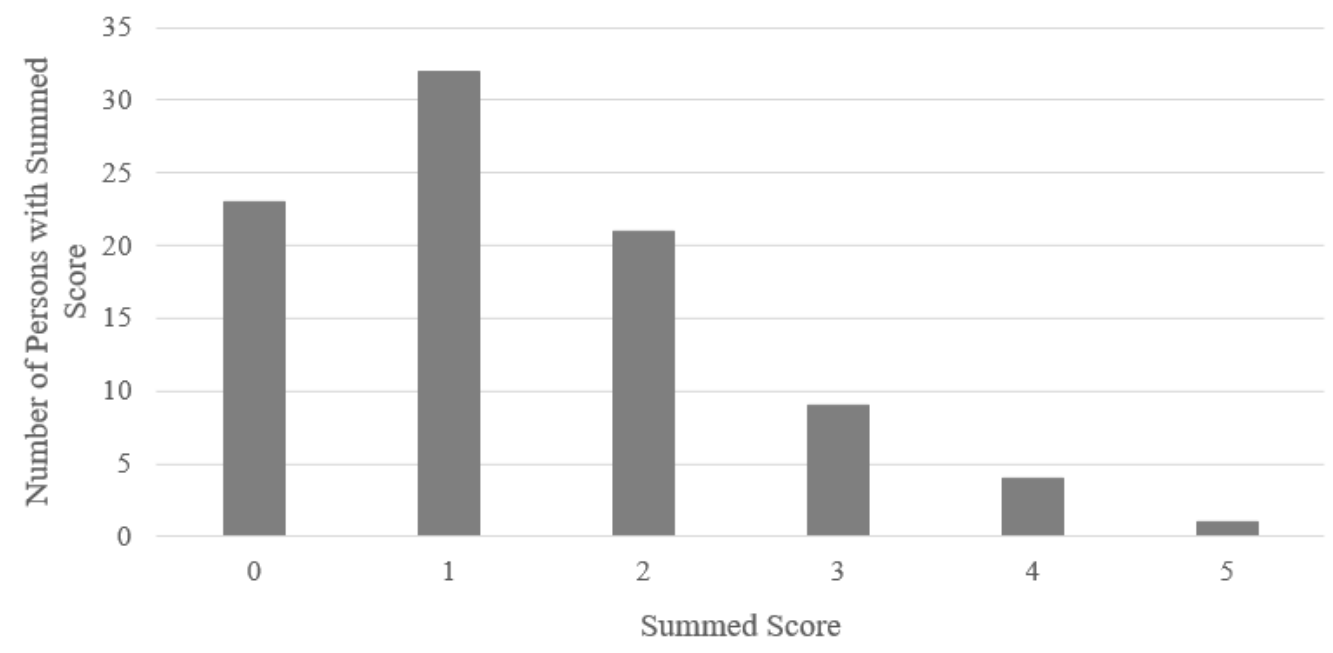

Figure 5. HCR-20 ${ }^{\mathrm{v} 3}$ Risk Management Scale Summed Score. Figure represents the number of persons with each Summed score on the risk scale of the HCR- $20^{13}$.

Several risk factors from each measure were quite common. The most common STATIC99R supported risk factors within this population were having an unrelated (93.4\%) or stranger victim (74.4\%), followed by never having lived with an intimate partner (47.9\%) and being under 35 years of age $(42.1 \%)$. The most common HCR-20 historical and clinical factors were a history of problems with major metal illness (89.3\%), recent problems with symptoms of major mental illness (77.7\%), recent problems with insight (69.4\%), a history of problems with treatment or supervision response (63.6\%), a history of problems with substance use $(55.4 \%)$, and a history of problems with relationships (51.2\%). Though data was provided less consistently for risk management factors, as described on the HCR-20 ${ }^{\mathrm{V}}$, it appears the most common risk management concern in this group was future problems with treatment or supervision support (57\%).

\section{Prediction of Outcomes}

\section{Predictive effect of Static-99R risk factors on disposition decisions.}

Static-99R total summed score. Separate binary logistic regression analyses examined the predictive effects of Static-99R summed scores on Review Board decision outcomes (i.e. 
detention, conditional discharge, absolute discharge, and community living privilege). The overall models examining the effect of summed Static-99R scores on decision outcomes were not significant (detention order $\left[x^{2}=3.678(p=.055)\right]$; conditional discharge $\left[x^{2}=1.081, p=.298\right]$; absolute discharge $\left[x^{2}=2.519, p=.113\right]$; and community living $\left.\left[x^{2}=3.727, p=.054\right]\right)$. Similarly, summed Static-99R score did not explain a significant amount of variance in any model (detention order $[B=.309, S E=.168, p=.065$ (Odds Ratio=1.362)]; conditional discharge $[B=-$ .199, $S E=.195, p=.307(O R=.819)]$; absolute discharge $[B=-.385, S E=.254, p=.129$ (OR=.680)]; and community living $[B=-.257, S E=.138, p=.062(O R=.773)])$.

A linear regression analysis examined the predictive effect of summed Static-99R score on the total length of time spent under the purview of the Review Board. The overall regression model was significant $(F(1,86)=11.956, p=.001)$, with an adjusted $R^{2}$ of .112 . Results indicated that length of stay under the purview of the Review Board increased by 5.47 months ( $S E=1.581$ ) for each Static-99R risk factor present $(p=.001)$.

\section{Predictive effect of $\mathrm{HCR}-20^{\mathrm{v} 3}$ risk factors on disposition decisions.}

HCR-20 ${ }^{V 3}$ total summed score. Separate binary logistic regression analyses examined the predictive effects of HCR- $20^{\mathrm{V} 3}$ total summed scores on Review Board decision outcomes (i.e. detention, conditional discharge, absolute discharge, and community living privilege). The overall models examining the effect of total summed HCR-20 ${ }^{\mathrm{V} 3}$ scores on decision outcomes were significant. The model for the effect of HCR-20 total summed scores on detention orders was significant $\left(x^{2}=22.762, p<.001\right)$, and had a Nagelkerke $R^{2}$ value of .358 . The HCR-20 $0^{\mathrm{V} 3}$ total summed score accounted for a significant amount of variance in decisions to detain persons found NCRMD $(B=.476, S E=.122, p<.001)$. Odds ratios indicate that with each additional HCR- 
$20^{\mathrm{V} 3}$ supported risk factor present, persons found NCRMD were 1.61 times more likely to be detained.

The model for the effect of HCR-20 ${ }^{\mathrm{V} 3}$ total summed scores on conditional discharge was significant $\left(x^{2}=5.294, p=.021\right)$, and had a Nagelkerke $R^{2}$ value of .110 . The HCR-20 ${ }^{\mathrm{V} 3}$ total summed score accounted for a significant amount of variance in decisions to detain persons found NCRMD $(B=-.239, S E=.111, p=.031)$. Odds ratios indicate that with each additional HCR$20^{\mathrm{V} 3}$ supported risk factor present, persons found NCRMD are 1.3 times less likely to be conditionally discharged $(O R=.787)$. Similarly, the model for the effect of HCR-20 $0^{\mathrm{V} 3}$ total summed scores on absolute discharge was significant $\left(x^{2}=18.997, p<.001\right)$, and had a Nagelkerke $R^{2}$ value of .456. The HC-20 $2{ }^{\mathrm{V} 3}$ total summed score accounted for a significant amount of variance in decisions to absolutely discharge ( $B=-.784, S E=.264, p=.003)$. Odds ratios indicate that with each additional HCR-20 ${ }^{\mathrm{V} 3}$ supported risk factor present, the likelihood of a persons found NCRMD being absolutely discharged approximately halved (OR=.457).

The model for the effect of HCR- $20^{\mathrm{V} 3}$ total summed scores also significantly predicted if persons found NCRMD were living in the community at the time of their current disposition $\left(x^{2}=18.830, p<.001\right)$, and had a Nagelkerke $R^{2}$ value of .264 . The HCR-20 ${ }^{\mathrm{V} 3}$ total summed score accounted for a significant amount of variance in allowing persons found NCRMD to reside in the community $(B=-.336, S E=.089, p<.001)$. Odds ratios indicate that with each additional HCR$20^{\mathrm{V} 3}$ supported risk factor present, persons found NCRMD are 1.4 times less likely to be allowed to live in the community $(O R=.715)$.

A linear regression analysis examined the predictive effect of total HCR $-20^{\mathrm{V} 3}$ summed scores on the total length of time spent under the purview of the Review Board. The overall regression model was significant $(F(1,86)=18.872, p<.001)$, with an adjusted $R^{2}$ of .170 . Results 
indicated that length of stay under the purview of the Review Board increased by 3.364 months $(S E=.774)$ for each HCR-20 ${ }^{\mathrm{V} 3}$ risk factor present $(p<.001)$.

HCR-20 ${ }^{V 3}$ historical, clinical, and risk management summed scores. To examine which scales of the HCR $-20^{\mathrm{V} 3}$ contributed to its predictive effects of Review Board decision making, binary logistic regression examined the effects of the summed scale scores of decisions. Detention orders were predicted by the HCR $-20^{\mathrm{V} 3}$ scales, overall $\left(x^{2}=30.431, p<.001\right)$, and with a Nagelkerke $R^{2}$ value of .465 . The historical scale of the HCR-20 23 did not significantly contribute to the explained variance in this model $(B=.226, S E=.157, p=.151)$. However, both the clinical $(B=.702, S E=.347, p=.043)$ and risk management scales $(B=1.343, S E=.502, p=.007)$ did contribute significantly to the explained variance in the model. For each increase in summed score on these scales, odds ratios indicated persons found NCRMD were 2.0 and 3.8 times more likely to be detained.

Detention orders were predicted by the HCR $-20^{\mathrm{V} 3}$ scales, overall $\left(x^{2}=30.431, p<.001\right)$, and with a Nagelkerke $R^{2}$ value of .465 . The historical scale of the HCR-20 ${ }^{\mathrm{V} 3}$ did not significantly contribute to the explained variance in this model $(B=.226, S E=.157, p=.151)$. However, both the clinical $(B=.702, S E=.347, p=.043)$ and risk management scales $(B=1.343$, $S E=.502, p=.007)$ did contribute significantly to the explained variance in the model. For each increase in summed score on these scales, odds ratios indicated persons found NCRMD were 2.0 and 3.8 times more likely to be detained.

Conditional discharges were predicted by the HCR-20 ${ }^{\mathrm{V} 3}$ scales, overall $\left(x^{2}=8.963\right.$, $\mathrm{p}=.030)$, and with a Nagelkerke $R^{2}$ value of .185 . Neither the historical scale $(B=-.079, S E=.158$, $p=.618)$ nor the clinical scale $(B=.047, S E=.315, p=.882)$ significantly contributed to the explained variance in this model. The risk management scale $(B=-1.073, S E=.514, p=.037) \mathrm{did}$ 
contribute significantly to the explained variance in the model. For each increase in summed score on the risk management scale, odds ratios indicated persons found NCRMD were much 2.9 times less likely to receive a conditional discharge $(O R=.342)$.

Absolute discharges were predicted by the HCR- $20^{\mathrm{V} 3}$ scales, overall $\left(x^{2}=27.593\right.$, $\mathrm{p}<.001)$, and with a Nagelkerke $R^{2}$ value of .636 . Neither the historical scale $(B=-.281, S E=.276$, $p=.309)$ nor the risk management scale $(B=-1.444, S E=1.123, p=.199)$ significantly contributed to the explained variance in this model. The clinical scale $(B=-2.379, S E=1.060, p=.025) \mathrm{did}$ contribute significantly to the explained variance in the model. For each increase in summed score on the clinical scale, odds ratios indicated persons found NCRMD were 10.8 times less likely to receive an absolute discharge (OR=.093).

Community living was predicted by the HCR- $20^{\mathrm{V} 3}$ scales, overall $\left(x^{2}=22.383, p<.001\right)$, and with a Nagelkerke $R^{2}$ value of .313 . Neither the historical scale ( $B=-.245, S E=.127, p=.054$ ) nor the risk management scale ( $B=-.543, S E=.293, p=.064)$ significantly contributed to the explained variance in this model. The clinical scale $(B=-.530, S E=.257, p=.039)$ did contribute significantly to the explained variance in the model. For each increase in summed score on the clinical scale, odds ratios indicated persons found NCRMD were approximately half as likely to live in the community $(O R=.588)$.

A linear regression analysis examined the predictive effect of HCR- $20^{\mathrm{V} 3}$ summed scales on the total length of time spent under the purview of the Review Board. The overall regression model was significant $(F(3,82)=6.796, p<.001)$, with an adjusted $R^{2}$ of .170 . Results indicated that the historical and clinical scales significantly contributed to the explained variance in length of stay under the purview of the Review Board. An increase in score on the historical scale increased a person found NCRMD's length of time under purview by 3.794 months ( $S E=1.291$, 
$p=.004)$. An increase in score on the clinical scale increased length of time under purview by 4.768 months ( $S E=2.402, p=.050$ ). The risk management scale did not significantly contribute to the explained variance in length of time spent under purview of the Review Board $(B=1.931$, $S E=2.762, p=.486)$.

Predictive effect of hospital or clinical recommendation on disposition decisions. Analyses examined if hospital or clinician recommendations had a predictive effect on disposition decisions. Hospital or clinician recommendations did not have any significant predictive effect with respect to the overall models, nor independent effects on variance. This was true for detention orders $\left(x^{2}=.107, p=.744 ; B=.288, S E=.863, p=.739\right)$, conditional discharges $\left(x^{2}=1.041, p=.308 ; B=-.967, S E=.890, p=.277\right)$, absolute discharges $\left(x^{2}=1.393, p=.238\right.$; $B=18.858, S E=14210.362, p=.999)$, and community living $\left(x^{2}=.683, p=.409 ; B=-.619, S E=.745\right.$, $p=.406)$.

\section{Predictive effect of risk factors and time spent under purview of the Review Board on}

outcomes. Hierarchical binary logistic regressions examined the predictive effect of time and risk factors on disposition outcomes at the end of the study period. In each analysis, time spent under purview was entered into step 1. Step 2 then added the Static-99R and HCR-20 ${ }^{\mathrm{V} 3}$ total summed scores.

Neither step 1 nor step 2 of the hierarchical regression significantly predicted detention orders $\left(x^{2}=.772, p=.380 ; x^{2}=5.171, p=.075\right.$, respectively). However, in step 2, HCR $-20^{\mathrm{V} 3}$ total summed score did make a significant independent contribution to the overall explained variance in the model $(B=.187, S E=.090, p=.038)$, while time $(B=.000, S E=.010, p=.971)$ and Static-99R summed score $(B=-.082, S E=.164, p=.616)$ did not. 
Neither step 1 nor step 2 of the hierarchical regression significantly predicted conditional discharge $\left(x^{2}=.110, p=.740 ; x^{2}=.866, p=.648\right.$, respectively). No variables in step 2 made a significant independent contribution to the model (time: $B=-.009, S E=.014, p=.544 ; \mathrm{HCR}-20^{\mathrm{V} 3}$ : $B=.006, S E=.119, p=.959$; Static-99R: $B=.175, S E=.225, p=.438)$.

Step 1 of the hierarchical regression did not significantly predict absolute discharge $\left(x^{2}=.467, p=.494\right)$. However, step 2 improved upon the model and significantly predicted absolute discharge $\left(x^{2}=7.573, p=.023\right)$. HCR-20 $0^{\mathrm{V} 3}$ total summed score made a significant independent contribution to the model $(B=-.218, S E=.098, p=.025)$. Neither time $(B=.005$, $S E=.010, p=.615)$ nor Static-99R summed score $(B=-.018, S E=.175, p=.918)$ made a significant contribution.

Similarly, step 1 of the hierarchical regression did not significantly predict community living ( $\left.x^{2}=.049, p=.826\right)$, while step $2 \operatorname{did}\left(x^{2}=8.285, p=.016\right)$. HCR $-20^{\mathrm{V} 3}$ total summed score made a significant independent contribution to the model ( $B=-.234, S E=.096, p=.015)$. Neither time $(B=.015, S E=.011, p=.177)$ nor Static-99R summed score $(B=.010, S E=.169, p=.951)$ made a significant contribution. 


\section{Discussion}

This thesis examined the characteristics of persons found NCRMD for sexual offences, and the ways in which decisions are made about them by Review Board tribunals. Analyses first provided a description of this population, with respect to their gender, age, ethnicity, psychopathological diagnoses, personal history, criminal history, and the characteristics of the offences. Descriptive analyses also considered the characteristics of the Review Board Reasons documents themselves.

Persons found NCRMD for sexual offences were characterized by several demographic characteristics. They were on average 35 years old, about $96 \%$ male, and quite culturally diverse, with $32.6 \%$ being born outside of Canada, and $4.3 \%$ having an Indigenous background. The most common diagnoses in this group were schizophrenia spectrum/psychotic disorder and substance use disorder. Diagnoses were often comorbid, and psychological disorders were often comorbid with alcohol or substance use disorders. These findings are largely similar to the findings of Crocker and colleagues (2015). However, it does appear that persons found NCRMD for sexual offences have higher proportions of male persons, and may have slightly more diverse backgrounds, though this is challenging to comment upon confidently, given this thesis' sample size.

Persons found NCRMD were often unemployed at the time of the offence, and approximately 1 in 5 persons found NCRMD had a history of unstable employment. At the time of the index offence, $14 \%$ of the sample was homeless. The majority of persons found NCRMD were single at the time of the offence. These findings also replicate the findings of Crocker and colleagues (2013) in their sample of persons from the three largest Canadian provinces of persons found NCRMD for SVOs. However, this thesis found that persons found NCRMD spent 
considerably more time under purview than Crocker and colleagues (2013) (3.6 years vs. 1.8 years, respectively). This may be due to provincial differences in the provision of dispositions. Past research has suggested that, even after controlling for personal and psychosocial factors, persons found NCRMD in Ontario spend more time under detention than other provinces (Crocker et al., 2015a). Given that the current sample is exclusively from Ontario, while Crocker and colleagues sample was taken from the three largest Canadian provinces, this may help explain this discrepancy. However, future research should seek to clarify this further.

The characteristics of the persons found NCRMD for sexual offences in this sample suggest that many of the persons in this sample not only have several areas of risk as identified in the Central Eight (Andrews \& Bonta, 2006; Andrews \& Bonta, 2010), but also that this group experiences disadvantage and marginalization in several domains. Research has shown that various aspects of marginalization can increase the likelihood of arrest and prosecution across offence types (e.g. Lievore, 2004), thus, the disadvantage and marginalization evidenced in the current sample may amplify risk related concerns. This would also be an important consideration for clinicians to consider in case management, as these intersecting areas of marginalization may potentially increase challenges of reintegrating this group into society effectively, and ensuring they receive the supports that they need during rehabilitation and discharge.

Offences were typically sexual assaults or indecent acts. Sexual assaults were typically contact offences, and consisted of seemingly impulsive contact behaviours, such as fondling or grabbing their victim, who were most often female. More intrusive offence behaviours, such as penetrating the victim in some way were less common. Indecent acts typically comprised of noncontact behaviours such as exposure or masturbation. Two thirds of offences took place in a public space, and about half of offences had witnesses to the offence. This pattern of behaviour 
indicates that persons found NCRMD for sexual offences in this sample seem to be offending in seemingly disinhibited ways. Though some aspects of these offending patterns could indicate elevated risk (e.g. frequent stranger victims), it would be important to consider to what degree this accurately describes risky offence behaviours in this group. This also raises important questions about the relationship between disinhibition and risk. Does the intent behind a behaviour influence risk, or are disinhibited behaviours that mimic high risk behaviours equally as risky?

We then analyzed the data to examine the following hypotheses. First, that Review Boards would be inconsistent in their consideration of risk assessment tools, and risk relevant information in their decision making. Second, that Review Boards would not specifically consider the use of structured risk assessments that consider sexual offence specific risk in their Reasons for decisions. Third, that persons found NCRMD for sexual offences would display risk related characteristics. Fourth, that beyond general risk factors, persons found NCRMD for sexual offences would present with risk factors for re-offense as included on sex offence specific risk assessments. Finally, that despite the presence of risk factors, dispositions would be unrelated to the presence of most empirically validated risk factors.

All five hypotheses were all at least partially supported. The first two hypotheses, that Review Boards would consider risk assessments inconsistently, and sexual offence specific risk assessment even more so, were both supported. Only 33 cases (35.8\%) mentioned a risk assessment was conducted in some way, and only 20 cases (21.7\%) referenced the type of tool(s) used. The most often discussed tools were the HCR-20, Psychopathy Checklist Revised (PCL-R) and the Violence Risk Appraisal Guide (VRAG). All of these tools are designed to assess for general or violent recidivism risk. Only four cases noted implementing a sexual offence specific 
risk tool (4.3\%). Thus, it does appear that, at best, risk assessments are considered inconsistently by Review Boards, and this is particularly true of sexual offence specific risk assessments.

Though this is much lower than would be ideal, it does appear to be a slight increase from findings of Crocker and colleagues (2014), who noted only about 17\% of hearings mentioned structured risk tools. This could indicate that in the past few years, discussion of structured risk assessment has increased. Alternately, it may be that structured risk assessments are considered slightly more often in cases of sexual offending, due to the perceived riskiness of these offences. Regardless, though this may indicate slight improvements, it is still quite low when one considers that, ideally, all cases should be considering evidence based factors in decision making about persons found NCRMD.

Despite an inconsistent reporting of risk assessments, it was found that persons found NCRMD for sexual offences presented with both general and sexual offence specific risk factors for offending, in line with the third and fourth hypotheses. Given this finding, it is quite problematic that Review Boards do not often use or acknowledge their use of empirically supported assessments in their decisions. Given findings from this work, as well as past research by Crocker and colleagues (2013) and Moulden and colleagues (2014) that show persons found NCRMD for sexual offences can present with similar risk factors as persons who commit sexual offences in the criminal justice system, not using appropriate and evidence based information to guide decisions is not justifiable.

Our final hypotheses stated that presence of risk factors would be unrelated to disposition decisions. This hypothesis was partially supported. Presence of Static-99R risk factors did not predict any type of Review Board decision. This suggests that when making decisions about a person found NCRMD's disposition, they may not be considering the presence of historical risk 
factors known to be empirically related to sexual risk, or may be ignoring or overriding these factors in favour of other factors. As mentioned above, given the presence of many empirically supported risk factors in this population, this begs the question of what information Review Boards are using to determine risk in the absence of the information provided by structured risk tools. However, presence of Static-99R risk factors did predict the total length of time spent under the purview of the Review Board. This suggests that while historical, sexual offence specific risk factors may not be explicitly cited in disposition decisions, those NCRMD persons scoring as higher risk on the Static-99R are spending greater lengths of time in the forensic mental health system. Alternately, higher risk persons found NCRMD for sexual offences may engage in riskier or more problematic behaviours while under the Review Board, which would likely extend their stay in the forensic mental health system. Though it is appropriate that lower risk persons found NCRMD are being discharged more quickly, future research would benefit from examining if the level of management and intervention persons receive while under the purview of Review Boards are similarly matched to one's risk level.

Presence of HCR-20 ${ }^{\mathrm{V} 3}$ risk factors predicted Review Board decisions to a much greater degree than either Static-99R risk factors, or time spent under purview of the Review Board. The total number of HCR-20 $0^{\mathrm{V} 3}$ risk factors present predicted several types of Review Board decisions, and the total length of time spent under the purview of the Review Board. These results were in the direction one would expect, with higher risk persons found NCRMD receiving more restrictive dispositions, and spending more time under the purview of the review board, and lower risk persons found NCRMD receiving dispositions allowing greater degrees of freedom, and spending shorter lengths of time under purview. This may suggest that unlike sexual offence specific risk factors, these more general factors are being considered to a greater 
degree in immediate disposition decisions, and seemingly influence the length of time spent in the forensic mental health system. This was particularly true of clinical and risk management related information of the HCR-20 ${ }^{\mathrm{V} 3}$. These findings are consistent with past research that shows the HCR-20 ${ }^{\mathrm{V} 3}$ can predict some forms of Review Board decisions (Côté et al., 2012; Crocker et al., 2014; Wilson et al., 2015; Wilson et al., 2016). This is encouraging, as it does show the potential for Review Boards to integrate risk information into decisions, and suggests that with further research and outreach to Board members, there is the potential for the use of risk information in decisions to continue and improve.

When the presence of Static-99R risk factors, HCR-20 ${ }^{\mathrm{V} 3}$ risk factors, and time were considered together in a model to predict outcomes, a similar pattern emerged. Time had no effect on final dispositions in the study period, which suggests persons found NCRMD are not simply "passed through the system" or receiving absolute discharges (or any other form of decisions) merely as a function of time spent in the system. This was an encouraging finding, as the NCRMD defense itself is not a time delimited sentence, nor is time spent in the forensic system meant to be a punishment (Winko v. British Columbia, 1998). Instead, it is meant to be a rehabilitative designation matched to a person found NCRMD's situation (Winko v. British Columbia, 1998). These findings - that time spent under purview does not predict movement through the forensic system - suggest that the forensic mental health system and Review Boards are not treating these cases as sentences or punishments.

Similar to the findings regarding current dispositions, presence of Static-99R risk factors did not predict any type of Review Board decisions at the last disposition during the study period. HCR $-20^{\mathrm{V} 3}$ risk factors on the other hand were predictive of detention orders, absolute discharges, and community living privileges at the last known disposition during the study 
period. This is once again consistent with past research which shows that information on the HCR-20 ${ }^{\mathrm{V} 3}$ can influence Review Board decisions (Côté et al., 2012; Crocker et al., 2014; Wilson et al., 2015; Wilson et al., 2016). However, one would assume that, due to the dynamic nature of the HCR-20 ${ }^{\mathrm{V} 3}$, the number of risk factors present in persons for NCRMD for sexual offences would change over time. Thus, this finding could also indicate that early levels of clinical functioning may continue to influence decisions even if the number of risk factors present is subject to change. 


\section{Implications}

These findings add to the burgeoning discussion of Review Board decision making, and add more specific context regarding decisions made about persons found NCRMD for sexual offences, specifically. Further, these findings highlight several interesting implications and areas for further discussion and exploration. These include implications for research, clinical practice, and policy in the forensic mental health system.

\section{Review Boards Reasons Documents are Inconsistent}

Our results found that Review Boards provided highly inconsistent information in the Reasons documents. This finding is in line with past research which has also suggested Review Boards can be inconsistent with respect to the information they provide (Crocker et al., 2015b). This was true with respect to several characteristics of the documents, from the length of the document itself, to the types of information provided. The most consistent information provided was a psychiatric diagnosis. However, even this information which is highly relevant to persons found NCRMD, in that the presence of a mental disorder is central to the viability of the defense itself, was absent in $7.5 \%$ of cases. Historical information about the person found NCRMD, which is often risk relevant (i.e. RNR model, historical risk factors) was missing in $18.5 \%$ of cases, and criminal history, long understood to be one of the best predictors of future risk (Gendreau, Goggin, \& Little, 1996), was absent in $20.7 \%$ of cases. Yet, the most inconsistent information disclosed in these documents was that information relating to the use and interpretation of risk assessments; $64.1 \%$ of cases made no reference to a formal risk assessment in any way.

Considering that the Review Board's most important and challenging task is to predict risk ( $R$ v. Owen, 2003), and that evidence based risk assessment provide an avenue to improve 
these efforts, this is very troubling. It also may be an artefact of Review Boards not recognizing that this information would be helpful in understanding how decisions are made, but would also provide stronger evidence to support their decisions. Currently, the guidelines for the production of Reasons documents are simply that "The Board must give written reasons for each disposition" (Ontario Review Board, 2011). This is a limited guideline, and may leave room for interpretation, or a lack of recognition of where it would be helpful to consistently state the type of information used in decisions. Clearer guidelines about what to report in their Reasons may improve consistency in reporting, and ensure evidence based information is influencing decisions.

\section{Persons Found NCRMD for Sexual Offences are a Generally Homogeneous Group}

Our sample of persons found NCRMD for sexual offences were found to be quite homogeneous with respect to the nature of their offences. This homogeneity may indicate several things. First, the common offence behaviours of offending in public, near witnesses, and against strangers could indicate that as opposed to selecting certain types of offences or victims, as other persons convicted of sexual offences might, the offences of persons found NCRMD for sexual offences may often be characterized by disinhibited and impulsive offence behaviours. This would be in line with the general conception that offences for which someone is found NCRMD are the result of the presence and expression of mental health concerns.

However, this would not explain cases outside this typical pattern found NCRMD. An alternate explanation for this homogeneity may be biased selection of cases that are perceived to have "high risk" characteristics, such as offending in public spaces against strangers, in a way that is unpredictable and thus perceived as threatening or unexplainable. Though mental health concerns are common amongst persons convicted of sexual offences and not found NCRMD as 
well, there may be something specific about this type of case that makes it more likely to be identified as a case where criminal responsibility may be in question. Alternately, other forms of more "severe" sexual offences against known persons may be more likely to be processed in criminal justice courts, due to perceptions of responsibility and harm, regardless of the presence, absence or influence of mental health in these cases. This potential selection bias bears further examination in order to facilitate equal and fair administration of justice.

\section{Need for Offence Specific Treatment Interventions in NCRMD populations}

Findings of this thesis support the suggestion that persons found NCRMD for sexual offences would likely benefit from offence related treatment options, in additional to medical management of their mental health concerns which is currently the main approach to the rehabilitation of persons found NCRMD in the forensic mental health system. A considerable proportion of the persons found NCRMD for sexual offences in this sample had criminal histories. Further, $47.8 \%$ of offences for which this sample was found to have been previously charged or convicted were for violent or sexual offences. This suggests that even prior to an NCRMD finding, where persons found NCRMD are presumed to have no mens rea, or criminal intent, this sample has been involved in sexual and non-sexual violent behaviour sufficient to result in criminal justice involvement without the NCRMD determination. This suggests these persons found NCRMD have pre-existing risk and offence related behaviours that would benefit from being addressed in the course of their treatment and management. Given the similarities in these characteristics between this sample of persons found NCRMD for sexual offences, and persons found NCRMD for a variety of offences (Crocker et al., 2015), the benefits of criminogenic treatment may also extend to the broader population of persons found NCRMD as well. 
This suggestion of need for offence specific treatment is further supported by the finding that persons found NCRMD for sexual offences do present with risk factors for reoffence, as outlined in empirically supported risk assessment tools. This sample had an average of 3.6 Static99R risk factors, and $7.3 \mathrm{HCR}-20^{\mathrm{V} 3}$ risk factors. Though the summed scores presented in this research do not represent true risk scores on these measures, the presence of this many risk factors on these measures likely indicates average to above average risk. This level of risk suggests there would likely be a benefit to persons found NCRMD receiving at least some criminogenic and sexual offence specific treatment as part of their rehabilitation in the forensic mental health system. As has been suggested in past research (Skeem et al., 2015), the serious mental illness facing persons found NCRMD could be treated as a responsivity factor in RNR based intervention, which would allow effective participation in this form of rehabilitation.

However, it is unlikely that this sexual offence specific treatment is being received. To my knowledge, no forensic mental health programs currently provide criminogenic treatment to persons found NCRMD of sexual offences. Nor is there any research commenting on the utility of such programs or their ability to be adapted for use in this population. This would be an interesting opportunity for those working in forensic mental health to explore how to best reduce risk in this group, and explore the options for designing best practice for persons found NCRMD, based on their offence behaviours and offending histories. This would also explore the capacity for specialized assessment and management of these persons to best maintain public safety and utilize resources in the forensic mental health system efficiently.

This implication also lends itself to a critical and often debated topic in the field - does mental illness contribute to one's risk, and if so, how? Though the debate continues, research suggests that treating mental illness alone does not reduce recidivism (Morgan et al., 2012; 
Skeem et al., 2015). Thus, until evidence suggests otherwise, it would be prudent for programs for persons found NCRMD to include both medical and psychological management of mental illness, but also psychological treatment targeted at reducing criminological risk.

\section{Factors Influencing Review Board Decisions}

Clinician or hospital recommendation. This thesis found that, similar to past findings (i.e. Côté et al., 2012; Crocker et al., 2011; Crocker et al., 2014; Hilton and Simmons, 2001; McKee et al., 2007), Review Board decisions had very high rates of agreement with hospital or clinician recommendations. These results showed that clinician recommendation did not predict any disposition. This suggests that agreement between clinician recommendation and Review Board decisions is similar across decisions and dispositions.

This contributes to an interesting discussion. If Review Boards are considering the hospital's or clinician's recommendations, even if the Review Board does not explicitly consider risk relevant factors in their decisions, the assessing clinicians should. Thus, if clinicians are administering empirically supported and valid risk assessment measures, in an unbiased and evidence based way, decisions about persons found NCRMD for sexual offences are likely to be appropriate to their level of risk. Yet, past research on clinical recommendations has raised questions about the degree to which forensic assessors and clinical teams include risk relevant information in reports and recommendations (Côté et al., 2012; Lyall \& Bartlett, 2010; Martin \& Martin, 2016; Wilson et al., 2015). Further, if Review Boards are not independently considering the presence of risk factors, there may not be a check or balance/review of the relevance adequacy of risk assessment. Despite these cautions, until there is strong evidence that risk assessments by forensic assessors are not valid, or are biased in some way, it is encouraging that 
Review Boards are typically making decisions in line with professional clinical opinion, as opposed to frequently straying from recommendations.

General criminogenic risk factors. Results suggested that more general risk factors for recidivism, such as those found on the HCR-20 ${ }^{\mathrm{V} 3}$, are more likely to predict all types of Review Board decisions and the total length of time spent under the purview of the Review Board. Further, the HCR-20 tools were the most commonly referenced in Review Board Reasons documents. Thus, results are in line with past findings that Wilson and colleagues (2016) who suggest that Review Board decisions are improving through increasing consideration of risk factors.

The predictive effect of the HCR- $20^{\mathrm{V} 3}$ seems to be coming from the clinical and risk management scales in disposition decisions. This may be due to more seemingly immediate concerns (such as symptomology, insight, and stability) and resources and support upon release are influencing more immediate decisions. This seems quite logical given the context. However, exclusive consideration of clinical items while neglecting to consider criminogenic risk factors (several of which can be found in the HCR- $20^{\mathrm{V} 3}$ historical scale), raises concerns about the relevance of mental health symptoms in examining risk (e.g. Bonta et al., 2014). Still, this concern is potentially mitigated by empirical research which shows the HCR- $20^{\mathrm{V} 3}$ can be predictive of risk (e.g. Pedersen et al., 2010).

It also appears that the effect of the HCR- $20^{\mathrm{v} 3}$ differs in magnitude between types of decisions, and may be based on clinical and risk management factors alone. Detention orders, conditional discharges, and community living privileges all had large effects from the clinical and/or risk management scales. The largest effect, however, was found for decisions about absolute discharge. The clinical scale was the only scale to explain a significant amount of 
variance in absolute discharge decisions, and for each additional clinical factor present persons found NCRMD were over 10 times less likely to receive this disposition. The considerable influence of clinical factors in this decision, without effects from historical or risk management factors, raises similar concerns about the effects of mental health on risk compared to criminogenic factors and factors related to stability upon release.

Sexual offence specific risk factors. Risk factors from the Static-99R may not be considered by Review Boards in their decisions about the threat a person found NCRMD for sexual offences presents to the public. However, these effects did exert influence in the appropriate directions. Additionally, these factors were predictive of the overall length of time spent under purview of the Review Board. Thus, it may be that persons found NCRMD with higher risk for sexual reoffence are monitored more strictly, or engage in riskier behaviours that can extend their time in the forensic system. This also suggests at least some improvement over past research which has suggested that the length of time spent under purview of the Review Board is related to non-risk related factors (for discussion of evidence, see Martin \& Martin, 2016). However, further attention is needed to examine the relevance and use of offence specific information in estimating threat to the public, and informing Review Board decisions.

Overall Outcomes. When the final disposition received by a person found NCRMD within the study period was considered, a similar pattern to that found for current dispositions emerged. Sexual offence specific risk factors did not predict disposition decisions at the end of the study period. This finding raises two points for discussion. First, as discussed throughout, this implies static risk factors may not be used in decisions, despite the generally unchanging nature of these factors making them likely as relevant to later risk as initial risk. Second, given that these static 
factors are unamenable to change, they may act as a sort of constant over time, while shifts in dynamic risk factors at the time of assessment are more influential to decision makers. 


\section{Limitations}

Naturally, this thesis' limitations must be considered. First, the sample suffers from some limitations. Efforts were made to include persons found NCRMD for sexual offences across Canada using the WestLaw Next Canadas’s database LawSource®. However, the search returned only cases from Ontario. This suggests that there may be some form of systematic bias within the database that would have affected data collection. WestLaw Canada's mandate is to provide coverage of reported and unreported court decisions, as well as Carswell Law reports. Clarification on the process for collecting cases for the database was sought from WestLaw's research support. Research support at WestLaw clarified that they aim to include all available cases in their databases and "encourage the courts and boards/tribunals/arbitrators to send all decisions (that are not covered by a publication ban) to [WestLaw]. Some decisions may be challenging to get, such as oral decisions from the bench. Practice varies among provinces, so Ontario courts may produce more written decisions on a particular offence, while other provinces have more oral decisions (Y.D. Zabelishensky, personal communication, May 19, 2017).”.

Inquiry as to how Review Board documents, specifically, were collected helped to clarify why data collection only resulted in eligible cases form Ontario. Currently, LawSource® includes: 1) all tribunal decisions published in print reporters beginning in 1997, 2) the full text of all decisions reported in Labour Arbitration Cases since 1948, 3) All key unreported decisions cited in a court decision or reported tribunal decision since 2000, 4) All key unreported decisions cited in Carswell analytical materials. Additionally, LawSource ${ }^{\circledR}$ has agreements with many tribunals across Canada, that ensure significant coverage of decisions (P. Franchi, personal communication, June 29, 2017). The inclusion of any decisions by tribunals not in agreement with LawSource ${ }^{\circledR}$ relies on independent submissions of decisions (P. Franchi, personal 
communication, June 29, 2017). Currently, the only provincial or territorial Review Board with such an agreement is the Ontario Review Board (WestLaw Next Canada, 2017). Thus, data collection may have only included cases from Ontario due to the consistency of reporting that would result from such an agreement, while other provinces and territories may only submit decisions more infrequently or inconsistently. In future, more efforts could be made to arrange similar agreements with Review Boards in additional provinces.

Finally, any other potential sources of selection bias (e.g. being more likely to include complicated cases or cases that went to appeal) were clarified. According to research support, decisions on which cases to include in the database are not made based on any preference on the level of court that hears a case (P. Franchi, personal communication, June 29, 2017). Case collection does not disregard cases from lower courts, or make less of an effort to collect said cases (P. Franchi, personal communication, June 29, 2017). However, there may be more attention paid to ensuring court decisions that will have great impact on the Canadian legal landscape (e.g. Supreme court rulings) are received consistently (P. Franchi, personal communication, June 29, 2017). As such, research support suggests that there should not be a selection bias that would have affected the present thesis, particularly in light of the separate issue collecting tribunal cases, addressed above (P. Franchi, personal communication, June 29, 2017).

Another limitation is that, due to search limitations and inclusion criteria, cases of sexual assault or of offences with sexual elements that may have received non-sexual charges could not be identified. For example, cases that may have been pled down to an assault charge, or which may have been charged as violent offences only at the time of arrest would not be apparent in data collection. Thus, results cannot provide commentary on how decisions are made about such 
offences in the forensic mental health system. Considering that the Static-99R does consider such cases, future research should seek to include cases where offence charges and convictions may not have sexual offences charge or conviction names, but did include sexual misbehaviour. This would provide even broader context and support for the use of this tool in the NCRMD population.

Our sample was relatively small, despite broad search parameters. This may be due to the availability of documents in the WestLaw database. Alternatively, it may be due to only a small percent of offences being committed by persons with mental disorders, and who are later found eligible for the NCRMD defence. Regardless of the reasoning behind this, the current analyses were limited by the statistical power available based upon sample size. Future research would benefit from increasing sample size, and from the ability to include cases of persons found NCRMD for sexual offences from across Canada.

This thesis used only Review Board Reasons documents to comment upon the presence and consideration of risk factors, and their consideration by Review Boards. Thus, this work only comments upon those factors deemed relevant in some way by Review Boards to warrant their inclusion in the Reasons documents. As discussed throughout this paper, information provided was inconsistent at best. Though this is an interesting and potentially meaningful finding in and of itself, and allows us to consider what assessments and risk factors are discussed and can thus be said to influence decisions, it cannot be assumed that there is no error in the estimation of risk factors in this sample. Considerable missing information on risk factors means that there could be some risk factors either present or absent in the sample, that could affect their estimations of risk and potential progression through the forensic mental health system. The inability to access 
full risk assessments and hospital reports does not allow us to clarify the issue of what is available to Review Boards versus what is considered or reported by Review Boards.

Having access to only Review Board Reasons documents also results in a limited ability to comment upon the role of ethnicity and bias in the process of decision making within the Forensic Mental Health system. Factors related to ethnicity are only commented upon in such documents, when these factors are "notable" in some way (e.g. mitigating factors, issues of support and community). Thus, this thesis was only able to comment upon such "notable" factors, as opposed to a full examination of the sample's ethnicity. However, even with this limitation there was considerable diversity in this sample, with about $32 \%$ being born outside of Canada, and about $4 \%$ being of Indigenous status. This raises questions about the degree to which bias within the criminal justice system as a whole may influence the identification of persons eligible for the NCRMD defence, judicial decisions about the appropriateness of the NCRMD offence, and how these persons move through the forensic mental health system once found NCRMD. 


\section{Future Directions}

Our findings replicated previous research that has identified Review Board decisions as having very high rates of agreement with clinician recommendation. Thus, it would be beneficial for future research to examine, on a large scale, the practices of forensic clinicians in the Canadian forensic mental health system. Ideally, this research would identify the tools being used by assessing clinicians, fidelity to recommended assessment procedures, and consideration of the predictive validity of the tools being used in this particular sample. This study could also comment upon the degree to which clinicians assess for general and offence specific factors, and what they perceive to be the most important information to include in an assessment and report for Review Boards. This work would lend greater insight into what factors are affecting the progression of persons found NCRMD through the forensic mental health systems, and opportunities to continue or improve upon best practices in forensic assessment.

In terms of next steps in assessing how Review Boards reach decisions, a qualitative or mixed methods study of factors Review Board members consider influential to their decisions would be of great benefit. Through interviewing members of various provincial Review Boards, such research could clarify how assessments and risk information are used, and which factors are most important and under which circumstances. Results of this study could identify areas where the understanding of risk derived from research, and use of risk relevant information applied in the practice of making disposition decisions may or may not diverge. This research could also guide efforts to translate the empirical knowledge of risk into informed practice within Review Boards, where necessary. Likely targets of such efforts might assist Review Boards in the basic principles of risk, the importance of recognizing the effectiveness of risk assessments in a forensic context, and the potential bias of unstructured clinical decisions. 
Little research has examined the risk for recidivism in persons found NCRMD. Further, no research has examined the validity of the Static-99R, and other sexual offence specific risk tools, in the NCRMD population. Current findings suggest that this group does present with historical and static risk factors that elevate risk for sexual recidivism. This provides impetus for specific research examining the utility of this tool in this population. The Static-99R manual does state that there is "no reason to suspect that the recidivism estimates for Static-99R would not be applicable" (p.16) to persons with major mental disorders, since there were a significant number of persons with major mental disorders in the tool's development and norming samples. However, the NCRMD defense itself is theoretically grounded in the concept that there is something fundamentally different about the offences by persons who are found to be NCRMD. Thus, future research should examine the predictive validity of this tool in this population, specifically, and potential differences in recidivism estimates in this population. Findings would lend support to the manual's suggestion that this tool is appropriate in a variety of correctional or forensic populations with major mental disorders. This would clarify how this tool could be used effectively to provide information of recidivism risk in persons found NCRMD for sexual offences.

Finally, future work should extend current findings, with greater consideration to issues of ethnicity and bias. It has been very well established that there is racial and ethnic bias in the criminal justice system (Owusu-Bempah, \& Wortley, 2014). With respect to sexual offending, Brankley and Lee found that both Black and Indigenous persons were overrepresented in the criminal justice system in a large Canadian sample (2016). Current findings suggested that at least $38 \%$ of persons found NCRMD for sexual offences in this sample were born outside of Canada, or of Indigenous status. This is in line with findings that the NCRMD population is 
becoming more ethnically diverse (Simpson et al., 2014). Though no research has controlled for ethnicity in examining Review Board disposition decisions, studies on revocation of conditional discharge do suggest persons of minority status are more likely to be returned to detention after release (Callahan, \& Silver, 1998; Cohen, Spodak, Silver, \& Williams, 1988; Monson, Gunnin, Fogel, \& Kyle, 2001; Tellefsen, Cohen, Silver, \& Dougherty, 1992). This begs further examination of the ways in which ethnicity may influence both the administration of the NCRMD defence in the justice system, as well as the ways in which bias has the potential to occur in the forensic mental health system, and in Review Board decisions. This could provide some clarity on ethnicities being overrepresented in the forensic mental health system, and how biases related to ethnicity could affect the ways in which persons of differing ethnicities move through the system and towards absolute discharge. 


\section{Conclusion}

This thesis examined the characteristics of Review Board Reasons for decisions about persons found NCRMD for sexual offences. This thesis also examined the characteristics of this group, and the degree to which presence of empirically supported risk factors predicted Review Board decisions. Current findings suggest that persons found NCRMD are a fairly homogenous group that do present with both general and sexual offence specific risk factors for recidivism.

However, Review Board decisions were only predicted by risk factors found on the HCR $-20^{\mathrm{V} 3}$, and in particular, those factors related to clinical functioning and risk management. These findings provide impetus for further examination of the ways in which structured and empirically supported risk assessments, particularly sexual offence specific risk assessments, can continue to improve Review Board decisions for persons found NCRMD for sexual offences. 


\section{Appendix}

\section{Not Criminally Responsible Sexual Offence Coding Guide}

\section{Notes on the Coding Guide}

- Reading the Coding Guide:

(1) Case Number [CaseNumb] (Number, \#\#): The case number is the identifying number
present at the beginning of each document.
- For example: For the $\mathrm{R}$ v Jones file you would look at the file name, "001 - $\mathrm{R} \mathrm{v}$
Jones.doc". The case number is "001"

1. Excel Column Number: Each column in Excel will be numbered to aid readers with identifying variables in the database and the coding dictionary.

2. Variable Name: A meaningful title for the variable

3. Variable Label: A less meaningful title that is necessary for use in SPSS and Excel

4. Type of Variable: This gives you an idea of which kind of variable this is. Options include:

- Number: A variable comprised only of numbers. Be careful to avoid spaces.

- Categorical: A variable whose options have been predetermined. For example Gender is a categorical variable with "1" meaning men and "2" meaning women.

- Date: This variable will be a date. Dates will be coded year first, month second, in this format YYYYMM. So, if the date to be coded is July the $1^{\text {st }}$ of 2015 I would code 201507, I would not code the day.

- Dummy Coding: A variable that is dummy coded will always be 1 or 0.1 indicates the variable is present, e.g., you may often code Tertiary Source "1" as you are using judgments from WestLaw. You may rarely code Primary Source as "1" unless you have direct access primary source information like crime scene photographs.

- String: This means that the variable is text based. Try to keep your writing terse.

5. Variable Format: To standardize data entry for numbers the format of numbers is given. Each "\#" represent a number. No decimals or commas will be used in the sample. If you see three "\#" as in the example above you must always enter three numbers even if the number is 10 you would enter "010". No spaces.

6. Variable Definition: Information will often be provided to interpret the variable.

7. Examples: Examples will also be provided if the variable is particularly confusing

8. Example Data: In the example if something is underlined and in quotations, then this is a direct example of what is to be entered in this situation. 


\section{Coding Guide}

I. Sorting Variables: These variables will be responsible for sorting the cases in the database.

(1) Case Number [CaseNumb] (Number, \#\#\#\#\#): The case number is the identifying number present at the beginning of each document.

(2) Document Number [CaseDoc] (Number, \#\#): The casenumber-document number

(3) Offender Name [OffName] (String variable): For the offender name, please record in the following format: LAST NAME, First Name Middle Name.

(4) Index Offence Number [OffNumb] (Number, \#\#\#): Please indicate, chronologically, which sexual offence is being coded on the current line (i.e. if there are two offences, the first line should be coded " 1 " and look at the first offence, the second line should be coded " 2 " and look at the second offence)

(5) Coder ID [CID] (String variable): Please enter your name.

(6) Date Entry was Coded [CodingDate] (Date, YYYYMMDD): This is the date you coded this line of data.

(7) Sexual Interference - s. 151 [SexInt] (Dummy Code, 1 or 0): Every person who, for a sexual purpose, touches, directly or indirectly, with a part of the body or with an object, any part of the body of a person under the age of 16 years.

(8) Invitation to Sexual Touching - s. 152 [SexT] (Dummy Code, 1 or 0): Every person who, for a sexual purpose, invites, counsels or incites a person under the age of 16 years to touch, directly or indirectly, with a part of the body or with an object, the body of any person, including the body of the person who so invites, counsels or incites and the body of the person under the age of 16 years,

(9) Sexual Exploitation - s. 153 [SexE] (Dummy Code, 1 or 0): Every person commits an offence who is in a position of trust or authority towards a young person, who is a person with whom the young person is in a relationship of dependency or who is in a relationship with a young person that is exploitative of the young person, and who

(a) for a sexual purpose, touches, directly or indirectly, with a part of the body or with an object, any part of the body of the young person; or

(b) for a sexual purpose, invites, counsels or incites a young person to touch, directly or indirectly, with a part of the body or with an object, the body of any person, including the body of the person who so invites, counsels or incites and the body of the young person.

(10) Voyeurism - s. 162 [SexV] (Dummy Code, 1 or 0): Every one commits an offence who, surreptitiously, observes - including by mechanical or electronic means - or makes a visual recording of a person who is in circumstances that give rise to a reasonable expectation of privacy, if

(a) the person is in a place in which a person can reasonably be expected to be nude, to expose his or her genital organs or anal region or her breasts, or to be engaged in explicit sexual activity;

(b) the person is nude, is exposing his or her genital organs or anal region or her breasts, or is engaged in explicit sexual activity, and the observation or recording is done for the purpose of observing or recording a person in such a state or engaged in such an activity; or

(c) the observation or recording is done for a sexual purpose. 
(11) Obscene Publication - Child Pornography - s. 163.1 [SexCP] (Dummy Code, 1 or 0): In this section, child pornography means

(a) a photographic, film, video or other visual representation, whether or not it was made by electronic or mechanical means,

(i) that shows a person who is or is depicted as being under the age of eighteen years and is engaged in or is depicted as engaged in explicit sexual activity, or

(ii) the dominant characteristic of which is the depiction, for a sexual purpose, of a sexual organ or the anal region of a person under the age of eighteen years;

(b) any written material, visual representation or audio recording that advocates or counsels sexual activity with a person under the age of eighteen years

(c) any written material whose dominant characteristic is the description, for a sexual purpose, of sexual activity with a person under the age of eighteen years

(d) any audio recording that has as its dominant characteristic the description, presentation or representation, for a sexual purpose, of sexual activity with a person under the age of eighteen years

(12) Indecent Acts - Exposure - s. 173 [SexEx] (Dummy Code, 1 or 0): (1) Everyone who willfully does an indecent act in a public place in the presence of one or more persons, or in any place with intent to insult or offend any person, (2) Every person who, in any place, for a sexual purpose, exposes his or her genital organs to a person who is under the age of 16 years

- Also include here other "Indecent Acts"

(13) Sexual Assault - s.265, s.271 CC [SexAs] (Dummy Code, 1 or 0):

(1) A person commits an assault when: (a) without the consent of another person, he applies force intentionally to that other person, directly or indirectly; (b) he attempts or threatens, by an act or a gesture, to apply force to another person, if he has, or causes that other person to believe on reasonable grounds that he has, present ability to effect his purpose; or (c) while openly wearing or carrying a weapon or an imitation thereof, he accosts or impedes another person or begs.

(2) This section applies to all forms of assault, including sexual assault, sexual assault with a weapon, threats to a third party or causing bodily harm and aggravated sexual assault.

(3) For the purposes of this section, no consent is obtained where the complainant submits or does not resist by reason of (a) the application of force to the complainant or to a person other than the complainant; (b) threats or fear of the application of force to the complainant or to a person other than the complainant; (c) fraud; or (d) the exercise of authority.

(14) Sexual Assault with a weapon, threats to a third party, or causing bodily harm - s.265, s.272 CC [SexAsW] (Dummy Code, 1 or 0): (1) Every person commits an offence who, in committing a sexual assault, (a) carries, uses or threatens to use a weapon or an imitation of a weapon; (b) threatens to cause bodily harm to a person other than the complainant; (c) causes bodily harm to the complainant; or (d) is a party to the offence with any other person.

(15) Aggravated Sexual Assault - s. 265, s.273 [SexAsAg] (Dummy Code, 1 or 0): (1) Everyone commits an aggravated sexual assault who, in committing a sexual assault, wounds, maims, disfigures or endangers the life of the complainant.

(16) Total Number of Sexual Offence Findings [TotConv] (Number, \#\#\#): This is total number of sexual findings from all offences in the index findings.

(17) Total Number of Sexual Offences [TotSO] (Number, \#\#\#): This is total number of sexual offences.

(18) Total Number of Findings [TotOff] (Number, \#\#\#): This is total number of NCR findings, including sexual charges and others, in the index offence disposition 
II. Details about the Source Information: The purpose of this section is to provide information on where the data was coded. This includes coding WestLaw and all other source information.

(19) West Law [WestLRB] - Review board report (Dummy Code, 1 or 0): Code 1 if the file you are using to code is a review board report

(20) Source Date [SorDa] (Date, YYYYMMDD): Record the date the source file was published.

(21) Word Count - Source [WordSo] (Number, \#\#\#\#\#\#): Using a word processor count how many words comprise the entire source file.

(22) Diagnosis provided [Pdx] (Dummy Code, 1 or 0): Code 1 if, within the Reasons, a diagnosis is provided. The diagnosis (at least 1 ) must be confirmed. Code 0 if only symptoms are discussed.'

(23) Background provided [Pbg] (Dummy Code, 1 or 0): Code 1 if, within the Reasons, a background is provided for the offender. This must include at least some personal and historical information about the offender's life prior to the index offence (eg. family details, relationships, education, employment). Code 0 if the document notes the background/personal history was in the hospital report, and won't be repeated in the reasons, or these details are otherwise absent.

(24) Criminal history provided [Pchx] (Dummy Code, 1 or 0): Code 1 if, within the Reasons, at least some details of the offenders criminal history (or lack thereof) are provided. Code 0 if the document notes the criminal history was in the hospital report, and won't be repeated in the reasons.

III. Details about the Offence: Here you will code information about the offence

(25) Date of Index Offence [DateOff] (Date, YYYYMMDD): Code the date of the index sexual offence being considered in the current disposition

(26) Provincial Location of Offences [ProvLoc] (Categorical, \#\#): I want you to indicate the province in which the offences took place using the following codes:

- $\underline{01}$ - British Colombia

- $\underline{\mathbf{0 2}}$ - Alberta

- $\underline{\mathbf{0 3}}$ - Saskatchewan

- $\underline{\mathbf{0 4}}$ - Manitoba

- $\underline{\mathbf{0 5}}$ - Ontario

- $\underline{\mathbf{0 6}}-$ Quebec

- $\quad \underline{07}$ - Newfoundland and Labrador

- $\underline{\mathbf{0 8}}$ - New Brunswick

- $\underline{09}$ - Nova Scotia

- $\underline{\mathbf{1 0}}$ - Prince Edward Island

- $\underline{\mathbf{1 1}}$ - Yukon Territory

- $\underline{\mathbf{1 2}}$ - Northwest Territories

- $\underline{\mathbf{1 3}}$ - Nunavut

(27) Location of Sexual Offence [LocSO] (String): Record the town or city where the offence took place.

(28) Name of Location of Sexual Offence [LocSONam] (String): Record the name of the property 
(29) Gender [Gender] (Categorical, 1 or 2): 1 for Male, 2 for Female.

(30) Age at Hearing [AgeHear] (Number, \#\#): This is the age of the individual at the time of disposition.

(31) Age at Index offence [AgeIndex] (Number, \#\#): This is not a straightforward item. The age given to you will likely be at the time of the trial. Therefore, you need to figure out the year the decision was published and subtract from that the year of the first offence. Then subtract this number from the offender's age OR use a provided date of birth

(32) Aboriginal [Abor] (Dummy Code, 1 or 0): Code 1 if the defendant was identified as aboriginal, native Canadian, first nations, metis, Inuit, etc.

(33) Born outside Canada [Born] (Dummy Code, 1 or 0): Code 1 if the offender was identified as being born outside of Canada

(34) Homeless [HomLe] (Dummy Code, 1 or 0): Code 1 if there is evidence that the offender was homeless at the time of the offence. This includes living at a homeless shelter.

(35) Offenders Town [OffTown] (String): Copy down the town where the offender resides at time of index

(36) Ever Married [MArr] (Dummy Code, 1 or 0): Code 1 if ever married/common law (at the time of the offence)

(37) Ever Divorced [Div] (Dummy Code, 1 or 0): Code 1 if the offender was ever divorced (at the time of the offence)

(38) History of Unstable Relationships [UnRel] (Dummy Code, 1 or 0): Code 1 if there is evidence the individual had one or more intimate relationships that included behavioural and/or emotion dysregulation. Examples of this include reports of domestic violence, fighting that caused problems, several periods of separation.

(39) Relationship [Rela] (Dummy Code, 1 or 0): Code 1 if there is any evidence that the individual was, at the time of the offence, in a committed relationship.

(40) Relationship Status [RelStat] (Categorical, \#\#): Select from the following options the code that best fits the offender during the time of the offence.

- $\underline{\mathbf{0 1}}$ - Single

- $\underline{\mathbf{0 2}}-$ Monogamous relationship (not living together)

- $\underline{\mathbf{0 3}}$ - Monogamous relationship (living together)

- $\underline{\mathbf{0 4}}$ - Engaged

- $\underline{\mathbf{0 5}}$ - Married/Common Law

- $\underline{\mathbf{0 6}}$ - Separated

- $\underline{\mathbf{0 7}}$ - Divorced

- $\underline{\mathbf{0 8}}-$ Widow(er)

(41) Children [Child] (Dummy Code, 1 or 0): Code 1 if there is any evidence that the offender has children.

(42) Living Situation of Offender [Liv] (Dummy Code, 1 or 0): Code 1 if the offender lives with another person at the time of the index offence. Code 0 if the offender lives alone.

(43) Living Situation of Offender - Describe [LivDes] (String): If [Liv] is coded 1 (the offender lives with another person), describe who it is the offender lives with.

(44) Social Isolation [SocIso] (Dummy Code, 1 or 0): Code 1 if there is evidence that the offender was socially isolated.

(45) Employment [emp] (Categorical, \#\#): I want you to indicate which job the individual had using one of the following classifications from the International Standard classification of Occupations (for more details on each class see: https://en.wikipedia.org/wiki/International_Standard_Classification_of_Occupations) .

- $\underline{\mathbf{0 1}}$ - No Job - include here students who are not working

- $\underline{\mathbf{0 2}}$ - Managers (e.g., Administrative and commercial managers, production managers, manufacturing managers, hospitality, retail and other services managers) 
- $\underline{\mathbf{0 3}}$ - Professionals (e.g., Science, engineering, doctors, nurses, midwives, paramedics, professors, teachers, financial professionals, sales and marketing, legal professionals, journalists, authors, linguists, creative and performing artists).

- $\quad \underline{\mathbf{0 4}}$ - Technicians and Associate Professionals (e.g., physical and science engineering technicians, process control technicians, ship and aircraft controllers, medical and pharmaceutical technicians, health associate professionals, sale and purchasing agents, brokers, sports and fitness workers, artistic, cultural, and culinary associate professionals)

- $\underline{\mathbf{0 5}}$ - Clerical Support Workers (e.g., General and keyboard clerks, secretaries, tellers, money collectors, client information workers, numerical clerks, transport clerks)

- $\underline{\mathbf{0 6}}$ - Service and Sales workers (e.g., personal service workers, cooks, bartenders, hairdressers, waiters, housekeep supervisors, beauticians, protective services)

- $\quad \underline{\mathbf{0 7}}$ - Skilled Agricultural, forestry, and Fisher Workers (e.g., market gardeners and crop growers, animal producers, forestry and related workers, hunters and trappers, subsistence workers)

- $\quad \underline{\mathbf{0 8}}$ - Craft and Related Trades Workers (e.g., building and related trades workers, electricians, painters, metal workers, handicraft and print workers, food processing, wood workers, garment workers)

- $\quad \underline{09}$ - Plan and Machine Operators and Assemblers (e.g., stationary plant and machine operators, mining and mineral plant operators, assemblers, drivers and mobile plant operators, heavy truck drivers, ship deck crews, bus drivers)

- $\quad \underline{10}$ - Elementary Occupations (e.g., cleaners and helpers, agricultural, forestery, and fishery laborers, laborers in mining, food preparation assistants, street and related sales and service workers, refuse workers)

- $\underline{11}$ - Armed Forces Occupations

(46) Employment Description [EmpDes] (String): I want you to describe the job.

(47) Unstable Employment [UnEmp] (Dummy Code, 1 or 0): Code 1 if there is evidence that the individual had several short-term jobs or was often fired from jobs.

(48) Employed During Offence [EmpOff] (Dummy Code, 1 or 0): Code 1 if the individual was employed during the time of the offence. Code 1 if offender is employed, but on a sick leave or leave of absence, as this means the offender has a job, and is expected to return.

(49) Education Level [Edu] (Categorical, \#\#): I want you to indicate the highest level of education the individual has achieved.

- $\underline{\mathbf{0 1}}$ - Did not complete high school

- $\underline{\mathbf{0 2}}$ - High School Graduate/Equivalency Only

- $\underline{\mathbf{0 3}}$ - Some College

- $\underline{\mathbf{0 4}}$ - Completed College

- $\underline{\mathbf{0 5}}$ - Some University

- $\underline{\mathbf{0 6}}$ - Completed Undergraduate Degree

- $\underline{\mathbf{0 7}}$ - Some Graduate or Professional (e.g., doctor, lawyer) Education

- $\underline{\mathbf{0 8}}$ - Completed Graduate or Professional (e.g., doctor, lawyer) Education

(50) Juvenile Delinquency [JuvD] (Dummy Code, 1 or 0): Code 1 if there is evidence that the individual engaged in antisocial behaviour under the age of 18 (e.g., previous convictions, truancy, expulsion).

(51) Any Previous Charges [PrevChar] (Dummy Code, 1 or 0): Code 1 if the individual has been charged for offences prior to the index offences.

(52) Any Previous Convictions [PrevConv] (Dummy Code, 1 or 0): Code 1 if there is evidence that the individuals had any previous convictions. Do not code 1 for conditional discharges as this is not a conviction, though conditional discharges will still be coded 1 under "previous charges"0 
(53) Any Previous NCR findings [PrevNCR] (Dummy Code, 1 or 0): Code 1 if there is evidence the individual had been previously found NCR for any offence

(54) Age at First Charge [AgeFirstChar] (Number, \#\#): Age given that the individual was charged with their first offence.

(55) Age at First Conviction [AgeFirstCon] (Number, \#): Age given that the individual was convicted with their first offence. Maybe the same as their first charge

(56) Age at First NCR finding [AgeFirstNCR] (Number, \#\#): Age given that the individual was first found NCR

(57) Number of Previous Convictions [PreCon] (Number, \#\#\#): Number of previous convictions.

(58) Number of Previous NCR findings [PreNCR] (Number, \#\#): Number of previous NCR findings

(59) Previous Sexual Offence [PrevSO] (Dummy Code, 1 or 0): Code 1 if there is evidence that the individuals had any previous sexual offence convictions or NCR findings. For example see sexual charges above.

(60) Previous Non Violent Offence [PrevNon] (Dummy Code, 1 or 0): Code 1 if there is evidence that the individuals had any previous non violent convictions or NCR findings

- Break and Eater

- Theft/Stolen property

- Drugs

- Burglary (unarmed)

- Grand Theft Auto

- Escape

- DUI no injury

- Forgery/Fraud/Racketeering/Gambling/Bribery

- Traffic conviction

- Pollution

- Prostitution

(61) Previous Violent, Non-Sexual Offence [PrevVio] (Dummy Code, 1 or 0): Code 1 if there is evidence that the individuals had any previous violent convictions (e.g., robbery, assault, murder) or NCR findings

- Assault

- Robbery

- Weapons conviction or anything when the person is armed

- Carjacking

- Kidnapping

- DUI Injury

- Manslaughter/Murder

- Forcible confinement

(62) Previous Arson Offence [PrevArs] (Dummy Code, 1 or 0): Code 1 if there is evidence that the individuals had any previous arson offence convictions or NCR findings

(63) Risk Assessment [RiskAss] (Dummy Code, 1 or 0): Code 1 if there is eveidence a formal risk assessment was conducted by a psychological professional. (PCL-R can be included here, even though not a formal risk assessment, If presented as a risk assessment measure in the context of the hearing)

(64) Risk Level [Risk] (Categorical, \#\#): Individuals risk is determined by actuarial or structured professional judgment completed by psychological professionals, not by unstructured determinations by legal professionals. As part of legal proceedings, an individual may have completed a risk assessment. This may be reported as part of their mitigating factors or in a summary of their mental health status. If a risk assessment was completed, please indicate which of the following categories of risk was assigned. 
- $\underline{\mathbf{0 1}}$ - High Risk

- $\underline{\mathbf{0 2}}$ - Moderate to High (High to Moderate) Risk - Only use if this phrase is used

- $\underline{\mathbf{0 3}}$ - Moderate Risk

- $\underline{\mathbf{0 4}}$ - Low to Moderate (Moderate to Low) Risk - Only use if this phrase is used

- $\underline{\mathbf{0 5}}$ - Low Risk

(65) Risk Assessment Tool [RiskTool] (String): If risk is assessed by a psychological professional, and is reported above, please enter the name of the risk assessment used.

\section{Psychological Factors}

- Only code the presence " 1 " or absence " 0 " of a mental illness when you have sufficient evidence to make that determination. If a mental health professional did not provide testimony for the case, or there was no review of medical history, then do not assume that the absence of evidence is indicative that mental illness was not present.

(66) Concerns Around Competence to Stand Trial [CompTrial] (Dummy Code, 1 or 0): Code 1 if there was ever any mentioned concern (either founded or unfounded) that the individual may not be competent to stand trial for the current offence or past offences. This includes mention of the individual being assessed for competence to stand trial.

(67) Evidence of Any Psychological Disorder [AnyPsyDis] (Dummy Code, 1 or 0): Code 1 if there is evidence/diagnosis that indicates that the individual has any psychological disorder by report of a mental health professional. If any of the following diagnostic variables are coded, one, this should be coded " 1 ".

(68) Describe diagnoses [DX] (String): Please enter the names of official diagnoses given to the offender

(69) Evidence of Paraphilia [AnyParaDis] (Dummy Code, 1 or 0): Code 1 if there is evidence/diagnosis that indicates that the individual has any paraphilia. If any of the following are likely present (including provisional, differential diagnoses, and rule outs), as determined by the report of a mental health professional, code " 1 ":

- Voyeuristic Disorder

- Exhibitionistic Disorder

- Frotteuristic Disorder

- Sexual Masochism Disorder

- Sexual Sadism Disorder

- Pedophilic Disorder

- Fetishistic Disorder

- Transvestic Disorder

- Other specified, or unspecified, paraphilic disorder

(70) Evidence of Any Anxiety Disorder [AnyAnxDis] (Dummy Code, 1 or 0): Code 1 if there is evidence/diagnosis that the individual has had previous/current problems with anxiety by report of a mental health professional. A diagnosis of any anxiety disorder is sufficient for coding " 1 ". Below is a list of the acceptable Anxiety Disorders. If any of the following are present, code " 1 ":

- Acute Stress Disorder

- Agoraphobia

- Body Dysmorphic Disorder

- Disinhibited Social Engagement Disorder

- Excoriation (Skin Picking) Disorder

- Generalized Anxiety Disorder 
- Hoarding or Hoarding Disorder

- Obsessive-Compulsive Disorder

- Panic Disorder (History of Panic Attacks also counts)

- Posttruamtic Stress Disorder

- Reactive Attachment Disorder

- Specific Phobia

- Selective Mutism

- Separation Anxiety Disorder

- Social Anxiety Disorder/ Social Phobia

- Trichotillomania (Hair-Pulling) Disorder

- Any of the above in the context of Substance/Medication Induce Disorder

- Any of the above in the context of Another Medical Condition

- Other Specified versions of any of the above

- Unspecified versions of any of the above

(71) Evidence of Experiencing Trauma [TrauEx] (Dummy Code, 1 or 0): Code 1 if there is evidence/diagnosis that indicates that the individual has been the victim of trauma. Trauma is defined as exposure to: death, threatened death, actual or threatened serious injury, or actual or threatened sexual violence either through direct exposure, witnesses, or indirectly through a close relative or friend.

(72) Evidence of Any Mood Disorder [AnyMood] (Dummy Code, 1 or 0): Code 1 if there is evidence/diagnosis that indicates that the individual has had previous/current mood problems (e.g., depression, mania, bipolar) by report of a mental health professional. If any of the following are present, code " 1 ":

- Bipolar I or II

- Cyclothmic Disorder

- Major Depressive Disorder

- Persistent Depressive Disorder or Dysthymia

- Disruptive Mood Dysregulation Disorder

- Premenstrual Dysphoric Disorder

- Any of the above in the context of Substance/Medication Induce Disorder

- Any of the above in the context of Another Medical Condition

- Other Specified versions of any of the above

- Unspecified versions of any of the above

(73) Evidence of Any Psychotic Disorder [AnyPsych] (Dummy Code, 1 or 0): Code 1 if there is evidence/diagnosis that indicates that the individual has a history of/current psychosis, hallucinations, or delusions. A psychotic disorder diagnosis (e.g., schizophrenia, schizoaffective) is sufficient for coding " 1 ". If any of the following are present, code " $\underline{\text { ": }}$

- Schizotypal Personality Disorder (also code for Personality Disorder being present)

- Delusional Disorder

- Brief Psychotic Disorder

- Schizophreniform Disorder

- Schizophrenia

- Schizoaffective Disorder

- Catatonia

- Any of the above in the context of Substance/Medication Induce Disorder

- Any of the above in the context of Another Medical Condition

- Other Specified versions of any of the above

- Unspecified versions of any of the above 
(74) Any Neurodevelopmental Disorder [AnyNeur] (Dummy Code, 1 or 0): Code 1 if the individual has been given a diagnosis of neurological disorder by a mental health professional. If any of the following are present, code " 1 ":

- Intellectual Disability (Also code under Intellectual Disability)

- Global Developmental Delay

- Language Disorder

- Speech Sound Disorder

- Childhood Onset Fluency Disorder (Stuttering)

- Social (Pragmatic) Communication Disorder

- Unspecified Communication Disorder

- Autism Spectrum Disorder

- Attention-Deficit/Hyperactivity Disorder

- Specific Learning Disorder

- Motor Disorders

- Any of the above in the context of Substance/Medication Induce Disorder

- Any of the above in the context of Another Medical Condition

- Other Specified versions of any of the above

- Unspecified __ versions of any of the above

Evidence of Any Traumatic Brain Injury [AnyTBI] (Dummy Code, 1 or 0): Code 1 if there is evidence that the individual has had any injury to his head. Common examples would be a history of concussion, accidents or incidents where the individual became unconscious due to physical injury, and history of abuse that included insults to the head.

(76) Evidence of Intellectual Disability [AnyID] (Dummy Code, 1 or 0): Code 1 if there is evidence/diagnosis that indicates that the individual has significant intellectual impairments as adjudged by a mental health professional. Poor academic performance is NOT sufficient for coding this item a 1 .

(77) Evidence of History of Alcohol Problems [HisAlco] (Dummy Code, 1 or 0): Code 1 if there is evidence/diagnosis that indicates that the individual has had previous/current problems with alcohol. A diagnosis of alcohol disorder is sufficient for coding " 1 ". If the only evidence of alcohol problems is with the current offence then code 0 .

(78) Evidence of History of Substance Use Problems [HisSub] (Dummy Code, 1 or 0): Code 1 if there is evidence/diagnosis that indicates that the individual has had previous problems with abusing illicit, recreational, or prescription substances. A diagnosis of substance use disorder is sufficient for coding " 1 ". If the only evidence of substance use problems is with the current offence then code 0 .

(79) Evidence of Any Dissociations [AnyDissoc] (Dummy Code, 1 or 0): Code 1 if there is evidence/diagnosis that indicates that dissociation occurred. Dissociation are characterized by a disruption of and/or discontinuity in the normal integration of consciousness, memory, identity, emotion, perception, body representation, motor control, and behaviour. If any of the following are present, code " 1 ":

- Dissociate Identity Disorder (formerly known as Multiple Personality Disorder)

- Dissociative Amnesia

- Depersonalization/ Derealization Disorder

(80) Intelligence [IQ] (Categorical, \#\#): In some psychological reports, doctors will evaluate the individuals IQ. Please report, using the general categories used below, if a licensed medical professional comments upon the individuals intelligence

- $\underline{\mathbf{0 1}}$ - Low or Below Average Functioning

- $\underline{\mathbf{0 2}}$ - Normal Range

- $\underline{\mathbf{0 3}}$ - High or Above Average Functioning 
(81) Presence of Any Personality Disorder Other than Psychopathy or ASPD [AnyPersDis] (Dummy Code, 1 or 0): Code 1 if the individuals has received a personality disorder diagnosis other than Antisocial PD or Psychopathy. If any of the following are present, code "1":

- Paranoid Personality Disorder

- Schizoid Personality Disorder

- Schizotypal Personality Disorder (also code for psychotic disorder)

- Borderline Personality Disorder

- Histrionic Personality Disorder

- Narcissistic Personality Disorder

- Avoidant Personality Disorder

- Dependent Personality Disorder

- Obsessive-compulsive Personality Disorder (DO NOT DOUBLE CODE for Anxiety)

Psychopathy or ASPD Present [ASPD] (Dummy Code, 1 or 0): Code 1 if the individual has received a diagnosis of ASPD or has been assessed with the PCL-R and has a score above 30. A diagnosis by report of a mental health professional is needed, not simply the musing of the judge that the individual has a history of antisocial behaviour.

(83) Concerns about Psychopathy or ASPD [ASPDlite] (Dummy Code, 1 or 0): Code 1 if the individual has not been formally assessed for ASPD or Psychopathy (using the PCL-R) but there are concerns that psychopathy is present or there is note that psychopathic or antisocial personality traits are present. If a person is assessed with the PCL-R, score highly (e.g., 20 or 25) but do not cross the 30 cut off, give this item a 0.

(84) Suicidality [suici] (Dummy Code, 1 or 0): Code 1 if the individual has had any history of suicide attempts.

(85) Nonsuicidal Self-Injury [NSSI] (Dummy Code, 1 or 0): Code 1 if there is any evidence the individual has a history of non-suicidal self harm (e.g., cutting, burning, hitting himself).

\section{Judgment \& Sentencing}

(1) Judge Last Name [JudName] (String variable): For the judge's/board chairperson's name, please record the last name only.

(2) Initial hearing? [Initial] (Dummy Code, 1 or 0): Code 1 if the earliest document available, and thus being used for coding, is for the offender's initial disposition hearing

(3) Earliest Known Disposition [Disp1] (String): As indicated in the earliest available disposition document, what the earliest known disposition given to the offender? This may be the current disposition, or it may be referenced as a existing disposition prior to the current disposition

(4) Earliest Known Security level [Sec1] (String): What level of security was the offender designated to, if detained at their initial hearing, or the earliest hearing for which information is available? If on any form of discharge, enter 0 .

(5) Earliest Known Community living [CmP1] (Dummy Code, 1 or 0): Was the offender living in the community at the time of their initial hearing, or the earliest hearing for which information is available? Any form of discharge should be coded as 1 .

(6) Current Disposition [DispC] (String): As indicated in the earliest available disposition document, i.e. the one being used for coding, what disposition is given to the offender?

(7) Current Security level [SecC] (String): What level of security was the offender designated to in their current disposition, if detained? If on any form of discharge, enter 0

(8) Current Community living [CmPC] (Dummy Code, 1 or 0): Was the offender living in the community at the time of the current disposition being made? Any form of discharge should be coded as 1 
(9) Hospital recommendation [HR] (Dummy Code, 1 or 0): Did the current disposition (i.e. the one from the document being used for coding) agree with the recommendation being made by the hospital/clinical team? If yes, Code 1

(10) Months spent under the purview of the Review Board [YRB] (String): Based on the sum of collected documents pertaining to this offender and their index offence, enter the number of months spent under the purview of the Review Board (i.e. before being granted absolute discharge) within the follow up period, after the initial disposition for the sexual index offence. Count months from the date of being declared NCR, to the date of absolute discharge OR the end of followup (Dec 2015)

(11) Disposition at end of follow-up period [DispFU] (String): What was the disposition granted to the offender at their last hearing within the follow up period?

(12) Security level at end of follow-up period [SecFU] (String): What level of security was the offender designated to, if detained at the end of the follow up period? If on any form of discharge, enter 0

(13) Community living at initial hearing [CmPFU] (Dummy Code, 1 or 0): Was the offender living in the community at the end of the follow up period? Any form of discharge should be coded 1

(14) Sexual Recidivism [SexRec] (Dummy Code, 1 or 0): Code 1 if, from the sum of collected documents for this offender, there is evidence that the offender committed further sexual offences after the index offence. To be coded 1, this must be a formal charge and finding

(15) Violent Recidivism [VioRec] (Dummy Code, 1 or 0): Code 1 if, from the sum of collected documents for this offender, there is evidence that the offender committed further violent offences after the index offence. To be coded 1 , this must be a formal charge and finding

(16) Sexually inappropriate behaviour [Sexbx] (Dummy Code, 1 or 0): Code 1 if, from the sum of collected documents for this offender, there is evidence that the offender committed sexually inappropriate behaviour after the index offence, but this did not result in a formal charge/conviction/finding. For example, unwanted sexual behaviour directed towards a copatient or a staff member.

(17) Violent behaviour [Viobx] (Dummy Code, 1 or 0): Code 1 if, from the sum of collected documents for this offender, there is evidence that the offender engaged in violent behaviour after the index offence, but this did not result in a formal charge/conviction/finding. For example, aggressive and violent behaviour directed towards a co-patient or a staff member. Simply mentioning the offender has been aggressive, without further details is not sufficient to code 1 , as this is ambiguous (i.e. could refer to posturing, verbal behaviour, but not necessarily violence)

VII. Other Current NCR findings: If the offender had NCR findings other than Sexual Offending, then these need to be dummy coded. This does not include past offences.

(18) Arson Offence [ArsOff] (Dummy Code, 1 or 0): Any arson or firesetting offences

(19) Assault [Aslt] (Dummy Code, 1 or 0): Any assault offence

(20) Break and Enter [BandE] (Dummy Code, 1 or 0)

(21) Drugs [Drug] (Dummy Code, 1 or 0): Any offences related to drugs.

(22) Mischief [Mischief] (Dummy Code, 1 or 0 )

(23) Failure to Comply with a Probation Order/Recognizance [FailProb] (Dummy Code, 1 or 0$)$

(24) Fraud [Fraud] (Dummy Code, 1 or 0)

(25) Manslaughter [Mansla] (Dummy Code, 1 or 0)

(26) Murder [Murd] (Dummy Code, 1 or 0) 
(28) Weapons [Weap] (Dummy Code, 1 or 0): Any convictions related to weapons (other than assault with weapon [above]).

(29) Willful Damage [WilDam] (Dummy Code, 1 or 0)

(30) Other Non-Violent, Non-Sexual Convictions [NVNS] (Dummy Code, 1 or 0): Code 1 if the offender has another non-violent, nonsexual findings in the current index offence

(31) Other Violent, Non-Sexual Convictions [VioOff] (Dummy Code, 1 or 0): Code 1 if the offender has another violent, non-sexual conviction in the current index offence

Total Findings Count [TotalNCRCo] (Number, \#\#\#): This should be the sum of all counts in the current index offence findings (including all in this category and all sexual offence convictions

VIII. Crime Scene Variables: These variables are related to what happened during the sexual offence

(33) Alcohol Use - Any [CSV_Alcany] (Dummy Code, 1 or 0): Code 1, if there is any evidence that the individual used alcohol during the offence cycle. The offence cycle refers to the the processes of how the offence occurred.

(34) Contact [CSV_con] (Dummy Code, 1 or 0): Code 1 if this was a contact offence, code 0 if this was a non-contact offence.

(35) Death - Any [CSV_deat] (Dummy Code, 1 or 0): Code 1, if anyone died during the offence.

(36) Death - Accomplice [CSV_deatacc] (Dummy Code, 1 or 0): Code 1, if an accomplice or criminal associate died in the course of the offence

Death - Victims Accidental [CSV_deatvicac] (Dummy Code, 1 or 0): Code 1, if individuals, not including the offender, accidentally died during the offence. This can include first responders. Note if this is coded " 1 " then you must code Death - Any as " 1 ".

Death - Victims Intentional [CSV_deatvicin] (Dummy Code, 1 or 0): Code 1, if individuals, not including the offender, were intentionally killed during the offence. Note if this is coded " 1 " then you must code Death - Any as " 1 ".

Death Count [CSV_deatCo] (Number, \#\#): Count the number of people that died. Note if this is coded as greater than 0 then you must code Death - Any as " 1 ".

Environment of Offence [CSV_env] (Categorical, \#\#): Select the environment that best describes the location or environment of the offence

- $\underline{01}$ - In a residence - the offence took place in a private residence, perhaps that of the offender or victim. This code requires the location have been a relatively private space, physically. Include apartment building shared spaces (e.g. hallways) hotel rooms in this item, as they are a temporary residence, and a private space

- $\underline{\mathbf{0 2}}$ - At a party - The offence took place at a party, social gathering, or other location nearby such an event.

- $\underline{\mathbf{0 3}}$ - Public - outdoors - the offence took place in a public space, outdoors.

- $\underline{\mathbf{0 4}}$ - Public - indoors - the offence took place in a public space, indoors. This includes offices, jails, police departments, transportation stations/vehicles, etc.

(41) Injury - Any [CSV_inj] (Dummy Code, 1 or 0): Code 1, if anyone was physically injured during the offence. Do not include people who died in Injury items.

(42) Injury - Victims Accidental [CSV_ injvicac] (Dummy Code, 1 or 0): Code 1, if individuals, not including the offender, accidentally were injured during the offence. For example, a victim sustaining injuries from struggling in the course of the offence, without the offender explicitly attempting to cause those injuries. Note if this is coded " 1 " then you must code Injury - Any as “ 1 ”. 

individuals, not including the offender, were intentionally injured during the offence. For example, an offender purposefully beating a victim, causing mutilation, etc. Note if this is coded " 1 " then you must code Injury - Any as " 1 ".

(44) Injury - Level [CSV_injlev] (Categorical, \#): Select the best code for the level of injury reported by the victim, and other evidence.

- $\underline{01}-$ no injury

- $\underline{\mathbf{0 2}}$ - minimal injury - this would include defensive injuries, minor injuries such as bruises or scratches, and many of these injuries likely were not 'intentional' rather happening in the struggle of the offence

- $\quad \underline{\mathbf{0 3}}$ - moderate injury - this would include more serious injuries, perhaps consciously inflicted by the offender. These injuries would not be life threatening, but would cause considerable problems for the victim.

- $\underline{\mathbf{0 4}}$ - severe injury - the victim has been severely injured. They may have been beaten, have broken bones or fractures, or other serious injuries. These injuries were likely consciously inflicted, and resulting from considerable violence.

- $\underline{\mathbf{0 5}}$ - extreme injury - the victim has received extreme levels of injury. This may include mutilation, tissue damage, brain injury, prolonged or repeated violence, torture and other severe forms of violence.

(45) Multiple Victims [CSV_multivic] (Dummy Code, 1 or 0): Code 1 if this sexual offence had more than one victim.

(46) Multiple Perpetrators [CSV_multioff] (Dummy Code, 1 or 0): Code 1 if this offence had multiple perpetrators.

(47) Mutilation [CSV_mut] (Dummy Code, 1 or 0): Code 1 if there was evidence of victim mutilation.

(48) Series [CSV_ser] (Dummy Code, 1 or 0): Code 1 if this offence is part of a known series of offences. A series is defined as three or more similar offences, occurring as three distinct offences

(49) Sexual Acts - Anal Acts [CSV_anac] (Dummy Code 1 or 0): Code 1 if any sexual acts were conducted in the offence related to the anus.

(50) Sexual Acts - Anal Penetration [CSV_anpen] (Dumy Code, 1 or 0): Code 1 if there was any form of penetration to the victim's anus.

(51) Sexual Acts - Ejaculation [CSV_ej] (Dummy Code, 1 or 0): Code 1 if the offender was known to ejaculate during the offence

(52) Sexual Acts - Exposure [CSV_ex] (Dummy Code, 1 or 0): Code 1 if the offender exposed themselves

(53) Sexual Acts - Fondle/grabbing/slapping [CSV_fon] (Dummy Code, 1 or 0): Code 1 if the offence included fondling/grabbing/slapping the victim with sexual intent

(54) Sexual Acts - Hug [CSV_hug] (Dummy Code, 1 or 0): Code 1 if the offender hugged the victim

(55) Sexual Acts - Hump [CSV_hump] (Dummy Code, 1 or 0): Code 1 if the offender "humped," gyrated, or laid upon/against the victim (i.e. without intercourse)

(56) Sexual Acts - Kiss [CSV_kiss] (Dummy Code, 1 or 0): Code 1 if the offender kissed the victim in any way, or made considerable efforts to kiss the victim

(57) Sexual Acts - Objects \{CSV_ob] (Dummy Code, 1 or 0): Code 1 if any objects were actively used in commission of the offence

(58) Sexual Acts - Oral Acts [CSV_or] (Dummy Code, 1 or 0): Code 1 if there were oral sexual acts involved in the offence 
(59) Sexual Acts - Participation [CSV_par] (Dummy Code, 1 or 0): Code 1 if the offender attempted to get the victim involved in the commission of the offence. For example, performing sexual acts on the offender, participating verbally, etc.

(60) Sexual Acts - Masturbation [CSV_mas] (Dummy Code, 1 or 0): Code 1 if the offender masturbated as part of the offence

(61) Sexual Acts - Undress [CSV_und] (Dummy Code 1 or 0): Code 1 if the offender undressed the victim, or had the victim undress them/undressed themselves in commission of the offence.

(62) Sexual Acts - Urination or Defecation [CSV_ud] (Dummy Code, 1 or 0): Code 1 if the offence included urination or defecation.

(63) Sexual Acts - Vaginal Acts [CSV_vagac] (Dummy Code, 1 or 0): Code 1 if any sexual acts were conducted in relation to the victim's vagina.

(64) Sexual Acts - Vaginal Penetration [CSV_vagpen] (Dummy Code, 1 or 0): Code 1 if there was any form of penetration to the victim's vagina.

(65) Substance Use - Any [CSV_Subany] (Dummy Code, 1 or 0): Code 1, if there is any evidence that the individual used substances during the offence cycle. The offence cycle refers to the the processes of how the offence occurred.

(66) Victim Demo - Age [CSV_vicage] (String): Enter the victims numerical age

(67) Victim Demo - age group [CSV_vicageg]: Indicate if the victim was an adult, or a minor

- 01 - adult

- 02 - minor

(68) Victim Demo - Gender [CSV_vicgen] (Categorical, \#\#): Select the victims gender

- $\underline{01}$ - Male

- $\underline{02}$ - Female

- $\underline{\mathbf{0 3}}-$ Other

Victim - Count [CSV_vicCo] (Number, \#\#\#): Count the number of identifiable victims in all of the index sexual offences (total).

(70) Victim - Homeless [CSV_vichom] (Dummy Code, 1 or 0): Code 1 of the victim was homeless at the time of the offence.

(71) Victim Relationship- Acquaintances [CSV_vicacq] (Dummy Code, 1 or 0): Code 1, if the victims were acquaintances of the offender. This is a broad category, include individuals such as: friends, teachers, caregivers, and neighbours. Note if this is coded " 1 " then you must code Victim - Any as " $\underline{\text { ". }}$

(72) Victim Relationship - ExPartner [CSV_vicexp] (Dummy Code, 1 or 0): Code 1, if the victim used to be in a romantic relationship (of any kind) with the offender. Note if this is coded " 1 " then you must code Victim - Any as " 1 ".

(73) Victim Relationship - Family [CSV_vicfam] (Dummy Code, 1 or 0): Code 1, if the victim of this offence was related to the offender. If the only victim was a partner or spouse, code this 0 . Note if this is coded " 1 " then you must code Victim - Any as " 1 ".

(74) Victim Relationship - Friend [CSV_vicfri] (Dummy Code, 1 or 0): Code 1, if the victim of this offence was a friend to the offender. This item requires the victim and offender have a closer relationship than being acquaintances. Note if this is coded " 1 " then you must code Victim - Any as " 1 ".

(75) Victim Relationship - Partner [CSV_vicpar] (Dummy Code, 1 or 0): Code 1, if the victim was a current partner of the offender. Note if this is coded " 1 " then you must code Victim - Any as " 1 ".

(76) Victim Relationship - Professional/Colleague [CSV_vicprof] (Dummy Code, 1 or 0): Code 1 , if the victim was someone with whom the offender worked with at a job. Note if this is coded " 1 " then you must code Victim - Any as " 1 ". 
Victim Relationship - Stranger [CSV_vicstr] (Dummy Code, 1 or 0): Code 1, if the victim and the offender have never met 24 hours prior to the offence. They may have met within the 24 prior to the offence, but they would still be considered strangers. Examples: someone met at a bar within 24 hours of the offence. Note if this is coded " 1 " then you must code Victim - Any as “ 1 ”.

(78) Victim Relationship - Stalking [CSV_vicstlk] (Dummy Code, 1 or 0): Code 1, if the victim of the offence was also someone who the offender stalked. The offender may or may not have made direct contact with the victim. The victim may also be an ex-partner or maybe a stranger. The key concept for this item is that there is evidence of virtually any unwanted contact between two people that directly or indirectly communicates a threat or places the victim in fear. In rare situations, victims may not be aware that they are being stalked. Note if this is coded " 1 " then you must code Victim - Any as " 1 ".

(79) Victim Substances - Drugged [CSV_vicdr] (Dummy Code, 1 or 0): Code 1 if, as part of the offence, the offender drugged the victim, using alcohol, drugs, or other substances.

(80) Weapon [CSV_weap] (Dummy Code, 1 or 0): Code 1 if some type of weapon was used in the commission of the offence

(81) Witness [CSV_wit] (Dummy Code, 1 or 0): Code 1, if there was a witness to the committing of the offence who provided evidence to the police. Do not include individuals here who did not witness the offence taking place, i.e. character witness.

\section{Risk Assessment \& Risk Factors Supported by Validated Risk Tools}

(82) Static 99-R Use [S99R] (Dummy, 1 or 0): If the case includes a risk assessment using the Static 99-R, please code 1

(83) Static 99-R Raw Score [S99RS] (String): If a Static 99-R was implemented by a mental health professional, and a raw score was given, please enter it here. NOTE: This score should range from 0 to 12

(84) Static 99-R Risk Level [S99RR] (Categorical, \#\#): If a Static 99-R was implemented by a mental health professional, and a risk level was reported, please select the risk level given:

- 01 - Low Risk

- $\mathbf{0 2}$ - Moderate-Low Risk

- $\mathbf{0 3}$ - Moderate-High Risk

- 04 - High Risk

(85) Static 99-R Supported Risk Factor - Age [S99RRF1] (Categorical, \#\#): Score this item based on the offender's age at the time of release/potential release. FOR THE PURPOSE OF THIS STUDY: This is considered to be the time of the hearing, as the offender may be released thereafter

- $\mathbf{0 0}-60$ years +

- $\mathbf{0 1}-40$ to 59.9 years

- $\mathbf{0 2}-35$ to 39.9 years

- $\mathbf{0 3}-18$ to 34.9 years

(86) Static 99-R Supported Risk Factor - Never Lived with Intimate Partner [S99RRF2] (Dummy Code, 1 or 0): Code 0 if the offender has had an intimate relationship with a partner, including cohabitation for at least two years. If the offender has NEVER had an intimate relationship of two or more years, code this as 1. An intimate relationship refers to a relatively stable "marriage-like" relationship, including living with their partner a key facet of this item. An offender is still given a code of one under the following circumstances - years spent living with a the offender sexually abused if the living arrangement began after sexual abuse, years 
spent living with a child victim, marriage if cohabitation has been less than 2 years, incestuous relationships, has chosen to live a lifestyle without cohabitation (eg. Priesthood).

(87) Static 99-R Supported Risk Factor - Index Non-Sexual Violence Convictions [S99RRF3] (Dummy Code, 1 or 0): Code 0 if, at the time of the index offence (in this case, the NCR sexual offence) the offender had no simultaneous convictions for a non-sexual violent offence. Code 1 if the offender did have a simultaneous conviction for a non-sexual violent offence. To score 1 , the conviction must happen at the same sentencing occasion. Offences eligible for inclusion are:

- Aggravated Assault

- Arson

- Assault/Battery (EXCEPT where there is a sexual component)

- Assault causing bodily harm

- Assault Peace/Police Officer

- Attempted Abduction

- Attempted Robbery

- False Imprisonment

- Felonious Assault

- Forcible Confinement

- Give Noxious Substance ( to impair victim)

- Grand Theft Person (variation on Robbery and may be counted as Non-sexual violence)

- Juvenile Non-sexual Violence convictions count on this item

- Kidnapping

- Murder

- "PINS" Petition (Person in need of supervision - juvenile has been removed from home by judicial action due to violent actions. This would count as a conviction for Non-sexual violence.

- Robbery

- Threatening

- Using/pointing a weapon in the commission of an offence (NOT merely possession)

- Violation of a Domestic Violence Order (Restraining Order) (a conviction for)

- Wounding

(88) Static 99-R Supported Risk Factor - Prior Non-Sexual Violence, Any Convictions [99RRF4] (Dummy Code, 1 or 0): Code 0 if, the offender has no separate convictions for a non-sexual violent offence that predate the index offence. Code 1 if the offender did have a separate conviction for a non-sexual violent offence prior to the index offence. To score 1 , the conviction must happen at a different sentencing occasion. Offences eligible for inclusion are the same as listed above, in [99RRF3].

(89) Static 99-R Supported Risk Factor - Prior Sex Offences [99RRF5] (Dummy Code, 1 or 0 0): NOTE: This item has been changed from the coding rules of the Static 99R coding manual for the purposes of this study (since we are considering the presence of risk factors, and any prior factor would affect risk, this is justifiable, but will be qualified in results) This CANNOT be used to calculate an official Static 99-R score. FOR THIS DATABASE: If the offender has any prior sexual offences, including both charges and convictions, and violations of probation, parole, or conditional release with sexual misbehaviour code 1 . If the offender does not have any prior sexual offences, code 0 .

(90) Static 99-R Supported Risk Factor - Prior Sentencing Dates [99RRF6] (Dummy Code, 1 or 0): Code 1 if the offender's criminal record indicates four or more separate sentencing dates prior to the index offence. You should count the distinct occasions the offender was sentenced, regardless of how many charges or convictions there were. Do not count the index offence 
sentencing, do not count trials where the offender is found not guilty, do not count technical violation (i.e. breaching a condition of parole), do not count acquittals or overturned/appealed convictions. Do not include trivial offences (i.e. That could not result in incarceration or community supervision, such as most driving offences)

(91) Static 99-R Supported Risk Factor - Any Convictions for Non-Contact Sex Offences [99RRF7] (Dummy Code, 1 or 0): Code 1 if the offender's criminal record indicates a separate conviction for a non-contact sexual offence. Cod 0 if the offender's criminal record does not show a separate conviction for a non-contact sexual offence. This category requires a conviction for a non-contact sexual offence such as:

- Exhibitionism

- Possessing obscene material

- Obscene telephone calls

- Voyeurism

- Exposure

- Elicit sexual use of the Internet

- Sexual Harassment (Unwanted sexual talk)

- In certain jurisdictions "Criminal Trespass" or "Trespass by Night" may be used as a charge

The criteria for non-contact sexual offences are strict: the offender must have been convicted, and the offence must indicate non-contact sexual misbehaviour. The "Index" offence(s) may include a conviction for a non-contact sexual offence and this offence can count in this category. If there is a charge for some other offence (e.g. Disorderly conduct for a charge of exposure [plea down]), this can be coded based on the behaviour included in the charge. DO NOT code 1 for charges and rrest, or self-report.

(92) Static 99-R Supported Risk Factor - Unrelated Victims [99RRF8] (Dummy Code, 1 or 0): For all offences committed against children, or non-consenting adults (NOT offences such as prostitution/pandering, possession of child pornography, and public sex with consenting adults), base this code off of all available credible info, including self-report, victim accounts, and collateral accounts. ONLY CODE INTENTIONED VICTIMS, not others who may be accidental victims, unwittingly coming across the offence. Code 1 if the offender has victims outside of their immediate family. Code 0 if all victims are within the immediate family. Related refers to relationships sufficiently close marriage would be prohibited (parents, siblings, cousins, uncles/aunts, nieces/nephews, grandparent, stepsiblings), spouses, and step-relationship of 2 or more years.

(93) Static 99-R Supported Risk Factor - Stranger Victims [99RRF9] (Dummy Code, 1 or 0): For all offences committed against children, or non-consenting adults (NOT offences such as prostitution/pandering, possession of child pornography, and public sex with consenting adults), base this code off of all available credible info, including self-report, victim accounts, and collateral accounts. ONLY CODE INTENTIONED VICTIMS, not others who may be accidental victims, unwittingly coming across the offence. Code 1 if the offender has victims who were strangers at the time of offence. Code 0 if all victims were known to the offender for at least 24 hours before the offence. The criteria for being a stranger are very high. Even a slight 
degree of knowing is enough for a victim not to be a stranger. If the victim knows the offender at all for more than 24 hours, the victim is not a stranger. For example, if the victim was a convenience store clerk and they recognized the perpetrator as someone who had been in on several occasions to buy cigarettes, the victim would no longer be a stranger victim. If a child victim can say they recognize the offender from around the neighborhood and the perpetrator has said "Hi" to them on occasion, the child is no longer a stranger victim. The evaluator must determine whether the victim "knew" the offender twenty-four hours (24) before the assault took place. The criteria for "know/knew" is quite low but does involve some level of interaction. They need not know each other's names or addresses. However, simply knowing of someone but never having interacted with them would not be enough for the victim to count as "known". Sometimes offenders attempt to access or lure victims over the Internet. This is a special case and the threshold for not being a stranger victim is quite low. If the offender and the victim have communicated over the Internet (e-mail, or telephone) for more than twenty-four hours (24 hours) before the initial face to-face meeting, the victim (child or adult) is not a stranger victim. In cases of "stalking" or stalking-like behaviours the offender may know a great deal about the victim and their habits. However, if the victim does not know the offender when they attack this still qualifies as a stranger victim

(94) Static 99-R Supported Risk Factor - Male Victims [99RRF10] (Dummy Code, 1 or 0): For all offences committed against children, or non-consenting adults (NOT offences such as prostitution/pandering, possession of child pornography, and public sex with consenting adults), base this code off of all available credible info, including self-report, victim accounts, and collateral accounts. ONLY CODE INTENTIONED VICTIMS, not others who may be accidental victims, unwittingly coming across the offence. Code 1 if the offender has had any male sexual assault victims. Code 0 if all of the offender's sexual assault victims have been female. In the event of the offender attacking someone who presented as female, but who is actually male, accidentally, this does not count as a male victim. If the offender attacked the female presenting person, knowing they were male before the assault, code 1 for male victim.

(95) HCR-20 (V3) Use [HCR] (Dummy, 1 or 0): If the case includes a risk assessment using the HCR-20 (v3), please code 1

(96) HCR-20 (V3) Risk Level [HCRR] (Categorical, \#\#): If an HCR-20 was implemented by a mental health professional, and a risk level was reported, please select the risk level given:

- 01 - Low Risk

- 02 - Moderate-Low Risk

- $\mathbf{0 3}$ - Moderate Risk

- 04 - Moderate-High Risk

- 05 - High Risk

(97) HCR-20 (V3) Supported Risk Factor - History of problems with violence [HCRH1] (Dummy, 1 or 0): If the offender has a history of problems stemming from violent, including actual, attempted, or threatened physical harm that violates social norms, that result in severe (potential) physical or psychological harm to victims, or imposition of severe legal or other consequences on one or two occasions OR if there is a clear pattern of violence resulting in at least moderate harm to victim or at least moderate or other consequences, code 1 . Three or more distinct occasions of violence are needed to establish a pattern. Arson/firesetting, kidnapping/confinement, and sexual violence that involves actual threatened or attempted bodily harm to another person meet the definition of violence.

(98) HCR-20 (V3) Supported Risk Factor - History of problems with other antisocial behaviour [HCRH2] (Dummy, 1 or 0): If the offender has a history of problems stemming from the perpetration of antisocial behaviour other than violence, including actual, attempted, or planned violation of rights or safety/well-being of others, or social norms, resulting in severe (potential) personal or social harm, or severe legal or other consequences on one or two 
occasions OR if there is a clear pattern of antisocial behaviour resulting in at least moderate harm to victim or at least moderate or other consequences, code 1 . Three or more distinct occasions of antisocial behaviour are needed to establish a pattern. Antisocial behaviour includes acts, attempts, or plans motivated by financial or material gain or sexual gratification, activity related to substances, or groups/gangs

(99) HCR-20 (V3) Supported Risk Factor - History of problems with relationships [HCRH3] (Dummy, 1 or 0): If the offender has a history of serious problems establishing or maintaining stable personal relationships that results in a lack of positive social or emotional support, code 1 . Problems may be due to a lack of desire, ability or opportunity, and can relate to intimate and non-intimate relationships. Problems can include singlehood, selection of age- inappropriate partners, multiple relationship breakdowns, serious relationship conflicts, social isolation, conflictual relationships, alienation from friends or family, or relationships with negative influences, or inappropriate sexualization of non-intimate relationships. A lack of relationships is noteworthy, even if the person is institutionalized.

(100) HCR-20 (V3) Supported Risk Factor - History of problems with employment [HCRH4] (Dummy, 1 or 0): If the offender has a history of serious problems seeking, maintaining, or abiding by the rules of legal employment, post-secondary education, or educational or training problems, code 1. Problems can include long or frequent periods of unemployment, financial difficulties, inability to provide for basic needs, refusal to seek legitimate employment, frequent job changes, numerous firings/quittings, poor work performance, or serious conflict with coworkers or bosses. Problems with employment are relevant, even if the individual has been institutionalized or been on disability pension, and institutional employment can reduce estimation of risk.

(101) HCR-20 (V3) Supported Risk Factor - History of problems with substance use [HCRH5] (Dummy, 1 or 0): If the offender has a history of serious problems with the use of, abuse of, or dependence on mind or mood altering substances, including alcohol, illicit drugs, licit drugs, or incidental substances that cause impairment in psychosocial functioning or mental or physical health, code 1. Casual or infrequent use of alcohol or "minor drugs" such as marijuana should not be coded as 1 unless there is evidence of functional impairment (e.g. charges or convictions, repeated criminal activity without charge (greater than possession). Interference includes mental and physical functioning, employment, recreation, and interpersonal relationships.

(102) HCR-20 (V3) Supported Risk Factor - History of problems with major mental disorder [HCRH6] (Dummy, 1 or 0): If the offender has a history of major mental disorders characterized by disturbances in cognition or affect, that are serious, persistent, and interfere with a person's functioning in important life domains, code 1. In particular, the presence of three major types of mental disorder should be considered - psychotic disorders, major mood disorders, and other major mental disorders. To code 1, the disorder should affect the ability to perform everyday tasks, interfered with major life domains, is chronic, has led to multiple psychiatric hospitalizations, has not responded well to intervention, presence of disorientation or confusion, and interference with ability to care for self. NOTE: Personality disorder should not be coded here.

(103) HCR-20 (V3) Supported Risk Factor - History of problems with personality disorder [HCRH7] (Dummy, 1 or 0): If the offender has a history of serious problems resulting from fixed and maladaptive personality traits related to interpersonal style, behaviour controls, emotionality, cognitive style and sense of self, including disturbance of social relationships or failure to fulfill roles and obligations, code 1 . The problems must be chronic and pervasive, and indicative of usual functioning, not situational. Diagnosis of personality problems should conform with an accepted nosological system, and accepted form of assessment. The problems should interfere with employment or education, place self or others at risk of negative experiences events or outcomes, and interfere with rehabilitative efforts. 
(104) HCR-20 (V3) Supported Risk Factor - History of problems with traumatic experiences [HCRH8] (Dummy, 1 or 0): If the offender has a history of experiencing harmful or traumatic events, at an time during the lifespan, that may disrupt normative development, attachment processes, or learning of prosocial attitudes and problem solving skills, including victimization/trauma (physical, psychological, or sexual abuse or victimized in other fear- or safety-inducing ways, as well as witnessing severe violence, being bullied, stalked, or experiencing accidental injury) and adverse childrearing experiences (including violence, coercive or neglectful parental behaviour, parental antisocial behaviour, instability in home environment, or factors affecting developmental deficits), code 1.

(105) HCR-20 (V3) Supported Risk Factor - History of problems with violent attitudes [HCRH9] (Dummy, 1 or 0): If the offender has a history of entrenched violent attitudes, beliefs, values, or thoughts, including belief violent behaviour is justified in achieving personal or material goals, or that support the use of violence, code 1 . This can be inferred from patterns of consistent behaviours or tendencies, and includes minimization and denial of violence, associations with violent peers, enjoying the suffering of others, pro-criminal attitudes, criminal self-concept, dismissive or negative attitudes about law enforcement/criminal justice/judicial systems/officials.

(106) HCR-20 (V3) Supported Risk Factor - History of problems with treatment or supervision response [HCRH10] (Dummy, 1 or 0): If the offender has a history of serious problems complying with or responding to forensic, mental health, or correctional treatment, rehabilitation, or supervision plans designed to improve the person's psychosocial adjustment or mental health and/or reduce the chances of violence, code 1 . This can include things like poor motivation, unwillingness or refusal to attend, take medication or conform to supervision, and poor treatment or medication response. Consider a supervision failure serious if it resulted in the individual being re-apprehended or re-institutionalized. NOTE: if the offender has never had a period of institutional or community supervision, code 0 .

(107) HCR-20 (V3) Supported Risk Factor - Recent problems with insight [HCRC1] (Dummy, 1 or 0): If the offender has recent problems with lack of awareness, understanding or appreciation of one's violence-related functioning or the factors and processes that place the person at risk for violence, including insight into mental disorder, aggressiveness, and need for treatment, code 1. This includes denial or minimization. NOTE: refusal to accept medication or treatment, unless due to belief they do not have a disorder, risk for violence, or lack of severe disorder.

(108) HCR-20 (V3) Supported Risk Factor - Recent problems with violent ideation or intent [HCRC2] (Dummy, 1 or 0): If the offender has recent problems with violent ideation or intent (thoughts, plans, desires, fantasies, or urges to cause harm to others), code 1 . The intent or ideation should be serious (i.e. persistent and intrusive, associated with moderate/high intent, serious physical harm, about high lethal methods, or with an identifiable target), and should not occur only in the context of psychosis.

(109) HCR-20 (V3) Supported Risk Factor - Recent problems with symptoms of major mental disorder [HCRC3] (Dummy, 1 or 0): If the offender has recent problems with active symptoms of major mental disorder (as defined in H6), code 1. Recent includes current symptoms.

(110) HCR-20 (V3) Supported Risk Factor - Recent problems with instability [HCRC4] (Dummy, 1 or 0): If the offender has recent problems with maintaining stable adjustment with respect to affective (emotional disturbance/turbulence or labile mood), behavioural (e.g. Impulsive, irresponsible, reckless, disruptive, aggressive, or self-destructive behaviour that exposes self or others to risk), or cognitive functioning (serious disturbances of thought content/processes), code 1. NOTE: instability should be considered regardless of the apparent cause.

(111) HCR-20 (V3) Supported Risk Factor - Recent problems with treatment or supervision response [HCRC5] (Dummy, 1 or 0): If the offender has recent problems with accessing, 
attending, complying with intervention or management strategies to reduce risk for recidivism or violence/risk factors, code 1 . This includes issues with compliance and responsiveness, and should be coded regardless of the apparent cause.

(112) HCR-20 (V3) Supported Risk Factor - Future problems with professional services and plans [HCRR1] (Dummy, 1 or 0): If the offender is likely to have future problems with development of general plans that make use of appropriate use of professional service or plans, code 1. Plans are inadequate if they have not been communicate to others, are unclear or lacking in detail, fail to incorporate the findings or recommendations of previous evaluations, do not target critical risk factors, do not make use of appropriate professional service, or rely on inappropriate professional services. Relevant plans are those designed to ensure the offender has a positive, stable adjustment to institutional or community life that minimizes any violence risk posed.

(113) HCR-20 (V3) Supported Risk Factor - Future problems with living situation [HCRR2] (Dummy, 1 or 0): If the offender is likely to have future problems with their living situation in an institution or community, including domains of housing, employment, affiliations, neighbourhood, and exposure to risk-enhancing factors such as weapons or substances, and could destabilize risk-relevant functioning or expose them to risk enhancing factors, code 1. This should be evaluated on a case by case basis, based on the fit of the offender and their situation.

(114) HCR-20 (V3) Supported Risk Factor - Future problems with personal support [HCRR3] (Dummy, 1 or 0): If the offender is likely to have future problems with personal support (dayto-day interpersonal contact with social network expected to manage violence risk by facilitating their psychological and social adjustment), code 1. Plans may be inadequate if they have not been communicate to others, are unclear or lacking in detail, do not include an appropriate social network, rely on an inappropriate social network, or do no persons to provide personal support are available to the offender. This may be due to lack of ability or motivation, or social network in institution or community. Social networks include family, friends, neighbours, acquaintances, and co-workers.

(115) HCR-20 (V3) Supported Risk Factor - Future problems with treatment or supervision support [HCRR4] (Dummy, 1 or 0): If the offender is likely to have future problems with accessing, attending, being compliant with, or benefitting from interventions or management strategies to reduce risk for recidivism or violence or associated risk factors, code 1 . This is a judgement of likely compliance and responsiveness in the future.

(116) HCR-20 (V3) Supported Risk Factor - Future problems with stress or coping [HCRR5] (Dummy, 1 or 0): If the offender is likely to have future problems with coping eith stressful living circumstances and life event, code 1 . This includes major life stresses, or inadequate coping skills to deal with daily hassles and problems in living.

(117) STABLE-2007 Use [STBL] (Dummy, 1 or 0): If the case includes a risk assessment using the STABLE-2007, please code 1

(118) STABLE-2007 Risk Level [STBLR] (Categorical, \#\#): If the STABLE-2007 was implemented by a mental health professional, and a risk level was reported, please select the risk level given:

- 01 - Low risk

- 02 - Moderate risk

- 03 - High Risk

(119) STABLE-2007 Supported Dynamic Risk Factor - Significant Social Influences [STBL1] (Categorical, \#\#): This item taps into whether the offenders social influences will affect the offender's likelihood to reoffend. If the offender reports they will spend their time with people who promote (directly, or indirectly) antisocial attitudes, poor behavioural controls, and dysfunctional coping (therefore making the offender more likely to make poor decisions, be in risky situations, and reoffend), code 02 . If the offender reports they will 
spend their time with people who promote prosocial values, discourage criminal or risky behaviours, prevent victim access, and speak positively about the usefulness of treatment (making the offender less likely to reoffend), code 00. Social influences should have meaningful contact with the offender, and should not include persons paid to be in the presence of the offender (unless the professional goes above and beyond the call of duty to maintain a relationship with the offender). Ultimately this item asks - do they offender's social influence make them have a better, or worse chance of remaining offence free. Neutral influences, those with a mixture of positive and negative features, can be coded as primarily positive, negative, or as neutral (code 01). NOTE the following special considerations: children (not a social influence in childhood, evaluate adult children case to case), parents (consider past relationship, present relationship, and attitudes), spouses (nature of relationship, influence over offender, likelihood of facilitating victim access), employers (high threshold - must go beyond context of work, and relationship would continue if employment ended), professionals (beyond the call of duty), circle of support accountability (length of involvement and quality of relationships).

- $\mathbf{0 0}$ - not present, no concern

- $\mathbf{0 1}$ - factor is somewhat present, but not sufficient to justify a score of 2 , or there is uncertainty about its presence

- $\mathbf{0 2}$ - definitely present, definite concern (worthy of consideration in treatment, supervision and management)

(120) STABLE-2007 Supported Dynamic Risk Factor - Capacity for Relationship Stability [STBL2] (Categorical, \#\#): This item taps into the offender's ability to be involved in secure, intimate, adult relationships in two parts. First, having ever lives with an adult intimate partner (i.e. with consensual, sexual contact) for at least two years. Second, the quality of the offender's relationship. With respect to ever living with a partner, the following relationships do not apply: prison marriages/lovers, illegal relationships, victim relationships (unless established for over two years before onset of abuse), and underage relationships. Persons living a celibate lifestyle are not exempt, and would be considered as not having lived with a partner. If the offender is away from home on extended absences (e.g. work assignment) consider the nature and overall commitment of the relationship. With respect to the quality of the current relationship, if the offender is not in a relationship, consider this no relationship. Poor/not yet established relationships are those where the relationship is problematic or troublesome (infidelity, affairs, lack of intimacy, abuse, inequity, poor communication, frequent arguments or separations), is not expected to last, or in a relationship that is newly established. Acceptable relationships are those that are stable and committed, with no signs of obvious problems that would threaten the relationship (monogamous, intimate, equitable, free from abuse, without recent separations). Considering both of the parts, determine if, overall, the ability to have a stable relationship should be coded as 2 (Parts A and B both a concern), 1 (meets part A or B, but not both), or 0 (both parts acceptable).

- $\mathbf{0 0}$ - not present, no concern

- $\mathbf{0 1}$ - factor is somewhat present, but not sufficient to justify a score of 2 , or there is uncertainty about its presence

- $\mathbf{0 2}$ - definitely present, definite concern (worthy of consideration in treatment, supervision and management)

(121) STABLE-2007 Supported Dynamic Risk Factor - Emotional Identification with Children [STBL3] (Categorical, \#\#): ONLY SCORE THIS ITEM IF OFFENDER HAS A VICTIM UNDER 13. If they do not, code 03 (N/A). This item taps into if the offender has a feeling of being emotionally connected to children, and identifies with children (i.e. children less than 14 years old). If this item is present, the offender may find children to be less judgmental, more understanding, easier to relate to, or may have childlike interests and leisure activities, and may 
see children as "friends, and enjoy their company more than adults. The offender may also see child sexual abuse as equal/reciprocal, due to "love" between them, or attribute adult qualities, such as maturity, to the child victim. The offender's thoughts, feelings, and level of adult development, and time involved in children's activities, should be considered. Consider the number of behaviours, the broader context of behaviours, and if the offender has meaningful and appropriate friendships with adults. If an offender has indicators in many areas of their life, perceives important relationships with children, and attributes adult qualities to children, code 02. If an offender has fewer of these features, or only gives off a "child-friendly" persona to groom potential victims, code 1 . If an offender only has a single attribute (e.g. collects a specific toy type), code 0 .

- $\quad \mathbf{0 0}$ - not present, no concern (quality adult friendships, spends work and leisure time involved in age-relevant and appropriate activities)

- $\quad 01$ - factor is somewhat present, but not sufficient to justify a score of 2 , or there is uncertainty about its presence (minor, yet noticeable, interest or investment in children, and adult relationships seem immature. Offender attributes adult-like qualities to children, or perceives them as having a special ability to understand or communicate that he does not see in adults. Appears overly invested in activities of their children beyond a normal parental role).

- $\mathbf{0 2}$ - definitely present, definite concern (worthy of consideration in treatment, supervision and management) (prefers the company and activities of children to adults. The offender appears childlike himself and engages in child-oriented leisure and possibly work-related activities. Offender considers children to be his friends and may perceive them to have adult or adult-like qualities.)

- $\mathbf{0 3}-\mathrm{N} / \mathrm{A}$ - all victims are 14 or older.

(122) STABLE-2007 Supported Dynamic Risk Factor - Hostility towards women [STBL4] (Categorical, \#\#): This item taps into negative and/or hostile beliefs about women, which can impair ability to form warm, close, and egalitarian relationships with women. This can be expressed by sexist attitudes, stereotypical beliefs about women and their roles, and hatred based on cognitions, including perceptions of past wrongs and beliefs women are uniquely advantaged. Relationships with women are adversarial and/or conflicted/power imbalanced/exclusively sexual. Offender may feel women are suspicious, and their intentions malevolent, are inferior, not worthy of trust and respect, and their opinion disregarded. Women may be seen as a lower class of person, or as sexual objects, exclusively. This hostility will generally be pervasive in many life domains (e.g. work, leisure, socially). This item should tap into attitudes, no simply past behaviour. Violent history should consider the breadth of context for violence towards women, and if violence is perpetrated to women only, or males and females.

- $\quad 00$ - not present, no concern (does not appear to hold negative or hostile attitudes toward women and identifies positive, including non-sexual, relationships with women in his life. Alternatively, the offender currently has no significant relationships with women but does not appear to hold negative or hostile attitudes toward women and does not appear to have conflicts with women. There may be a negative relationship with one woman in the offender's life, but other relationships with women generally outweigh this one negative.)

- 01 - factor is somewhat present, but not sufficient to justify a score of 2, or there is uncertainty about its presence (some sexist or stereotypically traditional attitudes towards women and their roles. Interactions with women are not adversarial or conflicted but tend to be uneasy or to involve significant power imbalances. There may be documented domestic abuse within the context of one relationship. The offender appears to have primarily sexual relationships with women that lack interactions reflective of a warm, 
caring and egalitarian relationship. A typical offender who scores "1" would display more than one of the above indicators. It is also possible to score " 1 " for a single, blatant indictor (e.g., domestic abuse))

- $\mathbf{0 2}$ - definitely present, definite concern (worthy of consideration in treatment, supervision and management) (expresses negative, hostile and/or sexist attitudes toward women and their roles. There is evidence of conflict (which may or may not include overt violence) with a variety of women across several life domains, or there is little or no overt conflict but negative attitudes are pervasive, demonstrated in behaviour, and offence-related.

(123) STABLE-2007 Supported Dynamic Risk Factor - General social rejection/loneliness [STBL5] (Categorical, \#\#): This item examines how close the offender feels to others, and their general capacity to make friends and secure adult attachments. Loneliness may include, feeling socially rejected, that others do not care, feeling alone, or feeling alone due to shallow/impersonal relationships). This is primarily offender-perspective based. If the offender has few relationships but is content with this, code 1 . Also consider ability to make and maintain relationships before disclosure of offence, and skills/ability.

- $\mathbf{0 0}$ - not present, no concern (generally well integrated socially considering his current circumstances and the process of upheaval inherent in having been identified as a sexual offender.)

- $\quad 01$ - factor is somewhat present, but not sufficient to justify a score of 2, or there is uncertainty about its presence (has some weak connections to others. He may have some short term casual relationships, but no long term friends. He may maintain contact with family members but does not appear to have close relationships with them. OR The offender has no close relationships with others but reports he prefers this situation and does not feel lonely or rejected (i.e., the loner).)

- $\mathbf{0 2}$ - definitely present, definite concern (worthy of consideration in treatment, supervision and management) (reports frequently feeling lonely and rejected. He cannot identify social supports and has little or no contact with family members. He may present as socially inept with poor skills for attracting and maintaining personal relationships.)

(124) STABLE-2007 Supported Dynamic Risk Factor - Lack of Concern for Others [STBL6] (Categorical, \#\#): This item taps into a lack of concern that is widely evident in lifestyle and behaviour. Their interactions are selfish, ruthless and indifferent to the rights and wellbeing of others. They are characteristically egocentric and their relationships with others are utilitarian, rather than reciprocal or affectively warm and caring. They are willing to be cruel to meet their own needs and are unconcerned about the impact of their behaviour on others or about hurting others. They are often focused on their own concerns to the point that they are totally unaware of the damage they do to others. This lack of concern for others is pervasive and will be present in virtually all of their relationships or interactions. They will generally be known for taking opportunistic advantage of others. This lack of concern applies to both in-group and out-grup members, and may be described as indifferent, unfeeling, or callous by family/friends. This may include lack of concern/callousness for victim, but this is not sufficient to identify this item. The offender may report noo interest in feelings opinions of tohers, or feign shallow displays of emotion. They may be described as lacking empathy or sympathy towards others, and may present as cynical in outlook and disengaged from others. They may express general attitudes that you can't trust other people, so it's best to just look out for yourself. They may have a long and varied criminal history demonstrating a lack of concern or regard for the rights and well being of others and their personal property. This lack of concern may also be evident in reports from their family and friends indicating that they only contact them when they "want something", or that they are routinely disrespectful, selfish, and deceitful. 
- $\quad 00$ - not present, no concern (may be perceived as callous or indifferent towards another in limited and specific circumstances, but is generally sensitive to the views and needs of others. Most offenders scoring " 0 " would have an identifiable in-group with whom he is perceived as emotionally responsive, reciprocal in relationships, and caring. Offenders without a current in-group may also score " 0 " if they desire positive relationships with others, but are blocked by external circumstances or their own psychological limitations)

- $\mathbf{0 1}$ - factor is somewhat present, but not sufficient to justify a score of 2 , or there is uncertainty about its presence (perceived as substantially callous in one context, but shows warmth and concern in other relationships, such as towards family and long term friends. Alternatively, the offender is perceived as having a generalized lack of concern towards several others beyond solely their adversaries, but not towards their immediate family or close friends.)

- $\mathbf{0 2}$ - definitely present, definite concern (worthy of consideration in treatment, supervision and management) (perceived as selfish, ruthless, and uncaring towards others. He does not have any close or caring relationships and those who would be expected to be close to him (i.e., immediate family, friends) have indicated that he is selfish, cruel, or indifferent towards them. He is indifferent about the effects of his behaviour has on others and is characterized as a "user")

(125) STABLE-2007 Supported Dynamic Risk Factor - Impulsive Acts [STBL7] (Categorical, \#\#): This item is concerned with identifying those offenders who exhibit impulsive behaviour across a number of settings; not simply represented by the individual's history of sexual offending, but generally a "character trait" and typically evident from a relatively early age. These individuals generally have unstable lifestyles and their low self-control leads them to engage in risky behaviours with insufficient concern for the consequences. They are often easily swayed or tempted by opportunistic situations and will engage in behaviour that has a high likelihood of negative consequences with little forethought. They are easily bored and may be led into risky behaviours by others in an attempt to feel accepted or to integrate themselves into a group. Consider impulsive behaviour in a variety of settings. To score a 2 , the offenders must demonstrate impulsive behaviour in two or more life domains. Domains include financial (overspending, debt, impulsive buying, sped recklessly for advantage of others), vocational (history of quitting, unsafe work practice, frequent boredom related job change, quitting due to not liking someone), leisure (substances, partying thrill seeking, risky activities, accepting bets/dares), accommodation (transient, move without notice/telling others, crashing with friends), personal relationships/interactions (fighting/starting fights with bigger people, breaking plans, not honoring obligations because something came up, easily bored, changing social groups, lack of long term friendships), and other (reckless/dangerous driving, shoplifting/stealing, lengthy criminal history).

- $\mathbf{0 0}$ - not present, no concern (No problems, or impulsive behaviour is limited to sexual misbehaviour. The offender lives a relatively stable lifestyle and does not appear to be impulsive.)

- 01 - factor is somewhat present, but not sufficient to justify a score of 2 , or there is uncertainty about its presence (engages in occasional impulsive behaviour in one or more settings, but also has some areas of his life that are stable or has had periods of stability during his life. Impulsive behaviour may center around a hobby or an interest, such as the impulsive buying of articles for a hobby or interest that would seem non-affordable given the offender's present circumstances but other than that one area the offender's life seems well regulated. OR repeated high risk behaviour in only one context or life domain

- 02 - definitely present, definite concern (worthy of consideration in treatment, supervision and management) (Frequent impulsive behaviour in "more than one" life domain or setting (beyond their sexual offending). 
(126) STABLE-2007 Supported Dynamic Risk Factor - Poor Cognitive problem Solving [STBL8] (Categorical, \#\#): This item taps into ability to identify and solve everyday problems. They may have difficulty identifying future obstacles or problems that they could encounter. When presented with a problem, individuals with this deficit may dismiss the issue for themselves, voice the expectation that others need to change instead of themselves propose unrealistic solutions, or have difficulty generating any alternatives to resolve the problem. When competing possible options are presented, they will typically choose the easiest solution or the one with the most immediate "pay off" instead of evaluating the pros and cons of different options. Offenders with this behaviour often have problems with perspective-taking and have limited skills in evaluating the likely intermediate and long-term consequences of actions. They may view criminal activity as an easy and acceptable or viable alternative to dealing with a problem and, as a result, repeatedly place themselves in high risk situations. Offenders with deficits in this area routinely dismiss or fail to recognize the likely consequences of their actions, even when their intended actions are likely to make their problems worse. They often have difficulty following through on stated intentions, give up easily when faced with even minor obstacles, and lack long-term plans and vision. This problem constitutes a generalized skill deficit and, as such, would be evident throughout the offender's life. There are several components to problem solving which should be considered (identifying problems, generating alternatives, evaluating alternatives, choosing an action/following through, evaluating the outcome).

- $\mathbf{0 0}$ - not present, no concern (able to appropriately identify and address typical life problems in a variety of domains. He has a good sense of what he needs to work on and is able to discuss his plans for addressing them. His plans are realistic and he has dealt effectively with problems in the past.

- $\quad 01$ - factor is somewhat present, but not sufficient to justify a score of 2 , or there is uncertainty about its presence (history of poorly considered decisions but is willing to make changes. He is able to recognize areas of his life or decisions he has made that have caused him problems, but has deficits in one or more of the other components of effective cognitive problem solving)

- $\mathbf{0 2}$ - definitely present, definite concern (worthy of consideration in treatment, supervision and management) (frequently makes poor decisions and fails to identify obvious life problems in multiple domains. He also has difficulty generating workable alternatives or solutions to his problems. He may also have difficulty recognizing the likely negative consequences of actions even when pointed out to him. He lacks long term plans or goals, and will exhibit difficulty with choosing a course of action and appears unable to follow through.)

(127) STABLE-2007 Supported Dynamic Risk Factor - Negative Emotionality [STBL9] (Categorical, \#\#): This item refers to the tendency to feel victimized and generally mistreated by others, and to respond with anger and hostility to life's challenges. Some offenders have excessively negative reactions to routine problems, and their negative emotions provoke rash behaviours, such as reactive aggression, verbal outbursts, and poorly considered decisions. For other offenders, their negative emotionality manifests as a simmering grievance that may or may not have obvious links to current events. The key elements are that the negative emotion is intense (or disproportional to the triggering events), is externalized towards others, and interferes with the offender's personal and social functioning. Grievance may be manifested in an angry, hostile, and resentful presentation or, alternatively, the offender may present as being persistently victimized by others and appear hopeless and vulnerable to emotional collapse. In both cases the underlying feature is rumination over perceived grievances and/or victimization by others with little or no attempt to cope constructively. Attempts to encourage active coping are belittled or dismissed by the offender. Alternatively, offenders may take a more hopeless stance demonstrated by comments about "giving up", or saying "what's the use" or suicidal 
ideation based on the perception that the "world is against" them. Offenders may resist attempts to encourage them to reframe their cognitions or take responsibility for their own decisions and the resulting consequences. In some cases the offender may present with irrational feelings of persecution and chronic suspiciousness, and may have a psychiatric diagnosis marked by these types of cognitions.

- $\quad 00$ - not present, no concern (either expresses no sense of grievance or expresses occasional sense of grievance or victimization, but not beyond what would reasonably be expected given their experiences and situation. Offender is primarily focused on dealing with their current situation and not on blaming others.)

- $\mathbf{0 1}$ - factor is somewhat present, but not sufficient to justify a score of 2 , or there is uncertainty about its presence (Some hostility, resentment, or sense of victimization that appears beyond what would reasonably be expected. Offender presents as angry and forward motion in his life is stalled by his feelings of injustice. Although he has spent considerable time thinking about these issues, he is willing to move on when prompted. The offender does not bring up his grievance issues spontaneously but is willing and possibly eager to discuss them when asked.)

- $\mathbf{0 2}$ - definitely present, definite concern (worthy of consideration in treatment, supervision and management) (appears to ruminate on perceived injustices and grievances. He clings to resentment and frequently returns the discussion to his grievances during the interview. The offender may present as angry and resentful or he may present as self-indulgent, self-pitying, hopeless, and suggest he is "giving-up". This score would include offenders who present with irrational feelings of persecution and chronic suspiciousness, possibly associated with a mental disorder.) and the degree to which an offender's sexual thoughts and behaviours interfere with interpersonal and/or prosocial functioning. This item concerns impersonal sex, and is not concerned with high rates of sexual activity in the context of a loving relationship. For sexual offender, much of sexual behaviour may be expressed by masturbation, and so this frequency should be considered. Some offenders self-report that they consider their sexual thoughts or behaviours to be excessive or intrusive. However, high sex drive and high levels of sexual preoccupation should be considered problematic even if the offender views his level of sexual activity as acceptable or normative. Examples of offenders with clear problems in this area are those who self-report struggling to control their sexual thoughts or activities, offenders who report feeling plagued by sexual thoughts, offenders with a history of prostituting themselves, or those who regularly cruise for and engage in impersonal sexual activity, such as at bars or in bathhouses. An example of high sex drive would include reported sexual outlet (orgasm) on "most days" (i.e., more than 15 times per month), either through solitary sexual activity or sexual activity with a partner. Other examples are early onset of sexual activity, a history of multiple (more than 30) sexual partners of which many were casual sexual encounters, selfreport of a high sex drive, or reports of inability to control sexual behaviour in a controlled environment. Examples of sexual preoccupation would include regular use of prostitutes, regular attendance at strip bars or massage parlours, recurrent sexually-oriented internet or telephone use (particularly resulting in high telephone bills or interference with other prosocial activities such as missing events due to time spent on the computer), having large pornography collections, and collection of non-pornographic magazines for sexual. The offender may also use excessive sexual content in everyday conversations, such that the offender continually uses sexual references, suggestive language, or double entendres at a rate noticeably greater than other men. The offender may also display preoccupation with his own or other's sex crimes, and self-report disturbing or distressing sexual thoughts or dreams. Alternately and rarely, a focus on avoiding sexual thoughts or activities may be evidence of preoccupation - the denial of 
sexuality is less important than the energy and effort devoted to its inhibition. Whether these factors are "above average" should be considered, as should context

- $\quad \mathbf{0 0}$ - not present, no concern (No evidence of sexual preoccupation or high sex drive. Frequency of sexual thoughts and behaviours is reasonable for offender's age and circumstances.)

- $\mathbf{0 1}$ - factor is somewhat present, but not sufficient to justify a score of 2 , or there is uncertainty about its presence (Some evidence of sexual preoccupation or elevated sex drive, given offender's age and circumstances. The offender may report regular use of pornography or there may be some evidence of impersonal sex. There is some concern that the offender includes an unusual amount of sexual content in everyday conversations, appears aroused or unusually focussed on interview questions with sexual content, or uses sexually inappropriate words during the interview. Alternatively, the offender may present as preoccupied with avoiding sexual thoughts or behaviours.)

- 02 - definitely present, definite concern (worthy of consideration in treatment, supervision and management) (Clear evidence of any sexual preoccupation or multiple preoccupations. The offender is clearly pre-occupied with including sexual content in everyday conversations. The offender is obviously aroused by interview questions with sexual content, or he frequently uses sexually inappropriate words despite being counselled not to do so. Evidence of significant impersonal sexual activity. Self-report of high sex drive in comparison to similar males, in itself, is insufficient to score a "2". However, if the offender reports intrusive sexual thoughts or reports repeated behaviours that are clearly beyond that of most sexual offenders then a " 2 " may be safely scored.)

(129) STABLE-2007 Supported Dynamic Risk Factor - Sex as Coping [STBL11] (Categorical, \#\#): This item taps into whether sex or thoughts about sex are used to manage emotions, and to self-soothe/mitigate unwelcome feelings of tension, anger, hostility, or anxiety in a way that it becomes the dominant coping strategy, without emotional flexibility to use other strategies. Those offenders who use sex to cope in this way usually show increased sexual activity during periods of stress or dysfunction. Much of this sexual behaviour appears driven, and is likely to be inappropriate, costly, or has a high probability of negative consequences. Sexualised coping behaviour will be seen in multiple life domains. Sexual activity as coping may include either solitary activities or sexual activity with a partner. In a limited number of cases, sexual thoughts or activity may be the offender's only coping strategy; however, in most cases the offender will also have other coping strategies on which they rely.

- $\quad \mathbf{0 0}$ - not present, no concern (no history of using sexual thoughts or behaviours as a coping strategy. The offender has repeatedly experienced significant life stress without resorting to sexual fantasy or behaviour. He may report decreased sexual thoughts and activities during times of stress.)

- 01 - factor is somewhat present, but not sufficient to justify a score of 2 , or there is uncertainty about its presence (some use of sexual thoughts or behaviour to cope when stressed, but the offender is able to identify other coping strategies (either positive or negative) that he also uses during times of stress. Sexualised coping may have contributed to his offending behaviour.)

- $\mathbf{0 2}$ - definitely present, definite concern (worthy of consideration in treatment, supervision and management) (Negative emotions, life events, or stressors typically invoke sexual thoughts or behaviours. Although the offender may also have other coping strategies, these are rarely used and the main coping strategy is sexual thoughts or behaviours.)

(130) STABLE-2007 Supported Dynamic Risk Factor - Deviant Sexual Interests [STBL12] (Categorical, \#\#): This item focuses on assessing whether the offender is sexually interested in or is sexually aroused by activities, situations, people, or objects that are illegal, inappropriate, 
or highly unusual. For example, the offender may be sexually interested in children, nonconsenting sexual interactions with adults, voyeurism (peeping), exhibitionism (flashing), Sadism, masochism, swinging, or have one or more fetishes (feet, shoes/boots, , urine, feces, latex, rubber, baby paraphernalia, enemas, cross dressing, etc). An "interest" is something that the offender would choose if they had unhindered selection over their sexual activity. It may be their ideal sexual fantasy. Recall - all sexual offenders have engaged in deviant sexual behaviour, but not all sexual offenders have deviant sexual interests. Behaviour can in part be used to evaluate this item, but alone may not be sufficient. Reports from the offender, diagnosis of paraphilia, or specialized measures/testing may be used/reported upon. To score, count the number of victims $(0=1$ victim, $1=2-7$ victims, $2=8+)$, number of deviant victims $(0=0,1=1$, $2=2+)$, and reports about sexual interest $(0=$ only normal, $1=$ suspect deviance, $2=$ deviance described/admitted or has material evidence), and specialized testing (as available; $0=$ normal interest, $1=$ mixed results, $2=$ deviant preference). FOR THE PURPOSES OF THIS PROJECT: score each of these domains from 0-2, then take the most common score as the score for below.

- $\mathbf{0 0}$ - not present, no concern

- 01 - factor is somewhat present, but not sufficient to justify a score of 2 , or there is uncertainty about its presence

- $\mathbf{0 2}$ - definitely present, definite concern (worthy of consideration in treatment, supervision and management)

(131) STABLE-2007 Supported Dynamic Risk Factor - Cooperation with Supervision [STBL13] (Categorical, \#\#): Offenders who resist rules, place themselves in risky situations, engage in rule violations, express a defiant attitude towards authority figures, and who display oppositional behaviour towards those in a supervisory role are at an increased risk to reoffend. The offenders may see themselves as being at no risk to reoffend, and as a result they do not take the conditions of their supervision seriously and may place themselves in high risk situations. This item is based on the assessor's appraisal of whether the offender is working with or against the supervising officer and correctional authorities in the assessment and management of their sexual offending behaviour. It takes into account the offender's past performance while under supervision, as well as their current presentation to the assessor, and therapeutic alliance. There are a variety of ways offenders can fail to cooperate with supervision, including: disengagement, manipulation, and non-attendance. Consider cooperation within assessment, treatment, and general management. Also consider presence of misconduct reports, institutional charges, problematic/disrespectful behaviour towards staff/authority, breach of conditions, attitudes and interactions with staff, treatment notes, and willingness to make changes to avoid high risk situations.

- $\quad \mathbf{0 0}$ - not present, no concern (appears to be working with supervision and regularly follows through on instructions and attending appointments. He displays a cooperative and collaborative attitude during meetings, and appears to be forthcoming with information. He has completed prior periods of supervision without any major difficulties, and openly discusses the importance of abiding by conditions in the future as well as working with those involved in the management of his case.)

- 01 - factor is somewhat present, but not sufficient to justify a score of 2, or there is uncertainty about its presence (may have some history of being uncooperative with supervision in the past, more recent behaviour has been better but he still is not putting much effort into his own progress. An offender of this nature may place low value on supervisory efforts but will not confront directly. The offender may well have a poor attitude towards authority figures in general. The offender may or may not acknowledge that his past performance was a problem that he needs to work on, and he may say that he is going to try harder but on the whole you have seen little evidence of that to this juncture. Also included are offenders who for the most part appear to be cooperative with 
supervision, but who demonstrate occasional problems following the rules, with their attendance or participation in some aspects of the assessment. Often the "hallmark" of the " 1 " is ambivalence about the supervisory process, some days being "with" the program and some days being "against" the program.)

- $\mathbf{0 2}$ - definitely present, definite concern (worthy of consideration in treatment, supervision and management) (history of being non-compliant with prior conditions of supervision and his current behaviour continues to be uncooperative. The offender appears disengaged or uncommitted to supervision or treatment, and he is perceived to be engaging in deceptive or manipulative behaviours. Assessors may feel that they have no idea what is going on with the offender and his overall attitude towards supervision or treatment is poor. Supervisors may even feel that the case is deteriorating, and the offender is becoming more risky. Such offenders often will tell you there is no chance that they will recidivate, that they pose no risk to the community or others, and they do not see the need to make changes in their life to avoid risky situations) 


\section{References}

Abracen, J., Gallo, A., Looman, J., \& Goodwill, A. (2016). Individual community-based treatment of offenders with mental illness: Relationship to recidivism. Journal of Interpersonal Violence, 31(10), 1842-1858. doi: 10.1177/0886260515570745

Access to Information Act, R.S.C., 1985, c. A-1.

Andrews, D. A., \& Bonta, J. (2006). The psychology of criminal conduct (4th ed.). Newark, NJ: LexisNexis.

Andrews, D.A., \& Bonta, J. (2010). Rehabilitating criminal justice policy and practice. Psychology, Public Policy, and Law, 16(1), 39-55. doi: http://dx.doi.org/10.1037/a0018362

Andrews, D. A., Bonta, J., \& Wormwith, J. S. (2006). The recent past and near future of risk and/or need assessment. Crime \& Delinquency, 52(1), 7-27. doi: $10.1177 / 0011128705281756$

Blackburn, R. (2004). "What works" with mentally disordered offenders. Psychology, Crime \& Law, 10(3), 297-308. doi: 10.1080/10683160410001662780

Bonta, J. (1996). Risk-needs assessment and treatment. In A. T. Harland (Ed.), Choosing correctional options that work: Defining the demand and evaluating the supply (pp. 1832). Thousand Oaks, CA: Sage.

Bonta, J., \& Andrews, D. A. (2007). Risk-need-responsivity model for offender assessment and rehabilitation. Rehabilitation, 6, 1-22.

Bonta, J., Blais, J., \& Wilson, H. A. (2014). A theoretically informed meta-analysis of the risk for general and violent recidivism for mentally disordered offenders. Aggression and Violent Behavior, 19(3), 278-287. doi: https://doi.org/10.1016/j.avb.2014.04.014 
Bonta, J., Law, M., \& Hanson, R. K. (1998). The prediction of criminal and violent recidivism among mentally disordered offenders: A meta-analysis. Psychological Bulletin, 123, 123142. doi: http://dx.doi.org/10.1037/0033-2909.123.2.123

Brankley, A.E., Babchishin, K.M., Hanson, R.K. (2017). STABLE-2007 demonstrates predictive and incremental validity in assessing risk-relevant propensities for sexual offending: A meta-analysis. Unpublished manuscript.

Brankley, A.E., Helmus, L.M., \& Hanson, R.K. (2017). STABLE-2007 evaluator workbook revised 2017. In press.

Brankley, A. E., \& Lee, S. C. (2016, November). The utility of Static-99R and STABLE-2007 across different ethnic groups: A prospective field study. Symposium presented at the 35th Annual Research and Treatment Conference for the Association for the Treatment of Sexual Abusers, Orlando, Florida, USA.

Callahan, L. A., \& Silver, E. (1998). Revocation of conditional release: A comparison of individual and program characteristics across four U.S. states. International Journal of Law and Psychiatry, 21(2), 177-186. doi: 10.1016/S0160-2527(98)00011-9

Campbell, M.A., French, S., \& Gendreau, P. (2009). The prediction of violence in adult offenders: A meta-analytic comparison of instruments and methods of assessment. Criminal Justice and Behaviour, 36(6), 567-590. doi: 10.1177/0093854809333610

Cicchetti, D. V. (1994). Guidelines, criteria, and rules of thumb for evaluating normed and standardized assessment instruments in psychology. Psychological Assessment, 6(4), 284290. doi: http://dx.doi.org/10.1037/1040-3590.6.4.284 
Cicchetti, D.V., \& Sparrow, S.S. (1981). Developing criteria for establishing interrater reliability of specific items: Applications to assessment of adaptive behavior. American Journal of Mental Deficiency, 86(2), 127-137.

Cohen, M. I., Spodak, M. K., Silver, S. B., \& Williams, K. (1988). Predicting outcome of insanity acquittees released in the community. Behavioral Sciences and the Law, 6(4), 512-530. doi: 10.1080/j.1440- 1614.2006.01924.x

Côté, G., Crocker, A.G., Nicholls, T., \& Seto, M.C. (2012). Risk assessment instruments in clinical practice. Canadian Journal of Psychiatry, 57(4), 238-244. doi: http://dx.doi.org/10.1177\%2F070674371205700407

Criminal Code, R.S.C., 1985, c. C-46.

Criminal Code of Canada, R.S.C., 1985, c. C-46, s. 672

Criminal Code of Canada, R.S.C., 1985, c. C-46, s. 672.54

Crocker, A.G., Braithwaite, E., Côté, G., Nicholls, T.L., \& Seto, M.C. (2011). To detain or to release? Correlates of dispositions for individuals declared not criminally responsible on account of mental disorder. Canadian Journal of Psychiatry, 56(5), 293-302. doi:

$10.1177 / 070674371105600508$

Crocker, A.G., Charette, Y., Seto, M.C., Nicholls, T.L., Côté, M.C., Caulet, M. (2015a). The national trajectory project of individuals found not criminally responsible on account of mental disorder in Canada. Part 3: Trajectories and outcomes through the forensic system. Canadian Journal of Psychiatry, 60(3), 117-126. doi: 10.1177/070674371506000306

Crocker, A. G., Nicholls, T. L., Seto, M. C., Charette, Y., Côté, G., \& Caulet, M. (2015b). The National Trajectory Project of individuals found not criminally responsible on account of 
mental disorder in Canada. Part 2: the people behind the label. The Canadian Journal of Psychiatry, 60(3), 106-116. doi: 10.1177/070674371506000305

Crocker, A.G., Nicholls, T.L., Charette, Y., \& Seto, M.C. (2014). Dynamic and static factors associated with discharge dispositions: The national trajectory project of individuals found not criminally responsible on account of mental disorder (NCRMD) in Canada.

Behavioural Sciences and the Law, 32, 577-595. doi: 10.1002/bs1.2133

Crocker, A.G., Seto, M.C., Nicholls, T.L., \& Côté, G. (2013). Description and processing of individuals found not criminally responsible on account of mental disorder accused of "serious violent offences." Ottawa, ON: Department of Justice, Canada.

Dawes, R. M. (2005). The ethical implications of Paul Meehl's work on comparing clinical versus actuarial prediction methods. Journal of Clinical Psychology, 61, 1245-1255. doi: 10.1002/jclp. 20180

Demidenko E. (2007). Sample size determination for logistic regression revisited. Statistics in Medicine, 26, 3385-3397. doi: 10.1002/sim.2771

Demidenko E. (2008). Sample size and optimal design for logistic regression with binary interaction. Statistics in Medicine, 27, 36-46. doi: 10.1002/sim.2980

Douglas, K.S. (2014). Introduction to the special issue of the HCR-20 version 3. International Journal of Forensic Mental Health, 13(2), 91-92. doi:

http://dx.doi.org/10.1080/14999013.2014.913746

Douglas, K.S., Hart, S.D., Webster, C.D., \& Belfrage, H. (2013). HCR-20 Assessing Risk for Violence Version 3 (2013) Manual and Worksheets. Burnaby, British Columbia: Simon Fraser University. 
Douglas, K. S., Ogloff, J. R., \& Hart, S. D. (2003). Evaluation of a model of violence risk assessment among forensic psychiatric patients. Psychiatric Services, 54(10), 1372-1379. doi: http://dx.doi.org/10.1176/appi.ps.54.10.1372

Doyle, M. (2013, June). Predicting post-discharge community violence in England and Wales using the HCR: V3. In K. Douglas (Symposium Moderator), Version 3 of the HCR-20 (HCR-20-V3): Development, overview and initial evaluation (Part I). Symposium presented at the annual conference of the International Association of Forensic Mental Health Services, Maastricht, Netherlands.

Eher, R., Matthes, A., Schilling, F., Haubner-MacLean, T., \& Rettenberger, M. (2012). Dynamic risk assessment in sexual offenders using STABLE-2000 and the STABLE-2007: An investigation of predictive and incremental validity. Sexual Abuse, 24(1), 5-28. doi: $10.1177 / 1079063211403164$

Fazel, S., Singh, J.P., Doll, H., \& Grann, M. (2012). Use of risk assessment instruments to predict violence and antisocial behaviour in 73 samples involving 24827 people: Systematic review and meta-analysis. BMJ, 345, 4692. doi: https://doi.org/10.1136/bmj.e4692

Fernandez, Y. (2008, October). An examination of the inter-rater reliability of the STATIC-99 and STABLE-2007. In Poster presentation at the 27th Annual Research and Treatment conference of the Association for the Treatment of Sexual Abusers, Atlanta, GA.

Gendreau, P., Goggin, C., \& Little, T. (1996). Predicting Adult Offender Recidivism: What Works! (User Report No. 1996-07). Ottawa: Department of the Solicitor General of Canada. 
Hanson, R. K. (1998). What do we know about sex offender risk assessment? Psychology, Public Policy, and Law, 4(1-2), 50-72.

Hanson, R. K. (2009). The psychological assessment of risk for crime and violence. Canadian Psychology/Psychologie canadienne, 50(3), 172. doi: http://dx.doi.org/10.1037/a0015726

Hanson, R. K., Bourgon, G., McGrath, R. J., Kroner, D., D’Amora, D. A., Thomas, S. S., Tavarez, L. P. (2017). A Five-Level Risk and Needs System: Maximizing Assessment Results in Corrections through the Development of a Common Language. New York: The Council of State Governments Justice Center.

Hanson, R. K., \& Bussiere, M. T. (1998). Predicting relapse: A meta-analysis of sexual offender recidivism studies. Journal of Consulting and Clinical Psychology, 66(2), 348-362.

Hanson, R.K., Helmus, L-M., \& Harris, A.J.R. (2015). Assessing the risk and needs of supervised sexual offenders: A prospective study using STABLE-2007, Static-99R, and Static-2002R. Criminal Justice and Behaviour, 42(12), 205-1224. doi:

$10.1177 / 0093854815602094$

Hanson, R. K., Harris, A. J. R., Scott, T.-L., \& Helmus, L. (2007). Assessing the risk of sexual offenders on community supervision: The dynamic supervision project (User Report No. 2007-05). Ottawa, Ontario: Public Safety Canada. Retrieved from http://www.publicsafety.gc.ca/cnt/rsrcs/pblctns/ssssng-rsk-sxl-ffndrs/index-eng.aspx

Hanson, R. K., Lunetta, A., Phenix, A., Neeley, J., \& Epperson, D. (2014). The field validity of Static-99/R sex offender risk assessment tool in California. Journal of Threat Assessment and Management, 1(2), 102-117. doi: http://dx.doi.org/10.1037/tam0000014 
Hanson, R. K., \& Morton-Bourgon, K. E. (2005). The characteristics of persistent sexual offenders: A meta-analysis of recidivism studies. Journal of Consulting and Clinical Psychology, 73(6), 1154-1163.

Hanson, R.K., \& Morton-Bourgon, K.E. (2009). The accuracy of recidivism risk assessments for sexual offenders: A meta-analysis of 118 prediction studies. Psychological Assessment, 21(1), 1-21. doi: 10.1037/a0014421

Hanson, R.K. \& Thornton, D. (2000). Improving risk assessments for sex offenders: A comparison of three actuarial scales. Law and Human Behaviour, 24(1), 119-136. doi: 10.1023/A:1005482921333

Harrell, F., Lee, K.L., Matchar, D.B., \& Reichert, T.A. (1985). Regression models for prognostic prediction: Advantages, problems and suggested solutions. Cancer Treatment Reports, 69(10), 1071-1077.

Harrell, F.E. Jr., Lee, K.L., \& Mark, D.B. (1996). Multivariable prognostic models: Issues in developing models, evaluating assumptions and adequacy, and measuring and reducing errors. Statistics in Medicine, 15, 361-387.

Harris, A. J. R., \& Hanson, R. K. (2004). Sex offender recidivism: A simple question (Vol. 3). Ottawa, Ontario: Public Safety and Emergency Preparedness Canada.

Hart, S., Sturmey, P., Logan, C., \& McMurran, M. (2011). Forensic case formulation. International Journal of Forensic Mental Health, 10(2), 118-126. doi: $10.1080 / 14999013.2011 .577137$

Helmus, L., Hanson, R. K., Thornton, D., Babchishin, K. M., \& Harris, A. J. (2012). Absolute recidivism rates predicted by Static-99R and Static-2002R sex offender risk assessment 
tools vary across samples a meta-analysis. Criminal Justice and Behavior, 39(9), 11481171. doi: $10.1177 / 0093854812443648$

Hilton, N.Z., \& Simmons, J.L. (2001). The influence of actuarial risk assessment in clinical judgments and tribunal decisions about mentally disordered offenders in maximum security. Law and Human Behaviour, 25(4), 393-408. doi:

http://dx.doi.org/10.1023/A:1010607719239

Holzinger, B., Eucker, S., Kotter, S, Müller-Isberner, R. (2013). An overview of the work of the HCR: V3 workgroup of Haina Forensic Psychiatric Hospital. In K. Douglas (Symposium Moderator), Version 3 of the HCR-20 (HCR-20-V3): Development, overview and initial evaluation (Part I). Symposium presented at the annual conference of the International Association of Forensic Mental Health Services, Maastricht, Netherlands

Jansman-Hart, E.M., Seto, M.C., Crocker, A.G., Nicholls, T.L., Côté, G. (2011). International trends in demand for forensic mental health services. International Journal of Forensic Mental Health, 10, 326-336. doi: http://dx.doi.org/10.1080/14999013.2011.625591

Kelley, S. M., Barahal, R. M., Thornton, D., \& Olson, G. (2015, April). How do professionals assess sexual recidivism risk? An international survey of current practices. Paper presented at the joint conference of the Massachusetts Adolescent Sex Offender Coalition and the Massachusetts Chapter of the Association for the Treatment of Sexual Abusers, Marlborough, MA.

Kingston, D. A., Olver, M. E., Harris, M., Wong, S. C., \& Bradford, J. M. (2015). The relationship between mental disorder and recidivism in sexual offenders. International Journal of Forensic Mental Health, 14(1), 10-22. doi:

http://dx.doi.org/10.1080/14999013.2014.974088 
Krippendorff, K. (1980). Content analysis: An introduction to its methodology. Sage Publications, Beverly Hills, CA.

Kropp, P. R., \& Hart, S. D. (2004). The development of the Brief Spousal Assault Form for the Evaluation of Risk (B-SAFER): A tool for criminal justice professionals. Research and Statistics Division, Department of Justice.

Landis, J. R., \& Koch, G. G. (1977). The measurement of observer agreement for categorical data. Biometrics, 33(1), 159-174.

Latimer, J., \& Lawrence, A. (2006). The review board systems in Canada: Overview of results from the mentally disordered accused data collection study. Ottawa, ON: Department of Justice Canada.

Lievore, D. (2004). Recidivism of sexual assault offenders: Rates, risk factors and treatment efficacy (Vol. 80). Canberra: Australian Institute of Criminology.

Looman, J., \& Abracen, J. (2013). The risk need responsivity model of offender rehabilitation: Is there really a need for a paradigm shift? International Journal of Behavioral Consultation and Therapy, 8, 32-39. doi: http://dx.doi.org/10.1037/h0100980

Lyall, M., \& Bartlett, A. (2010). Decision making in medium security: Can he have leave? Journal of Forensic Psychiatry and Psychology, 21(6), 887-901. doi: http://dx.doi.org/10.1080/14789949.2010.500740

Mann, R.E., Hanson, R.K., \& Thornton, D. (2010). Assessing risk for sexual recidivism: Some proposals on the nature of psychologically meaningful risk factors. Sexual Abuse: A Journal of Research \& Treatment, 22(2), 1-27. doi: 10.1177/1079063210366039 
Martin, K., \& Martin, E. (2016). Factors influencing treatment team recommendations to review tribunals for forensic psychiatric patients. Behavioral Sciences \& the Law, 34(4), 551-563. doi: $10.1002 / b s l .2244$

McDermott, B. E., Scott, C. L., Busse, D., Andrade, F., Zozaya, M., \& Quanbeck, C. D. (2008). The conditional release of insanity acquittees: Three decades of decision-making. Journal of the American Academy of Psychiatry and the Law, 36(3), 329.

McDermott, B. E., \& Thompson, J. W. Jr. (2006). The review panel process: An algorithm for the conditional release of insanity acquittees. International Journal of Law and Psychiatry, 29, 101-111. doi: http:// dx.doi.org/10.1016/j.ijlp.2003.12.008.

McGrath, R. J., Cumming, G. F., Burchard, B. L., Zeoli, S., \& Ellerby, L. (2009). Current practices and emerging trends in sexual abuser management: The Safer Society 2009 North American Survey. Brandon, Vermont: Safer Society Press.

McGraw, K. O., \& Wong, S. P. (1996). Forming inferences about some intraclass correlation coefficients. Psychological Methods, 1(1), 30-46.

McKee, S.A., Harris, G.T., \& Rice, M.E. (2007). Improving forensic tribunal decisions: The role of the clinician. Behavioural Sciences and the Law, 25, 485-506. doi: 10.1002/bsl.768

Meehl, P.E. (1954). Clinical versus statistical prediction: A theoretical analysis and a review of the evidence. Minneapolis: University of Minnesota.

Morgan, R. D., Flora, D. B., Kroner, D. G., Mills, J. F., Varghese, F., \& Steffan, J. S. (2012). Treating offenders with mental illness: A research synthesis. Law and Human Behavior, 36(1), 37. doi: 10.1037/h0093964 
Monson, C. M., Gunnin, D. D., Fogel, M. H., \& Kyle, L. L. (2001). Stopping (or slowing) the revolving door: Factors related to NGRI acquittees' maintenance of a conditional release. Law and Human Behavior, 25(3), 257-267. doi: 10.1023/A:1010745927735

Moulden, H.M., Chaimowitz, G., Mamak, M., \& Hawes, J. (2014). Understanding how persons who committed sexual offences compare across psychiatric and correctional settings: Examination of Canadian mentally ill sexual offenders. Journal of Sexual Aggression, 20(2), 172-181. doi: http://dx.doi.org/10.1080/13552600.2013.794903

Neal, T.M.S., \& Grisso, T. (2014). Assessment practices and expert judgement methods in forensic psychology and psychiatry: An international snapshot. Criminal Justice and Behaviour, 41(12), 1406-1421. doi: 10.1177/0093854814548449

Ontario Review Board (2011, February 25). About us. Retrieved from http://www.orb.on.ca/scripts/en/about.asp

Ontario Review Board. (2015). Ontario review board annual report fiscal reporting period April 1, 2014-March 31, 2015. Toronto: ON.

Owusu-Bempah, A., \& Wortley, S. (2014). Race, crime, and criminal justice in Canada. In S. and M. Tonry (Eds.) The Oxford Handbook of Ethnicity, Crime and Immigration (p.281320). Oxford University Press: Toronto.

Pedersen, L., Rasmussen, K., Elsass, P. (2010). Risk assessment: The value of structured professional judgement. International Journal of Forensic Mental Health, 9, 74-81. doi: $10.1080 / 14999013.2010 .499556$

Peduzzi P, Concato J, Kemper E, Holford TR, Feinstein AR. (1996). A simulation study of the number of events per variable in logistic regression analysis. Journal of Clinical Epidemiology, 49(12), 1373-1379. doi: https://doi.org/10.1016/S0895-4356(96)00236-3 
Peterson, J., Skeem, J. L., Hart, E., Vidal, S., \& Keith, F. (2010). Analyzing offense patterns as a function of mental illness to test the criminalization hypothesis. Psychiatric Services, $61(12), 1217-1222$

Peterson, J. K., Skeem, J., Kennealy, P., Bray, B., \& Zvonkovic, A. (2014). How often and how consistently do symptoms directly precede criminal behavior among offenders with mental illness. Law and Human Behavior, 38(5), 439-449. doi: doi: http://dx.doi.org/10.1037/lhb0000075

Phenix, A., Fernandez, Y., Harris, A.J.R., Helmus, M., Hanson, R.K., \& Thornton, D. (2016). Static-99R coding rules: Revised-2016. Static-99R assessment manual, in press.

Phillips, H.K., Gray, N.S., MacCulloch, S.I., Taylor, J., Moore, S.C., Huckle, P., MacCulloch, M.J. (2005). Risk assessment in offenders with mental disorders: Relative efficacy of personal demographic, criminal history, and clinical variables. Journal of Interpersonal Violence, 20(7), 833-847. doi: 10.1177/0886260504272898

Priebe, S., Badesconyi, A., Fioritti, A., Hansson, L., Kilian, R., Torres-Gonzales, F., ... Wiersman, D. (2005). Reinstitutionalisation in mental health care: Comparison of data on service provision from six European countries. BMJ, 330, 123-126. doi: https://doi.org/10.1136/bmj.38296.611215.AE

Rotter, M., \& Carr, W. A. (2013). Reducing Criminal Recidivism for Justice-Involved Persons with Mental Illness: Risk/Needs/Responsivity and Cognitive-Behavioral Interventions. Report for Substance Abuse and Mental Health Services Administration, GAINS Center for Behavioral Health and Justice Transformation.

R. v. Owen (2003), 174 C.C.C. (3d) 1 (S.C.C.C.). 
Seto, M.C., Lalumière, M.L., Harris, G.T., Barbaree, H.E., Hilton, N.Z., Rice, M.E., Schneider, R.D. (2001). Demands on forensic mental health services in the province of Ontario. Report prepared for the Ontario Ministry of Health and Long-Term Care: Toronto, ON. Simpson, A. I., Penney, S. R., Seto, M. C., Crocker, A. G., Nicholls, T. L., \& Darby, P. L. (2014). Changing Characteristics of the Review Board Population in Ontario: A Population-Based Study from 1987-2012. Unpublished report, Ontario Mental Health Foundation. Retrieved from http://www.omhf.on.ca/_files/file.php?fileidfilerWJYH Bobhc\&filenamefile_Rising_ORB_numbers_study__Aug_5_Final_2014 .pdf

Singh, J. P. (2015). Violence risk assessment: what behavioral healthcare professionals should know. Revista de la Facultad de Medicina, 63(3), 355-356.

Skeem, J.L., Steadman, H.J., \& Manchak, S.M. (2015). Applicability of the risk-needresponsivity model to persons with mental illness involved in the criminal justice system. Psychiatric Services, 66, 916-922. doi: https://doi.org/10.1176/appi.ps.201400448

Stuart, H. (2003). Violence and mental illness: An overview. World Psychiatry, 2(2), 121-124.

Tellefsen, C., Cohen, M. I., Silver, S. B., \& Dougherty, C. (1992). Predicting success on conditional release for insanity acquittees: Regionalized versus nonregionalized hospital patients. Bulletin of the American Academy of Psychiatry and the Law, 20(1), 87-100.

Vittinghoff, E., \& McCulloch, C.E. (2007). Relaxing the rule of ten events per variable in logistic and Cox regression. American Journal of Epidemiology, 165, 710-718. doi: https://doi.org/10.1093/aje/kwk052

Webster, C. D., Douglas, K. S., Eaves, D., \& Hart, S. D. (1997). Assessing risk of violence to others. In C.D. Webster \& M.A. Jackson (Eds.), Impulsivity: Theory, assessment, and treatment (p. 251-277). New York, NY: The Guilford Press. 
WestLaw Next Canada. (2017, March). What's in LawSource ${ }^{\circledR}$ - Tribunals. Retrieved from westlawnextcanada.com

Wilson, C. M., Crocker, A. G., Nicholls, T. L., Charette, Y., \& Seto, M. C. (2015). The use of risk and need factors in forensic mental health decision-making and the role of gender and index offense severity. Behavioral Sciences \& the Law, 33(1), 19-38. doi:

$10.1002 / \mathrm{bsl} .2162$

Wilson, C. M., Nicholls, T. L., Charette, Y., Seto, M. C., \& Crocker, A. G. (2016). Factors Associated with Review Board Dispositions following Re-hospitalization among Discharged Persons found Not Criminally Responsible. Behavioral Sciences \& the Law, 34(2-3), 278-294. doi: 10.1002/bsl.2220

Winko v. British Columbia (Forensic Psychiatric Institute) (1998), 135 C.C.C. (3d) 129 (S.C.C.C.).

Yang, M., Wong, S.C.P., \& Coid, J. (2010). The efficacy of violence prediction: A meta-analytic comparison of nine risk assessment tools. Psychological Bulletin, 136(5), 740-767. doi: $10.1037 / \mathrm{a} 002047$ 